Bundesgesundheitsbl 2016 · 59:1189-1220

DOI 10.1007/s00103-016-2416-6

๑) Springer-Verlag Berlin Heidelberg 2016

\section{Händehygiene in Einrichtungen des Gesundheitswesens}

\author{
Empfehlung der Kommission für Krankenhaushygiene \\ und Infektionsprävention (KRINKO) beim Robert \\ Koch-Institut (RKI)
}

\section{Inhaltsverzeichnis}

Kategorien in der Richtlinie für Krankenhaushygiene und Infektionsprävention

1 Einleitung

2 Bezug zu anderen Empfehlungen der KRINKO sowie zum Arzneimittelund Medizinprodukterecht sowie zur Listung von Desinfektionsmitteln 2.1 KRINKO-Empfehlungen

2.2 Arzneimittelrecht

2.3 Listung von Desinfektionsmitteln (VAH- und RKI-Liste)

3 Die hygienische Händedesinfektion

3.1 Mikrobizide Wirksamkeit und Verträglichkeit

3.2 Prävention nosokomialer Infektionen

3.3 Voraussetzungen

3.4 Indikationen

Technik

4 Die Chirurgische Händedesinfektion

4.1 Mikrobizide Wirksamkeit und Verträglichkeit

4.2 Prävention postoperativer Wundinfektionen

4.3 Voraussetzungen

4.4 Indikationen

4.5 Technik

5 Die Händewaschung

5.1 Ausstattung medizinischer Handwaschplätze

5.2 Eigenschaften und Auswahl von Handwaschpräparaten

5.3 Indikationen

5.4 Technik

6 Maßnahmen zum Schutz vor Kontamination und vor Chemikalien

6.1 Medizinische Einmalhandschuhe und Schutzhandschuhe

6.2 Sterile Einmalhandschuhe

6.3 Vermeidung einer Kontamination

7 Anforderungen an Spender für Händedesinfektionsmittel und Handwaschpräparate

8 Qualitätssicherung der Händehygiene

8.1 Maßnahmen zur Verbesserung der Compliance

8.2 Ermittlung der Compliance

9 Hautschutz und Hautpflege

10 Rechtliche Aspekte

11 Empfehlungen

11.1 Hygienische Händedesinfektion

Voraussetzungen

Indikationen, Auswahl und Durchführung

Maßnahmen zur Verbesserung der Compliance und zur Qualitätssicherung

11.2 Chirurgische Händedesinfektion

Indikationen und Voraussetzungen

Durchführung

11.3 Medizinische Einmalhandschuhe und Schutzhandschuhe

11.4 Sterile OP-Handschuhe

11.5 Händewaschung

11.6 Hautschutz und Hautpflege

Literatur
Kategorien in der Richtlinie

für Krankenhaushygiene und Infektionsprävention

Die im nachfolgenden Dokument gegebenen Empfehlungen basieren auf den aktuellen Kategorien der Richtlinie für Krankenhaushygiene und Infektionsprävention aus dem Jahr 2010 [1]. Diese werden nachfolgend nochmals aufgeführt.

\section{Kategorie IA:}

Diese Empfehlung basiert auf gut konzipierten systematischen Reviews oder einzelnen hochwertigen randomisierten kontrollierten Studien.

Kategorie IB:

Diese Empfehlung basiert auf klinischen oder hochwertigen epidemiologischen Studien und strengen, plausiblen und nachvollziehbaren theoretischen Ableitungen.

Kategorie II:

Diese Empfehlung basiert auf hinweisenden Studien/Untersuchungen und strengen, plausiblen und nachvollziehbaren theoretischen Ableitungen.

Kategorie III:

Maßnahmen, über deren Wirksamkeit nur unzureichende oder widersprüchliche Hinweise vorliegen, deshalb ist eine Empfehlung nicht möglich.

\section{Kategorie IV:}

Anforderungen, Maßnahmen und Verfahrensweisen, die durch allgemein geltende Rechtsvorschriften zu beachten sind. 


\section{Einleitung}

Im vorliegenden Dokument wird die Empfehlung der KRINKO zur Händehygiene aus dem Jahr 2000 aktualisiert und erweitert.

Medizinische Einrichtungen wie Krankenhäuser, Einrichtungen für ambulantes Operieren, Geburtshäuser/Entbindungseinrichtungen, Vorsorge- und Rehabilitationseinrichtungen, vergleichbare Behandlungs- und Versorgungseinrichtungen sowie Dialyseeinrichtungen und Tageskliniken sind gemäß $\$ 23$ Absatz 5 Satz 1 Infektionsschutzgesetz (IfSG) zur Festlegung innerbetrieblicher Verfahrensweisen zur Infektionshygiene in Hygieneplänen verpflichtet [2]. Im Hygieneplan der Einrichtung sind die Indikationen für die Maßnahmen der Händehygiene in Abhängigkeit von den Arbeitsaufgaben und

\begin{tabular}{|c|c|}
\hline \multicolumn{2}{|c|}{ Abkürzungen } \\
\hline$A M G$ & Arzneimittelgesetz \\
\hline$A Q L$ & $\begin{array}{l}\text { Accetable Quality Limit (statistischer } \\
\text { Messwert für ein einheitliches } \\
\text { Qualitätsniveau bei der Herstellung } \\
\text { z. B. von medizinischen Einmalhand- } \\
\text { schuhen) }\end{array}$ \\
\hline ASTM & $\begin{array}{l}\text { American Society for Testing and } \\
\text { Materials }\end{array}$ \\
\hline BfArM & $\begin{array}{l}\text { Bundesinstitut für Arzneimittel und } \\
\text { Medizinprodukte }\end{array}$ \\
\hline$D V V$ & $\begin{array}{l}\text { Deutsche Vereinigung zur Bekämp- } \\
\text { fung der Viruskrankheiten }\end{array}$ \\
\hline$E S B L$ & extended-spectrum beta-lactamase \\
\hline$h$ & Stunde \\
\hline$H D M$ & Händedesinfektionsmittel \\
\hline IfSG & Infektionsschutzgesetz \\
\hline$K b E$ & Kolonie bildende Einheiten \\
\hline $\min$ & Minute \\
\hline MP & Medizinprodukt \\
\hline$M R E$ & multiresistente Erreger \\
\hline MRSA & $\begin{array}{l}\text { Methicillin resistenter Staphylococcus } \\
\text { aureus }\end{array}$ \\
\hline $\mathrm{NI}$ & nosokomiale Infektionen \\
\hline$O P$ & Operation \\
\hline PSA & Persönliche Schutzausrüstung \\
\hline RKI & Robert Koch-Institut \\
\hline TRBA & $\begin{array}{l}\text { Technische Regeln für Biologische } \\
\text { Arbeitsstoffe }\end{array}$ \\
\hline$V A H$ & Verbund für Angewandte Hygiene \\
\hline
\end{tabular}

den Besonderheiten der zu betreuenden Patienten einschließlich der Rahmenbedingungen, die Durchführung und die Maßnahmen zur Qualitätssicherung unter Berücksichtigung der unterschiedlichen Berufsgruppen (z.B. Pflegedienst, OP-Team, Physiotherapie, Ergotherapie, Logopädie, Hebammen, Reinigungsteam) im Detail festzulegen und allen Mitarbeitern zugänglich zu machen. Es empfiehlt sich, an Händedesinfektionsplätzen (z. B. im Stationsdienstzimmer, in der OP-Funktionseinheit, in unreinen Arbeitsräumen) einen Händehygieneplan anzubringen, der aus dem Desinfektionsplan als separate Empfehlung herausgelöst werden kann, um auf die Anliegen der Händehygiene (erregerabhängige Desinfektion, Hautschutz, Hautpflege, Hygiene der Spender) zu fokussieren. Darin wird die Durchführung der jeweiligen Maßnahme (die sog. $5 \mathrm{~W}$ : wer, was, wann, womit, wie) festgelegt. Diese sind in wischdesinfizierbaren Schutzhüllen oder in laminierter Form anzubringen. Die einschlägigen Bestimmungen der gesetzlichen Unfallverhütungsvorschrift sind hier mit einzuarbeiten. Jeder Mitarbeiter ist aktenkundig in den Hygieneplan einzuweisen. Durch Piktogramme kann die Aufmerksamkeit auf dieses Thema fokussiert werden.

Es ist zu empfehlen, Patienten und Besucher in die Maßnahmen der Händehygiene einzubeziehen. Hierfür empfiehlt es sich, durch geeignete Formen der Aufklärung (z. B. Flyer, Plakat, Patientenbroschüre) das Interesse für dieses Präventionsanliegen zu wecken und dadurch ein zusätzliches Präventionspotential zu etablieren [3].

Die nachfolgenden Empfehlungen gelten für alle in stationären und ambulanten Gesundheitseinrichtungen sowie in der ambulanten Betreuung pflegebedürftiger Menschen und der pflegerischen Betreuung von Heimbewohnern tätigen Personen, sofern sie in direkten ärztlichen oder pflegerischen Kontakt mit Patienten oder Bewohnern einschließlich der patientennahen Umgebung treten, nach Tätigkeiten mit erhöhtem Kontaminationsrisiko (z.B. Abfallentsorgung, Wechsel der Bettwäsche) oder vor reinen Tätigkeiten (z. B. Bereitstellung von Arzneimitteln, Wäsche u.ä.).
Zusätzlich zu den nachfolgenden Empfehlungen sind die Vorgaben des Arbeitsschutzes, z. B. die TRBA 250 [4] und die Empfehlungen der Berufsgenossenschaft für Gesundheitsdienst und Wohlfahrtspflege zu beachten [5].

Im Folgenden werden

- die Indikationen der hygienischen und der chirurgischen Händedesinfektion,

- die Indikationen für nicht sterile und sterile medizinische Einmalhandschuhe,

- Indikationen und Voraussetzungen für die Händewaschung,

- Anforderungen an Spender für HDM und Handwaschpräparate,

- erforderliche flankierende Maßnahmen wie Hautschutz und -pflege,

- Maßnahmen zur Qualitätssicherung mit dem Schwerpunkt der Interventionsmöglichkeiten zur Verbesserung der Compliance der hygienischen Händedesinfektion und - rechtliche Aspekte beschrieben.

\section{Bezug zu anderen Empfehlungen der KRINKO sowie zum Arzneimittel- und Medizinprodukterecht sowie zur Listung von Desinfektionsmitteln}

\subsection{KRINKO-Empfehlungen}

Die Händehygiene ist als wichtigste Maßnahme der Basishygiene integraler Bestandteil aller KRINKO-Empfehlungen, wobei spezifische Aufgabenstellungen der Händehygiene einschließlich der Bedeutung der Hände als Überträger von Krankheitserregern vor allem in den Empfehlungen zur Infektionsprävention in Pflege, Diagnostik und Therapie sowie zur Betriebsorganisation in speziellen Bereichen behandelt werden.

Bei der Erarbeitung fach- bzw. einrichtungsspezifischer Regelungen müssen daher zusätzlich auch diese entsprechenden Dokumente berücksichtigt werden. 


\subsection{Arzneimittelrecht}

Gemäß deutschem Arzneimittelrecht sind HDM mit medizinischer Zweckbestimmung i.d. R. Arzneimittel ${ }^{1}$ im Sinne des $\$ 2$ Arzneimittelgesetz (AMG) [6] und bedürfen gemäß $\$ 21$ AMG einer Zulassung durch die zuständige Behörde. Im Rahmen des Zulassungsverfahrens werden Wirksamkeit, Qualität, Sicherheit und Unbedenklichkeit geprüft.

Üblicherweise werden Desinfektionsmittelspender mit Einmalflaschen bestückt. Rechtlich ist ein Umfüllen nur unter bestimmten Voraussetzungen möglich. In $\$ 4$ Absatz 14 des AMG [7] ist das Umfüllen von Arzneimitteln aus größeren Gebinden in kleinere Behältnisse als Herstellen definiert, d.h. der Umfüllende wird zum Hersteller und benötigt gemäß $\$ 13$ Absatz 1 AMG eine Herstellungserlaubnis. Keiner Erlaubnis bedürfen gemäß $\$ 13$ Absatz 2 und 3 AMG Apotheken und Krankenhausapotheken im Rahmen des üblichen Apothekenbetriebs, d.h. im Rahmen ihres Versorgungsauftrags. Soweit das Umfüllen nicht im Rahmen des Versorgungsauftrags erfolgt, d.h. als Abgabe an Kunden der Apotheke, ist auch für die Apotheke eine Herstellungserlaubnis gemäß $\$ 13$ AMG erforderlich.

Das Umfüllen und Kennzeichnen von Desinfektionsmitteln in Arztpraxen und Krankenhäusern durch eigenes Personal für die Anwendung in der eigenen Einrichtung ist zwar als Herstellung gemäß $\$ 4$ Absatz 14 AMG anzusehen, unterliegt jedoch nicht dem Erfordernis einer Herstellungserlaubnis, da in diesen Fällen weder gewerbs- noch berufsmäßig hergestellt wird. Auch ein Inverkehrbringen findet in dieser Konstellation nicht statt, so dass die abgefüllten Arzneimittel nicht der Pflicht der Zulassung gemäß $\$ 21$ AMG unterliegen. Allerdings muss das Umfüllen nach $₫ 67$ Absatz 2 AMG der zuständigen Aufsichtsbehörde angezeigt werden und qualitätsgesichert erfolgen. Die

\footnotetext{
Die Europäische Union hat in dem Durchführungsbeschluss 2016/904 der Kommission vom 8. Juni 2016 festgelegt, dass 2-Propanol-haltige HDM als Biozidprodukte eingeordnet werden. Derzeit wird diese Einordnung aus fachlichen Gründen kontrovers diskutiert. Es ist daher unklar, ob sich diese Auffassung europäisch durchsetzen wird [9].
}

Qualitätssicherung umfasst u. a. die Reinigung und Sterilisation der Desinfektionsmittel-Behälter vor der Neubefüllung, das Umfüllen unter aseptischen Bedingungen und die ordnungsgemäße Kennzeichnung mit Umfüll- und Verfalldatum [8]. Wegen des Aufwands und der Sicherheit ist Einmalgebinden der Vorzug zu geben. In jedem Fall haftet der Umfüllende für sein hergestelltes Produkt [8]. Anlass für ein Vermeiden des Umfüllens ist, dass Bakteriensporen in Alkohol basierten Desinfektionsmitteln überleben und auf diesem Weg z. B. in eine Wunde gelangen können (Risiko von Gasbrand und Tetanus) [10, 11]. Das tatsächliche Risiko ist jedoch minimal. So konnten in Alkohol basierten Händedesinfektionsmitteln nach längerem Stehenlassen der geöffneten Flasche in $18 \%$ der Proben Bakteriensporen gefunden werden, jedoch weniger als eine Spore pro $10 \mathrm{ml}$ Händedesinfektionsmittel. In keinem Fall wurden Sporen pathogener Bakterienspezies identifiziert [12]. Dagegen liegt über die in-use Kontamination Chlorhexidin-basierter Handwaschpräparate ein umfangreiches Schrifttum vor [13].

Im Fall einer Infektion kann das Umfüllen von HDM haftungsrechtlich relevant werden. So wurde in einer Einrichtung umgefüllt und die HDM erwiesen sich in zwei überprüften umgefüllten Flaschen als kontaminiert, was in Verbindung mit weiteren Hygienefehlern zu einem richterlichen Urteil geführt hat [14].

\subsection{Listung von Desinfektionsmitteln (VAH- und RKI-Liste)}

In die jährlich aktualisierte Desinfektionsmittelliste des VAH [15] werden auf Antrag des Herstellers und nach Bewertung durch die Desinfektionsmittelkommission des VAH Präparate aufgenommen, sofern sie die Prüfanforderungen des VAH erfüllen [16]. Diese berücksichtigen auch europäische Normen [17-21] oder für den Nachweis der Viruzidie die Anforderungen der DVV/RKI-Leitlinie [22]. Hierbei ist die Indikation auf die prophylaktische Anwendung beschränkt.

Die Liste der vom RKI geprüften und anerkannten Desinfektionsmittel und -verfahren [23] enthält nur Präparate zur hygienischen und nicht zur chirurgischen Händedesinfektion, weil die Liste für behördlich angeordnete Desinfektionsmaßnahmen gemäß $\$ 18$ IfSG vorgesehen ist [2]. Zugleich ist es sinnvoll, im Fall von massiver bzw. sichtbarer Kontamination nach deren mechanischer Entfernung eine zweimalige Händedesinfektion durchzuführen.

\section{Die hygienische Händedesinfektion}

Die Hände des Personals werden bei Maßnahmen am Patienten sowie bei Kontakt mit der unmittelbaren Patientenumgebung mit potentiell pathogenen Erregern kontaminiert [24-30] und sind die wichtigsten Überträger von Krankheitserregern. Die hygienische Händedesinfektion gilt weltweit als die wirksamste Einzelmaßnahme zur Unterbrechung von Infektionsketten in Gesundheitseinrichtungen ebenso wie in Pflegeeinrichtungen und damit zur Prophylaxe von nosokomialen Infektionen [31-36]. Keine andere Maßnahme der Krankenhaushygiene hat eine so hohe epidemiologische Evidenz für den präventiven Nutzen für den Patienten. Bei Nichteinhaltung der Händedesinfektion werden Erreger nosokomialer Infektionen über die Hände der Mitarbeiter übertragen, vor allem bei Katheter-assoziierten Septikämien [37] und Pneumonien [38, 39]. Zusätzlich trägt die hygienische Händedesinfektion zum Eigenschutz bei [40]. Daher muss bei möglicher und tatsächlicher Kontamination eine hygienische Händedesinfektion durchgeführt werden, um die Weiterverbreitung der Erreger zu verhindern. Momentan ist keine wissenschaftliche fundierte Einteilung von einzelnen Tätigkeiten im Rahmen der Patientenversorgung in ein Risikoprofil vorgenommen. Bereits der Kontakt mit intakter Haut sowie mit Oberflächen und Gegenständen aus der unmittelbaren Patientenumgebung führt zu einer relevanten Kontamination der Hände [41-43].

Im Fall des direkten Kontakts der Unterarme mit dem Patienten oder mit kontaminierten Oberflächen, sind diese in die Durchführung der Desinfektion einzubeziehen. 


\subsection{Mikrobizide Wirksamkeit und Verträglichkeit}

Ziel der hygienischen Händedesinfektion ist die schnelle ausreichende Reduktion der transienten Flora (nicht zur eigenen Hautflora gehörend), so dass von den Händen nach bekannter oder vermuteter Kontamination kein Risiko der Weiterverbreitung von potentiell pathogenen Erregern ausgeht. Sofern die Alkohol basierten Rezepturen keinen remanent wirksamen antimikrobiellen Zusatz enthalten, ist die Wirkung der Alkohole nach deren Abdunstung beendet. Es gibt jedoch keinen Nachweis, dass durch Zusatz remanent wirkender Antiseptika (z. B. Chlorhexidin, Octenidin) zu Alkohol basierten Händedesinfektionsmitteln eine höhere präventive Wirksamkeit bei der hygienischen Händedesinfektion erreicht wird, weil allein die rasche Wirkung auf die transiente Flora zur Unterbrechung der Weiterverbreitung der oberflächlich anhaftenden Mikroorganismen entscheidend ist.

Das benötigte Wirkungsspektrum der HDM hängt von der angestrebten Verwendung ab, schließt aber in jedem Fall bakterielle Krankheitserreger und Hefen ein. Nach Versorgung von Patienten mit Viruserkrankungen bzw. nach Umgang mit virushaltigem Material ist in Abhängigkeit von der Art der zu erwartenden Viren $^{2}$ ein begrenzt viruzides (wirksam gegen behüllte Viren), begrenzt viruzid Plus wirksames (wirksam gegen Adeno-, Noround Rotaviren) [www.krankenhaushygiene.de/referate/d13b4982da4e67a8f40f1d8c674171ed.pdf] oder viruzides (wirksam gegen behüllte und unbehüllte Viren) [22, 44] anzuwenden. Sobald unbehüllte Viren im Stationsbereich oder bei zu versorgenden Patienten auftreten, z. B. Noroviren, ist die Umstellung auf ein HDM mit

2 Testviren für die Einstufung begrenzt viruzid: Vacciniavirus Stamm Elstree bzw. Modified Vacciniavirus Ankara und bovine Viral Diarrhea Virus Stamm NADL; Testviren für die Einstufung begrenzt viruzid Plus: Adenovirus Typ 5 Stamm Adenoid 75, murines Norovirus; Testviren viruzid: murines Norovirus Stamm S99, Polio-Impfstamm Typ I, Stamm LSc-2ab, Polyomavirus (SV40) Stamm 77 und Adenovirus Typ 5 Stamm Adenoid 75 [22, 44, www.krankenhaushygiene.de/referate/d13b4982da4e67a8f40f1d8c674171ed.pdf]. entsprechendem Wirkungsbereich vorzunehmen [44, 45], [www.krankenhaushygiene.de/referate/d13b4982da4e67a8f40f1d8c674171ed.pdf]. Bei der Pflege von Patienten mit offener Lungentuberkulose ist der Einsatz von Händedesinfektionsmitteln mit nachgewiesener Wirksamkeit gegen Tuberkulose (Präparate mit Wirkungsbereich A aus der RKI-Desinfektionsmittelliste) zu empfehlen [23].

Innerhalb der Alkohole besteht zumindest in Bezug auf die residente Hautflora eine positive Korrelation zwischen der Konzentration und der bakteriziden Wirksamkeit [46]. Bei gleicher Konzentration ist Propan-1-ol am wirksamsten und Ethanol am wenigsten wirksam [47]. Als Voraussetzung für die Listung müssen alkoholische Händedesinfektionsmittel in der deklarierten Einwirkungszeit ( $>30 \mathrm{~s}$ ) die gleiche oder eine signifikant höhere Wirksamkeit besitzen wie das Referenzverfahren Propan-2-ol $60 \%$ (v/v) bei $2 \times 30 \mathrm{~s}$ Anwendung. Bei alkoholischen Gelen wird die Wirksamkeit des Referenzverfahrens innerhalb von $30 \mathrm{~s}$ erst ab einem Ethanolgehalt $>85 \%(\mathrm{~g} / \mathrm{g})$ erreicht $[48,49]$ ansonsten wird 1 min Einwirkzeit benötigt [15]. Damit kann erklärt werden, warum bei Einführung eines alkoholischen Gels mit einem Ethanolgehalt von $54 \%(\mathrm{~g} / \mathrm{g})$, dessen Wirksamkeit damit nur im Bereich flüssiger antiseptischer Handwaschpräparate lag, trotz häufigerer Nutzung kein Einfluss auf die Rate nosokomialer Infektionen nachweisbar war [50].

Allein aus der Zubereitungsform Lösung oder Gel und der Zusammensetzung der Produkte kann keine Wirksamkeit abgeleitet werden. Grundlage für die Auswahl ist die deklarierte Wirksamkeit auf Basis der festgelegten Prüfanforderungen [16-22].

Gegenüber Viren ist Ethanol wirksamer als die Propanole, wobei behüllte Viren konzentrationsabhängig von allen $\mathrm{Al}$ koholen erfasst werden. Zur Inaktivierung unbehüllter Viren sind in der Regel eine hohe Ethanolkonzentration oder synergistische Kombinationen mit geringerem Gehalt alkoholischer Komponenten erforderlich [51-55].

Chlorhexidindigluconat, Octenidinhydrochlorid, Polihexanid, quaternäre Ammoniumverbindungen, Ampholyte, Phenolderivate und Triclosan bringen als
Zusatz zu alkoholischen Desinfektionsmitteln keine weitere Verstärkung der Wirkung, erhöhen aber Wirkstoff abhängig das Risiko von Unverträglichkeiten bzw. einer Resistenzentwicklung [56-60]. Bei PVP-Iod-Präparaten wird die Anwendung durch die Iodresorption limitiert [61]. Wässrige Lösungen auf Basis von Chlorabspaltern, PVP-(Polyvinylpyrrolidon-) Iod oder Peroxiden sind auf Grund ihrer geringeren Wirksamkeit, schlechteren Hautverträglichkeit als Alkohol basierte Präparate [62-68], wegen ihres schlechteren Ausbreitungsverhaltens (Spreitens) auf der Haut sowie der längeren Verdampfungszeit keine Alternative zur Anwendung Alkohol basierter Händedesinfektionsmittel in Gesundheitseinrichtungen.

Alkoholische HDM sind deutlich besser hautverträglich als die Händewaschung, weil durch die oberflächenaktiven Handwaschpräparate der Wasser-Lipid-Mantel der Hautoberfläche, verbunden mit einem Verlust wasserlöslicher Feuchthalter, antimikrobieller Schutzfaktoren und Alteration interzellulärer Lipiddoppelschichten, beeinträchtigt wird. Durch die damit verbundene Austrocknung kann die Hornschicht aufbrechen. Es entstehen Entzündungszeichen in der Epidermis und Kutis mit Verhornungsstörungen, an deren Ende eine nicht mehr nur durch Hautpflege reversible Ekzematisation steht [67]. Alkohol basierte HDM verursachen keine signifikante Veränderung der Hautbarriereeigenschaften und besitzen selbst bei vorirritierter Haut keine erhöhte Irritationspotenz. Vielmehr führte die Ethanol basierte Händedesinfektion bei Pflegepersonal, das vorher ausschließlich antiseptische Handwaschpräparate anstelle Alkohol basierter HDM anwendete, zu einer Verbesserung des Hautzustands [64, 65, 68]. Gegebenenfalls kann eine noch bessere Hautverträglichkeit durch Zusatz von Rückfettungssystemen zur alkoholischen Grundlage erreicht werden [69-71]. Bei adäquater Anwendung von Hautschutz und Hautpflege ist die Anwendung von Alkoholen nicht mit dem Risiko einer Irritationsdermatose verbunden [70]. Alkohole besitzen keine sensibilisierende Potenz [72]. Sowohl Ethanol als auch die beiden Propanole werden nur im Spurenbereich resorbiert [73, 74], so dass sich keine Gefährdung 
ableitet. Auch wenn bei Durchführung der praxisüblichen Händedesinfektion mit Ethanol basierten Händedesinfektionsmitteln am Tag der Durchführung und am Morgen nach der Anwendung in der Nachtschicht Ethylglucuronid als Abstinenzmarker im Urin gemessen werden kann [75], ist damit keine Gesundheitsgefährdung verbunden [76].

An isolierten Peritonealexplantaten bestehen Unterschiede in der Gewebeverträglichkeit zwischen den drei Alkoholen. So ist die Gewebeverträglichkeit von $80 \%$ Ethanol signifikant besser als von $60 \%$ Propan-2-ol [77], was bei Anwendung auf irritierter bzw. besonders empfindlicher Haut von Vorteil sein dürfte. Auch ist die inhalative Toxizität von Ethanol weitaus geringer als die der beiden Propanole [72], obwohl für keinen der Alkohole Intoxikationen durch Inhalation beschrieben sind [72]. Deshalb und auf Grund der besseren physiologischen Anpassung (Vorkommen und Abbau von Ethanol im Organismus) kann bei besonders empfindlichen Patienten (z.B. Neugeborene, Kleinkinder und Patienten mit Atemwegerkrankungen) überlegt werden, bevorzugt Ethanol basierte Präparate zur hygienischen Händedesinfektion anzuwenden.

Für alle Alkohole ist zu beachten, dass zurzeit keine sporizide Aktivität bei HDM mit tolerierbarer Hautverträglichkeit und praktikabler Einwirkungszeit erreichbar ist $[78,79]$. Besteht die Notwendigkeit, Bakteriensporen von den Händen zu entfernen, kann derzeit nach der Händedesinfektion nur eine gründliche Händewaschung mit einem Handwaschpräparat und Wasser empfohlen werden [80]. Sofern im Patientenzimmer oder der zugehörigen Sanitärzelle keine Handwaschmöglichkeit vorhanden ist, muss die nächst gelegene Waschgelegenheit aufgesucht werden, wobei auf dem Weg dahin eine Kontamination der Umgebung, z.B. der Türklinke, vermieden werden muss. Bei unbeherrschbaren Ausbrüchen mit Sporenbildnern können kurzfristig Peressigsäure haltige HDM eingesetzt werden

Im Deutschen Arzneibuch sind keine Anforderungen an HDM in Bezug auf die mikrobielle Reinheit des Fertigprodukts enthalten. Aus der fehlenden sporiziden Wirksamkeit der Alkohole ergibt sich als Anforderung, dass die Präparate keine
Bakteriensporen enthalten sollen. Vegetative Mikroorganismen können auf Grund der Eigenwirkung der Alkohole nicht im Produkt überleben.

\subsection{Prävention nosokomialer Infektionen}

Die Bedeutung der Händehygiene als eine der grundlegenden Maßnahmen zur Prävention von Transmissionen und Infektionen im Rahmen der Patientenversorgung ist mit hoher Evidenz belegt. Die WHO hat in ihrer Richtlinie von 2009 einen umfassenden Literaturreview zur Effektivität der Händehygiene bei der Prävention von Behandlungs-assoziierten Infektionen erarbeitet [33]. Bereits die erste Publikation durch Ignaz Philipp Semmelweis konnte die Effektivität der Händehygiene bei der Prävention von Behandlungs-assoziierten Infektionen eindrucksvoll belegen [81, 82]. Seitdem haben viele Untersuchungen den infektionspräventiven Einfluss einer gesteigerten Händehygiene-Compliance mit Alkohol basierten Desinfektionsmitteln in unterschiedlichen Settings nachgewiesen [34, 83-94]. Ebenso wurden durch die Eindämmung der Ausbreitung von MRE die Anzahl von mit MRSA, ESBL-Bildnern, Acinetobacter baumannii kolonisierten Patienten und von damit verbundenen Infektionen reduziert [95102]. Ebenso ist die Effizienz der Händedesinfektion bei der Beherrschung von Ausbrüchen nachgewiesen [103-106].

Auch wenn einige Studien eine gewisse Wirksamkeit antiseptischer Handwaschpräparate zeigen konnten [107-110], wird nicht die Wirksamkeit der Alkohole erreicht. Auf Grund der schlechteren Hautverträglichkeit und der längeren Einwirkungszeit sind antiseptische Handwaschpräparate daher keine Alternative für alkoholische Einreibepräparate.

\subsection{Voraussetzungen}

Die Voraussetzungen für eine effektive Händedesinfektion sind nur z. T. untersucht und leiten sich überwiegend aus der hygienischen Risikobewertung ab.

Klinik, Praxis, Pflegeeinrichtungen und andere medizinische Arbeitsbereiche sind mit sichtbar sauberen Händen und Fingernägeln zu betreten. Schmut- zige Hände und Fingernägel (z.B. nach Gartenarbeit) sind bereits zuhause $\mathrm{zu}$ säubern. Kommt es während der Tätigkeit zur Verschmutzung der Hände, sind ein Handwaschpräparat und zur Schonung der Haut nur bei Notwendigkeit eine $\mathrm{Na}$ gelbürste zu benutzen.

Kurzgeschnittene, mit den Fingerkuppen abschließende Fingernägel gewährleisten die Reinigung der subungualen Spatien und minimieren die Gefahr der Handschuhperforation an den Fingerkuppen. Nagellack ist abzulehnen, weil er die Sichtbeurteilung der Nägel behindert und mit steigender Tragedauer die Kolonisation auf den Nägeln zunimmt. Obwohl dieser Einfluss bei frischem Nagellack nicht nachweisbar war, ist die Empfehlung, keinen Nagellack im Gesundheitswesen zu tragen, berechtigt, weil das Alter des Nagellacks und dessen Güte (Mikrorisse u. ä.) in praxi nicht beurteilbar sind [111]. Die Bakteriendichte ist auf künstlichen Nägeln höher als auf natürlichen. Zugleich beeinträchtigen künstliche Nägel den Erfolg der Händehygiene und erhöhen die Perforationsgefahr für Einmalhandschuhe [112-116]. Wiederholt konnten künstliche Nägel als Quelle für NI bei immunsupprimierten Patienten und für Ausbrüche postoperativer Wundinfektionen identifiziert werden [117123]. Im Fall dermatologisch begründbarer Nagelbehandlungen sind die hiermit verbundenen Risiken in Absprache zwischen Betriebsarzt bzw. Dermatologen und Krankenhaushygieniker abzuwägen.

Schmuckstücke an Händen und Unterarmen behindern die sachgerechte Händehygiene und können dadurch zu einem Erregerreservoir werden [124]. Bei Intensivpflegepersonal korrelierte die Anzahl von Gram-negativen Erregern und $S$. aureus mit der Anzahl getragener Ringe [124]. Beim Tragen von Ringen war auf den Händen für Enterobacteriaceae und Nonfermenter eine erhöhte Trägerrate, allerdings keine erhöhte Transmissionsrate nachweisbar $[125,126]$. Aber auch wegen der Verletzungsgefahr ist das Tragen von Ringen nicht zulässig [4]. Schließlich führt das Tragen von Ringen zu erhöhter Perforationshäufigkeit von medizinischen Einmalhandschuhen (untersucht für OP-Handschuhe) [127]. 
Tab. 1 Vor- und Nachteile einzelner Händedesinfektionsmittel-Spendertypen (adaptiert nach WHO Guidelines on Hand Hygiene in Health Care [33]).

\begin{tabular}{|c|c|c|}
\hline Spendertyp & Vorteile & Nachteile \\
\hline $\begin{array}{l}\text { Wand- oder Bett-mon- } \\
\text { tierte Spender }\end{array}$ & $\begin{array}{l}\text { Lokalisation bekannt, als, „non -touch“ Systeme verwendbar, } \\
\text { für Personal, Patienten und Angehörige zugänglich }\end{array}$ & $\begin{array}{l}\text { Nicht immer günstig lokalisiert, um unmittelbare Verfügbar- } \\
\text { keit zu gewährleisten, können für Patienten und Angehörige } \\
\text { zur Gefahrenquelle werden, Spritzer auf dem Fußboden } \\
\text { können zu Schäden und Verfärbungen führen, aufwendige } \\
\text { Aufbereitung der Pumpsysteme }\end{array}$ \\
\hline $\begin{array}{l}\text { Mobile Spender mit } \\
\text { Dosierpumpen }\end{array}$ & $\begin{array}{l}\text { Unmittelbare Verfügbarkeit, } \\
\text { niedrigere Kosten, } \\
\text { für Personal, Patienten und Angehörige zugänglich }\end{array}$ & $\begin{array}{l}\text { Können leicht entfernt werden, } \\
\text { können für Patienten und Angehörige zur Gefahrenquelle } \\
\text { werden, falls keine Einmalpumpe, aufwendige Aufbereitung } \\
\text { der Pumpsysteme, je nach Füllzustand und Standort kann } \\
\text { die Standfestigkeit deutlich variieren }\end{array}$ \\
\hline Kitteltaschenflaschen & $\begin{array}{l}\text { Permanente unmittelbare Verfügbarkeit für das Personal, } \\
\text { erhöhen die wahrgenommene Kompetenz zur Durchführung } \\
\text { der Händedesinfektion im erforderlichen Umfang, für Patien- } \\
\text { ten und Angehörige nicht zugänglich, aber für bestimmte } \\
\text { Patienten nach Unterweisung möglich }\end{array}$ & $\begin{array}{l}\text { Wegen geringer Menge Logistik zum Nachschub notwendig, } \\
\text { höhere Kosten, höhere Umweltbelastung durch Einmalver- } \\
\text { wendung, Kontaminationsrisiko bei falscher Handhabung, } \\
\text { „Add ons“ wie Clips sind häufig vom Zulieferer abhängig }\end{array}$ \\
\hline $\begin{array}{l}\text { Automatische } \\
\text { Wandspender }\end{array}$ & $\begin{array}{l}\text { Bequeme Nutzung, zumindest unmittelbar nach Umstellung } \\
\text { höhere Inanspruchnahme, } \\
\text { ästhetisch ansprechend, „non-touch“ System, für Personal, } \\
\text { Patienten, Angehörige und Besucher zugänglich }\end{array}$ & $\begin{array}{l}\text { Nicht verwendbar, wenn elektronisches System nicht funkti- } \\
\text { oniert, hohe Wartungskosten, } \\
\text { Abhängigkeit von Zulieferer, Bestückung bedarf ggf. speziel- } \\
\text { ler Einweisung }\end{array}$ \\
\hline
\end{tabular}

Bei Vorliegen von Hautläsionen an den Händen ist es als ausreichend anzusehen, diese bei nichtchirurgischer Tätigkeit erreger- und ggf. flüssigkeitsdicht abzudecken (flüssigkeitsdichtes Pflaster) und darüber einen medizinischen Einmalhandschuh anzulegen. Voraussetzung ist, dass nach dem Ablegen der Handschuhe eine Händedesinfektion toleriert wird. Andernfalls sind die Mitarbeiter für die Dauer der Hautläsion patientenfern einzusetzen.

Beim atopischem Ekzem ist das Risiko der Besiedlung mit $S$. aureus einschließlich MRSA erhöht [128, 129]. Deshalb empfiehlt es sich, bei Mitarbeitern mit atopischem Ekzem und ggf. anderen chronischen Hauterkrankungen eine Kolonisation mit MRSA und ggf. anderen potentiell pathogenen Erregern auszuschließen und im Fall des Nachweises die Möglichkeit der Behandlung bzw. Dekolonisation zu überprüfen. Für die Dauer der Erregerfreisetzung sind die Mitarbeiter patientenfern einzusetzen.

Eine hohe Compliance der Händedesinfektion ist nur mit optimaler Ausstattung mit Händedesinfektionsmitteln erreichbar [34, 130, 131]. Es muss gewährleistet sein, dass für die Mitarbeiter keine zusätzlichen Wege entstehen, um im Verlauf der Patientenversorgung Zugang zum Händedesinfektionsmittel zu erhalten. Da die weitaus überwiegen- de Mehrheit der Indikationen zur Händedesinfektion direkt am Patienten entsteht, ist neben der durch die TRBA 250 vorgeschriebenen Ausstattung mit Händedesinfektionsmittelspendern die unmittelbare Verfügbarkeit direkt am $\mathrm{Pa}$ tienten zu gewährleisten [33]. Überall dort, wo eine Händedesinfektion durchgeführt werden muss, sind in unmittelbarer Nähe Desinfektionsmittel vorzuhalten. Für Patientenzimmer wird in Abhängigkeit von der Anzahl der Patientenbetten bettennah als Mindestausstattung ein Spender pro Patientenbett auf Intensiv- und Dialysestationen und auf Nicht-Intensivstationen ein Spender für zwei Patientenbetten sowie einer in der Sanitärzelle empfohlen. Die Art der eingesetzten Spender, d.h. fest an der Wand oder am Bett montierte Spender, mobile Spender mit Dosierpumpen oder Kittelflaschen, richtet sich nach den räumlichen Verhältnissen und den $\mathrm{zu}$ versorgenden Patienten (• Tab. 1). Z. B. kann es in der Geriatrie, Psychiatrie und Pädiatrie sowie ambulanten Diensten sinnvoll sein, auf Kittelflaschen sowie auf Spender am Visiten- oder Verbandwagen zurückzugreifen, um Gefährdungen der Patienten durch das Desinfektionsmittel auszuschließen. Ferner sind mobile oder montierte Spender an sauberen Arbeitsplätzen, am Visiten- oder Verbandwagen und in Schleusen vorzuhalten (• Tab. 1).
Benutzer von Kitteltaschenflaschen müssen darauf achten, dass die Flaschen sauber, ggf. mit Anbruchdatum beschriftet und das Etikett lesbar sind. Leere Kitteltaschenflaschen werden verworfen und sind nicht wieder zu befüllen. Nach ausreichender Benetzung beider Hände ist die Händedesinfektion erst nach dem Verschließen der Kittelflasche und ihrer $\mathrm{Zu}$ rückführung in die Tasche durchzuführen, um eine Rekontamination der Hände von Seiten der Kittelflasche zu verhindern.

\subsection{Indikationen}

Indikationen zur Händedesinfektion sind Situationen, in denen eine Händedesinfektion die Übertragung von potentiell pathogenen Erregern auf Patienten, Personal sowie Gegenstände und Oberflächen unterbricht. Beobachtungsstudien zur Händehygiene-Compliance zeigen immer wieder, dass es für die Mitarbeiter bei hoher Arbeitsbelastung mit häufigen Unterbrechungen von Arbeitsabläufen schwierig ist, eindeutig die Indikationen zur Händedesinfektion zu erkennen [132].

Die WHO hat basierend auf den Erkenntnissen zur Erregertransmission über die Hände die sich daraus ableitenden Indikationen in 5 Indikationsgruppen („five moments“) als Grundlage für die Schulung und das Training der Händedesinfektion zusammengefasst. Da- 


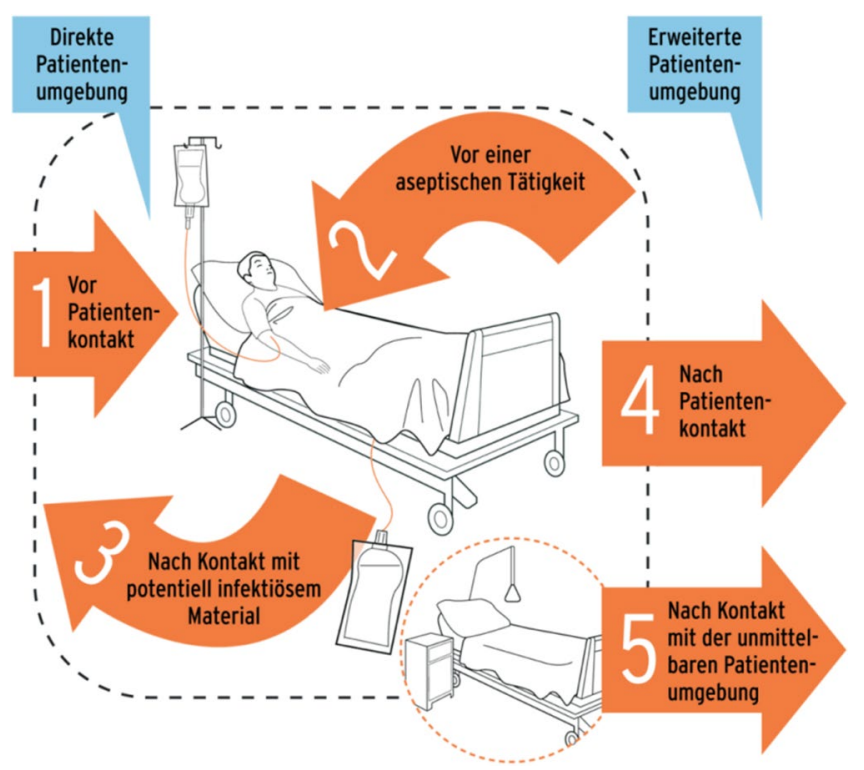

Abb. $1<$ Die 5 Indikationen der Händedesinfektion (adaptiert nach [134] und [33]). Mit freundlicher Genehmigung von Elsevier

durch soll zugleich das Wiedererkennen von Indikationen im Arbeitsablauf erleichtert werden. Darüber hinaus können Beobachtungen zur Compliance auf der Grundlage des Modells leichter standardisiert und verglichen werden [33]. Die fünf Indikationsgruppen beinhalten die Händedesinfektion unmittelbar vor Patientenkontakt, unmittelbar vor aseptischen Tätigkeiten, unmittelbar nach Kontakt mit potentiell infektiösen Materialien, nach Patientenkontakt und nach Kontakt mit der unmittelbaren Patientenumgebung (- Abb. 1). Diese Indikationen gelten in der stationären ebenso wie in der ambulanten Pflege. Grundsätzlich soll auch nach dem Ablegen steriler und unsteriler Schutzhandschuhe eine Händedesinfektion durchgeführt werden [33], weil eine Kontamination sowohl durch unbemerkte Perforation als auch beim Ablegen nicht auszuschließen ist.

Das WHO Modell definiert darüber hinaus eine unmittelbare und eine erweiterte Patientenumgebung. Die Indikationen zur Händedesinfektion ergeben sich aus der Abfolge der Tätigkeiten am Patienten sowie aus der Bewegung zwischen den definierten Bereichen.

Auf einer Dialysestation konnte durch Schulung und kritische Überprüfung von Arbeitsabläufen auf der Grundlage des Modells die Compliance der Händedesinfektion bei sinkender Anzahl von Indikationen um ca. $30 \%$ verbessert werden [133].

Sofern man das Handlungsmodell der „five moments" auf den niedergelassenen
Bereich überträgt, erscheint es adäquat, die Situation ,vor und nach Patientenkontakt" auf die körperliche Untersuchung zu begrenzen [http://www.aktion-sauberehaende.de/ash/module/ambulante-medizin/5-indikationen/]. Im Altenheim ist die Situation vergleichbar, d. h. eine Händedesinfektion ist vor und nach der Körperpflege oder beim Lagern eines Bewohners indiziert [http://www.aktion-sauberehaende.de/ash/module/alten-und-pflegeheime/5-indikationen/].

\section{Unmittelbare Patientenumgebung}

Sie umfasst die unmittelbare Umgebung des Patienten, d.h. typischerweise alle Oberflächen, die entweder direkt mit dem Patienten in Kontakt kommen (Bettwäsche, Bettgestell) oder häufig vom Patienten selbst oder im Verlauf der Versorgung des Patienten vom Personal berührt werden (z. B. Bettgestell, Nachttisch, geschlossene Infusions- und Drainagesysteme, Monitore). Dazu gehören z. B. auch das Beatmungsgerät und für die Dauer der Dialyse das Dialysegerät. Patienten nahe Oberflächen und Strukturen werden im Verlauf der Patientenversorgung rasch und in hohem Maß mit der jeweiligen $\mathrm{Pa}$ tientenflora kontaminiert [135-140].

Innerhalb der unmittelbaren Patientenumgebung werden kritische Bereiche definiert, in denen aseptische Tätigkeiten oder Handkontakte oder Kontakte zu potentiell infektiösen Materialien stattfinden wie z. B.

- mit natürlichen Körperöffnungen wie Mund, Nase, Augen
- mit nicht intakter Haut mit oder ohne Eröffnung von Körperhöhlen wie Wunden, OP-Wunden, Druckulcera usw.

- Behandlungs-assoziierte invasive Maßnahmen wie Injektionen und Punktionen

- mit Device-assoziierten kritischen Bereichen wie diskonnektierte Gefäßkatheter, diskonnektierte Drainageauffangbeutel usw..

\section{Erweiterte Patientenumgebung}

Sie beinhaltet alle darüber hinaus gehenden Bereiche, die seitens des Patienten kontaminiert werden können.

Die Indikationen der Händedesinfektion (• Tab. 2) ergeben sich aus verschiedenen Risiken seitens des Patienten und des Personals [134]. Entscheidend ist, dass durch die Händedesinfektion die Übertragung von Krankheitserregern verhindert wird.

Da sich die Händedesinfektion beim Personal als wirksamste Maßnahme zur Prävention nosokomialer Infektionen erwiesen hat und durch Händedesinfektion selbst in nichtmedizinischen Bereichen eine Herabsetzung gastrointestinaler und/ oder respiratorischer Infektionen bzw. Krankheitstage erreichbar war, ist davon auszugehen, dass auch Patienten davon profitieren, wenn sie selbst und ihre Angehörigen sich die Hände situationsabhängig desinfizieren. In Anlehnung an die WHO können die folgenden „Fünf Momente" für die Händedesinfektion des $\mathrm{Pa}$ tienten als relevant anzusehen [141]:

- Bei Betreten des Patientenzimmers,

- bei Verlassen des Patientenzimmers,

- vor Esseneinnahme,

- nach Benutzung der Sanitäreinheit (WC),

- vor und nach Kontakt mit der eigenen Wunde, mit Schleimhäuten oder vor Betreten von Risikobereichen.

Ergänzend ist ein Hinweis auf die Vermeidung unnötiger Kontakte mit Oberflächen im Krankenhaus sinnvoll. Falls das unvermeidbar ist, wird die anschließende Durchführung einer Händedesinfektion empfohlen.

\section{Technik}

Zur effizienten Unterbrechung der Erregerübertragung ist die korrekte 
Tab. 2 Typische Situationen mit Indikationen für die hygienische Händedesinfektion.

\begin{tabular}{|c|c|c|c|}
\hline Indikation & Beispielsituationen & Erläuterung & Kommentar \\
\hline $\begin{array}{l}\text { VOR direktem } \\
\text { Patientenkontakt }\end{array}$ & $\begin{array}{l}\text { Patient waschen, } \\
\text { Puls und Blutdruck messen, auskultieren, palpieren, } \\
\text { Physiotherapie usw. }\end{array}$ & $\begin{array}{l}\text { Unmittelbar vor dem direkten } \\
\text { Patientenkontakt }\end{array}$ & $\begin{array}{l}\text { Direkter Patientenkontakt ist } \\
\text { immer als Kontakt mit Haut, } \\
\text { Schleimhäuten oder Wunden } \\
\text { definiert }\end{array}$ \\
\hline $\begin{array}{l}\text { VOR aseptischen } \\
\text { Tätigkeiten }\end{array}$ & $\begin{array}{l}\text { Vor jedem Kontakt mit nicht intakter Haut und Wunden, } \\
\text { zwischen Entfernen des alten und Anlegen des neuen } \\
\text { Verbands, Injektionen und Punktionen, Konnektion/ } \\
\text { Diskonnektion geschlossener Systeme (Gefäßkatheter-, } \\
\text { Drainage- oder Beatmungssysteme), Vorbereiten von } \\
\text { Parenteralia, } \\
\text { Kontakt mit Schleimhäuten z. B. Mund- und Zahnpflege, } \\
\text { Zubereiten und Verabreichen von Sondennahrung }\end{array}$ & $\begin{array}{l}\text { Vor jeder Manipulation an Devices, } \\
\text { falls Handschuhe getragen wer- } \\
\text { den, Desinfektion der behand- } \\
\text { schuhten Hand (Einschränkungen } \\
\text { s. } 6.1 \text { ) } \\
\text { Wechsel von besiedelten/unrei- } \\
\text { nen zu nicht besiedelten/reinen } \\
\text { Bereichen }\end{array}$ & $\begin{array}{l}\text { Manipulation immer im Sinn von } \\
\text { Diskonnektion bzw. Eröffnen } \\
\text { geschlossener Systeme } \\
\text { z. B. vom Urogenitalbereich zur } \\
\text { Mundschleimhaut }\end{array}$ \\
\hline $\begin{array}{l}\text { NACH Kontakt mit } \\
\text { potentiell infektiösem } \\
\text { Material (Körper- } \\
\text { flüssigkeiten usw.) }\end{array}$ & $\begin{array}{l}\text { Nach Kontakt mit Schleimhäuten, Aspiration von und } \\
\text { Umgang mit Blut und } \\
\text { jeder Art von Sekreten, Wundversorgung, Entfernen } \\
\text { von Verbänden, Anlage/Absaugen und Entfernen von } \\
\text { endotrachealen Tuben usw. }\end{array}$ & $\begin{array}{l}\text { Nach dem Ausziehen der Hand- } \\
\text { schuhe, } \\
\text { nach Kontakt mit Körperflüssigkei- } \\
\text { ten, Schleimhäuten, nicht intakter } \\
\text { Haut oder Wundverbänden, } \\
\text { Wechsel von besiedelten zu nicht } \\
\text { besiedelten Körperbereichen }\end{array}$ & $\begin{array}{l}\text { Waschen in der Urogenitalregion } \\
\text { oder Entsorgung kontaminierter } \\
\text { Wäsche kann in diese Indikati- } \\
\text { onsgruppe eingruppiert werden }\end{array}$ \\
\hline $\begin{array}{l}\text { NACH direktem } \\
\text { Patientenkontakt }\end{array}$ & $\begin{array}{l}\text { Patienten waschen, } \\
\text { Puls und Blutdruck messen, auskultieren, palpieren, } \\
\text { Physiotherapie }\end{array}$ & $\begin{array}{l}\text { Unmittelbar nach dem direktem } \\
\text { Patientenkontakt }\end{array}$ & $\begin{array}{l}\text { Haut-, Schleimhaut- oder Wund- } \\
\text { kontakt }\end{array}$ \\
\hline $\begin{array}{l}\text { NACH Kontakt mit der } \\
\text { direkten Patientenum- } \\
\text { gebung }\end{array}$ & $\begin{array}{l}\text { Wechsel der Bettwäsche, } \\
\text { Einstellen der Tropfgeschwindigkeit am Infusionssystem, } \\
\text { Kontakt zu Monitoren, Rechnern und Medizingeräten, } \\
\text { Kontakt zum Bett und Nachtschrank sowie mit persönli- } \\
\text { chen Gegenständen des Patienten }\end{array}$ & $\begin{array}{l}\text { Kontakt mit Oberflächen und Ge- } \\
\text { genständen in der unmittelbaren } \\
\text { Patientenumgebung }\end{array}$ & $\begin{array}{l}\text { Dazu gehören auch das Beat- } \\
\text { mungsgerät und für die Dauer } \\
\text { der Dialyse das Dialysegerät }\end{array}$ \\
\hline
\end{tabular}

Durchführung der Händedesinfektion unerlässlich. Hierzu wird ein Volumen von etwa 3-5 $\mathrm{ml}$ bzw. der Menge, die in eine Hohlhand passt, so in beide Hände eingerieben, dass die gesamte Oberfläche der Hand, d.h. Fingerspitzen, Nagelfalze, Daumen, Fingerzwischenräume, Innen- und Außenflächen für die Dauer der vom Hersteller deklarierten Einwirkzeit (üblicherweise $30 \mathrm{~s}$ ) mit dem Desinfektionsmittel benetzt sind. Werden $<2 \mathrm{ml}$ appliziert, verringert sich die benetzte Fläche signifikant [142]. Das Desinfektionsmittel soll insbesondere an den Fingerspitzen, Nagelfalzen und Daumen eingerieben werden [143, 144]. Das wird allerdings oft nicht ausreichend berücksichtigt [145]. Beim Vergleich der in der DIN EN 1500 [17] vorgegebenen Bewegungsabfolge mit selbst gewählter Einreibetechnik mit dem Fokus der Benetzung der o.g. Handflächen konnte kein Vorteil zur Bewegungsabfolge der Prüfnorm nachgewiesen werden [143]. Allerdings ist eine standardisierte Bewegungsabfolge beim Erlernen der Technik sinnvoll.

\section{Die Chirurgische Händedesinfektion}

Die chirurgische Händedesinfektion ist Standard vor jedem operativen Eingriff [146], um präoperativ die transiente Flora der Hände zu eliminieren und die residente Flora der Hände für die Dauer der OP größtmöglich zu reduzieren. Zusätzlich wird das Kontaminationsrisiko durch das Tragen steriler OP-Handschuhe reduziert.

Für aseptisches Arbeiten an klinischen Reinraumplätzen z. B. in einer Hornhautbank, ist die chirurgische Händedesinfektion mit nachfolgendem Anlegen steriler Handschuhe zu empfehlen [147].

\subsection{Mikrobizide Wirksamkeit und Verträglichkeit}

Die Anforderungen an die Wirksamkeit unterscheiden sich gemäß DIN EN 12791 [18] nicht zwischen mikrobiziden Handwaschpräparaten und alkoholischen Einreibepräparaten; demzufolge war bei alternativer Anwendung je eines Vertreters beider Präparatetypen kein Unterschied auf die Rate postoperativer Wundinfek- tionen nachweisbar [148, 149]. Dennoch ist der Einsatz von Handwaschpräparaten keine Alternative für alkoholische Einreibepräparate zur chirurgischen Händedesinfektion, da die Hautverträglichkeit alkoholischer Einreibepräparate deutlich besser als von Handwaschpräparaten ist $[150,151]$. Auch das Kontaminationsrisiko beim Waschvorgang durch die Emission der Siphonflora beim Abspülen der Hände spricht gegen den Einsatz von Handwaschpräparaten [152, 153].

Für Alkohol basierte Präparate mit Zusatz von Chlorhexidin steht der Nachweis der höheren Wirksamkeit in Bezug auf die Prävention postoperativer Wundinfektionen aus. Auch wenn einige Studien zeigen, dass durch den Zusatz von Chlorhexidin die remanente Wirkung verbessert wird [154-156], ist bei der Ergebnisinterpretation zu berücksichtigen, dass keine Neutralisierung von Chlorhexidin in der Ausknetflüssigkeit durchgeführt wurde. Das führt ggf. zu einer Vermehrungshemmung noch verbliebener Bakterien, so dass falsch niedrige Koloniezahlen gemessen werden. Die Aussagekraft der Ergebnisse ist daher eingeschränkt. Hinzu 
kommt als weiterer Aspekt für den Verzicht auf die Anwendung von Alkoholen mit remanentem Zusatz, dass sich durch den Zusatz toxische Risiken ergeben können. So sind durch Chlorhexidin wenn auch selten anaphylaktische [157-159] und allergische Reaktionen beschrieben [160]. In diesen Fällen darf der Wirkstoff nicht weiter angewendet werden. Zugleich erhöht sich die Irritationspotenz von Alkoholen durch den Zusatz von Chlorhexidin [161]. Gegen den Einsatz Chlorhexidin basierter Händedesinfektionsmittel spricht ferner das Risiko der Resistenzentwicklung einschließlich der Möglichkeit von Kreuzresistenzen zu Antibiotika [162-180]. Allergische Nebenwirkungen sind auch für Triclosan (Prävalenz bis $0,2 \%$ ) und Benzalkoniumchlorid (Prävalenz bis $7,2 \%$ ) beschrieben $[59,150,151$, 181-186]. Die Gefahr der Resorption toxisch wirkender Mengen von Benzalkoniumchlorid besteht bei Einwirkung auf vorgeschädigter Haut nach längerer Kontaktzeit [187]. Auf Grund der Resorptionstoxizität ist der Einsatz von PVP-Iod in Alkohol basierten Händedesinfektionsmitteln abzulehnen [61].

Derzeit gibt es keine Grundlage zur Empfehlung einer routinehaften erneuten Durchführung der chirurgischen Händedesinfektion während der Operation in Abhängigkeit von der OP-Dauer.

\subsection{Prävention postoperativer Wundinfektionen}

Es ist davon auszugehen, dass durch die chirurgische Händedesinfektion das Risiko postoperativer Wundinfektionen gesenkt wird. Diese Schlussfolgerung lässt sich aus folgendem Sachverhalt ableiten. OP-Handschuhe können in bis zu $40 \%$ der Eingriffe bemerkt oder unbemerkt perforieren [147]. Experimentell wurde nachgewiesen, dass ausgehend von nicht desinfizierten Händen bei einer Handschuhperforation bis zu $10^{3}-10^{4}$ Kolonie bildende Einheiten $(\mathrm{KbE})$ die Wunde erreichen können [148]. Im Gegensatz dazu betrug die übertragene Menge bei zuvor desinfizierten Händen $<100 \mathrm{KbE}[148$, 149]. Damit wäre zu erklären, dass bei im Trageprozess perforierten OP-Handschuhen erst nach einer Tragedauer von $>90$ min ein Bakterientransfer nachweisbar war $[154,155]$. Ein Ausbruch postoperativer Wundinfektionen wurde dadurch verursacht, dass anstelle eines jodhaltigen Händedesinfektionsmittels eine nichtmedizinischen Seife verwendet wurde [188], d.h. auf Grund der bei längeren chirurgischen Operationen unvermeidbaren Handschuhperforation wurde auf Grund der fehlenden Händedesinfektion ein Ausbruch verursacht.

\subsection{Voraussetzungen}

Der OP-Bereich ist mit sichtbar sauberen Händen und Fingernägeln zu betreten. Schmutzige Hände und Fingernägel (z.B. nach Gartenarbeit) sind bereits zuhause, spätestens aber im unreinen Teil der Personalschleuse vor dem Anlegen der Bereichskleidung zu säubern. Kommt es während der Tätigkeit zur Verschmutzung der Hände, sind ein Handwaschpräparat und zur der Schonung der Haut nur im Bedarfsfall eine Nagelbürste zu benutzen.

Bezüglich Fingernägeln und Schmuckstücken an Händen und Unterarmen gelten die gleichen Voraussetzungen wie für die hygienische Händedesinfektion (s. 3.3) Hände und Unterarme sind wegen des Risikos der Wegbereitung von Hautirritationen und der damit verbundenen höheren Erregerabgabe nicht mit einer Bürste zu behandeln $[189,190]$.

Vor operativen Eingriffen sollen keine Nagelbettverletzung oder entzündliche Prozesse an der Hand vorliegen [190]. Bei Psoriasis mit Kolonisation durch $S$. marcescens und bei schwerer Onycholyse und Onychomykose eines Fingernagels mit gleichzeitigem subungualem Nachweis von P. aeruginosa wurde ein Ausbruch postoperativer Wundinfektionen trotz Tragens von OP-Handschuhen verursacht $[114,191]$. Unter sorgfältiger Risikoabwägung erscheint es bei nichtentzündlichen Veränderungen bzw. kleinen Verletzungen im Bereich der Hand jedoch vertretbar, die Operation mit zwei übereinander gezogenen Paar Handschuhen, ggf. nach vorheriger Applikation eines Wundantiseptikums mit remanenter Wirksamkeit (z. B. auf Basis von Octenidin) im Wundbereich durchzuführen [190]. Alternativ könnten antimikrobiell imprägnierte OP-Handschuhe die
Schutzwirkung verbessern [192]. Gegebenenfalls ist eine Vorstellung beim Betriebsarzt bzw. Facharzt für Dermatologie anzuraten.

Ringdosimeter können bei sachgerechter Anwendung aus Personalschutzgründen unter dem Aspekt der Risikoabwägung toleriert werden. Getragene Ringdosimeter sind unter Berücksichtigung der Herstellerangaben aufzubereiten, z. B. durch Einlegen in ein alkoholisches HDM für die Dauer von $10 \mathrm{~min}$. Danach kann der Ring ohne Klarspülen mit Wasser nach Lufttrocknung erneut auf die desinfizierte Hand angelegt werden [193].

\subsection{Indikationen}

Die chirurgische Händedesinfektion ist vor dem direktem Kontakt zum OP-Feld und zu sterilen MP oder Materialien sowie vor sonstigen Eingriffen mit gleichen Anforderungen an die Asepsis wie bei einer Operation durchzuführen. Im Unterschied zur hygienischen Händedesinfektion gibt es bei der Akzeptanz der Notwendigkeit einer chirurgischen Händedesinfektion vor Anlegen der sterilen Handschuhe kein Complianceproblem; letzteres kann nur die Durchführung und die Einhaltung der Zeitdauer betreffen.

\subsection{Technik}

Um die Sporenlast an den Händen zu reduzieren, wird empfohlen, die Hände vor der am OP-Tag erstmalig durchgeführten chirurgischen Händedesinfektion möglichst mit einem Abstand von $10 \mathrm{~min}$ vor der chirurgischen Händedesinfektion zu waschen und sorgfältig abzutrocknen [194]. Bei kürzerem Abstand wird die Wirksamkeit der Alkohole durch den Verdünnungseffekt der Restfeuchte tendenziell oder signifikant reduziert [195-199]. Eine Wiederholung der Händewaschung ist im weiteren Tagesablauf nur bei sichtbarer Verschmutzung erforderlich. Zur Waschung werden Hände und Unterarme bis zum Ellenbogen mit nach oben gerichteten Fingerspitzen und tief liegendem Ellenbogen während etwa 30-60 s mit einem Handwaschpräparat gewaschen. Länger dauernde Händewaschungen sind wegen potenzieller Hautschädigung ab- 
zulehnen, zumal dadurch keine weitere Verminderung der residenten Flora erreicht wird [200-202]. Zur Desinfektion werden die Hände und Unterarme für die Dauer der deklarierten Einwirkungszeit durch eine eingeübte Einreibetechnik benetzt. Bei der Händedesinfektion werden zunächst die Hautareale der Hand, dann des Unterarms bis zum Ellenbogen und nachfolgend wieder die Hände benetzt. In dieser Händedesinfektionsphase soll das Hauptaugenmerk beim Einreiben auf die Fingerkuppen, Nagelfalze und Fingerzwischenräume gelegt und eine lückenlose Benetzung erreicht werden. Für die Einwirkungszeit von 1,5 min [203] erwies sich folgendes Vorgehen als effektiv: Zunächst werden beide Hände (10 s) und im 2. Schritt beide Unterarme benetzt (10 s). Dem schließt sich die Händedesinfektionsphase (70 s) mittels Einreiben an [204]. Dabei hat die Anzahl der applizierten Portionen keinen Einfluss, solange die Hände über die Dauer der Einwirkungszeit mit dem Präparat benetzt gehalten werden [205]. Es ist zu beachten, dass dieses Vorgehen nur für Produkte mit einer deklarierten Einwirkzeit von 1,5 min untersucht wurde.

Die Hände sollen trocken sein, bevor die OP-Handschuhe angelegt werden, weil dadurch die Perforationsgefahr verringert [206], das Irritationsrisiko reduziert [207] und Wirksamkeit der alkoholischen Händedesinfektion bei 1 min Lufttrocknung signifikant verbessert werden [208, 209].

\section{Die Händewaschung}

\subsection{Ausstattung medizinischer Handwaschplätze}

Ein hygienischer Handwaschplatz muss mit Zulauf für warmes und kaltes Wasser ausgestattet sein [4]. Bei einer Neueinrichtung oder wesentlichen Umgestaltung eines Handwaschplatzes ist auf ein ausreichend groß dimensioniertes, tief ausgeformtes Handwaschbecken ohne Überlauf zu achten. Der Verzicht auf einen Überlauf im Waschbecken erscheint nicht nur hygienisch plausibel, sondern der kolonisierte Überlauf konnte als Ursache einer Häufung von Serratia liquefaciens Infektionen identifiziert werden [210]. Falls saubere Arbeitsflächen an den
Waschplatz angrenzen, sind diese durch einen Spritzschutz so abzuschirmen, dass es (insbesondere in Bereichen der Zubereitung von Medikamenten) nicht zu einer Kontamination der Umgebung kommen kann [211-213]. Der Handwaschplatz muss abhängig von den räumlichen $\mathrm{Be}$ dingungen mit wandmontierten Spendern für Händedesinfektionsmittel und Handwaschpräparat und mit Einmalhandtüchern ausgestattet sein [4]. Der Wasserstrahl darf nicht direkt auf den Abfluss gerichtet sein, um die Entstehung des erregerhaltigen Aerosols aus dem Siphon zu minimieren [194].

Hautpflegemittel können in Spendern oder in herkömmlicher Form als Tuben bereitgestellt werden. Ersteres hat den Vorteil der Herabsetzung des Kontaminationsrisikos des Hautpflegemittels, sofern Einmalgebinde eingesetzt werden. Zugleich wird die Nutzung erleichtert. Es ist als ausreichend anzusehen, wenn Hautpflegemittel z. B. im Stationsdienstzimmer, in Umkleiden und in Pausenräumen verfügbar sind.

Handwaschplätze müssen in Räumen oder in der Nähe von Räumen vorhanden sein, in denen diagnostische oder invasive Maßnahmen stattfinden, in Räumen, die der Vorbereitung solcher Maßnahmen dienen, sowie in unreinen Arbeitsbereichen bzw. in deren Nähe, aber z. B. nicht im Arztdienstzimmer. Für jedes Patientenzimmer sollte eine für die Beschäftigten leicht erreichbare Waschgelegenheit möglichst in der Sanitärzelle verfügbar sein, die analog wie der Handwaschplatz ausgestattet sein soll, damit sie im Bedarfsfall vom Personal genutzt werden kann. Das betrifft z. B. die Händewaschung nach Ablegen der Handschuhe nach der Versorgung von Patienten mit C. difficile assoziierter Diarrhoe oder nach unerwarteter massiver Verunreinigung/ Kontamination der Hände im Rahmen der Patientenversorgung.

Waschbecken, die von Beschäftigten mit direktem Patientenkontakt genutzt werden oder sich in kritischen Bereichen befinden, müssen eine handkontaktlose Bedienung mittels verlängerter Hebelarmatur ermöglichen oder mittels Fußoder Knieauslösung das Wasser freigeben, um eine Weiterverbreitung von Krankheitserregern zu verhindern. Sensorarma- turen bergen ein hygienisches Risiko, weil sich z.B. Gram-negative Nonfermenter ansiedeln können, was Ursache von Ausbrüchen war [214-220].

Spender für Einmalhandtücher müssen eine einfache Entnahme ermöglichen, ohne dass die nachfolgenden Handtücher und die Entnahmeöffnung kontaminiert werden. Für gebrauchte Handtücher ist ein Sammelbehälter (Papierkorb bzw. Plastiksack) vorzusehen und für dessen regelmäßige Entleerung Sorge zu tragen, um von Seiten der Patienten einer Entsorgung in die Toilette mit ggf. nachfolgender Verstopfung der Abwasserrohrsysteme vorzubeugen. Alternativ kommen Retraktivspender mit automatischem Vorschub des Textilhandtuchs in Betracht, das von einer Rolle abgespult und nach der Benutzung auf einer zweiten Rolle ohne Kontakt zur unbenutzten Handtuchrolle aufgerollt wird. Allerdings ist zu berücksichtigen, dass Stoffhandtücher auf Rollen häufig nicht einwandfrei funktionieren und im Gebrauch störanfällig sind.

Konventionelle Heißlufttrockner sind für Gesundheitseinrichtungen ungeeignet, weil die Trocknungswirkung im Vergleich zum Handtuch geringer ist [221223]. Nur ,jet air“ Händetrockner mit Infrarot erwiesen sich bei $10 \mathrm{~s}$ Anwendung dem Papierhandtuch in der Trocknungswirkung gleichwertig [224]. Da nach Händewaschung durch sorgfältige Händetrocknung die Translokation von Bakterien von den Händen auf Kontaktflächen signifikant herabgesetzt wird $[221,225]$, ist auch unter diesem Gesichtspunkt die Händetrocknung wichtig [226, 227]. Allerdings war nach vorher durchgeführter Händedesinfektion keine erhöhte Translokation durch Heißlufttrockner nachweisbar [228, 229]. Nach Händewaschung wird durch Papier- oder Textilhandtuch signifikant mehr Restflora als durch Heißlufttrockner entfernt [230-232]. Schließlich ist bei der Auswahl des Trocknungssystems zu berücksichtigen, dass Nutzer bezüglich Komfort und Nutzerfreundlichkeit Einmalhandtücher gegenüber Heißlufttrocknern bevorzugen [226] und die Lärmbelastung bei „jet air“ Trocknern in 0,5 m Entfernung $94 \mathrm{~dB}$ erreicht [224]. Für einen „,air blade“ Trockner wurde ermittelt, dass die Anzahl freigesetzter Tröpfchen beim Trocknungs- 
vorgang höher war und weiter reichte als bei Benutzung eines Papierhandtuchs. Die Autoren schließen nicht aus, dass bei Vorhandensein von Pathogenen auf den Händen die Umgebung mit ihnen kontaminiert werden könnte [233]. Ein Review kommt $\mathrm{zu}$ analoger Schlussfolgerung, dass durch ,jet air“ und Warmlufttrockner die Ausbreitung kontaminierter Aerosole begünstigt wird, so dass diese Trockner in medizinischen Einrichtungen und speziell in Baderäumen ungeeignet sein könnten [234].

Der Waschbeckenablauf ist ein offenes Erregerreservoir der Fäkal- und Oralflora des Patienten [235]. Beim Einlaufen von Wasser werden Bakterien bis zu 1,85 m im Umkreis aus dem im Siphon stehenden Abwasser emittiert [236]. Da die Ausbreitung von verschiedenen Faktoren beeinflusst wird, sollte man aus $\mathrm{Si}$ cherheitsgründen von $2 \mathrm{~m}$ ausgehen. Bei Siphonkontamination $>10^{5} \mathrm{KbE} / \mathrm{ml}$ ist die Übertragung von Bakterien auf die Hände des Pflegepersonals bei der Händewaschung nachgewiesen [153]. Mit $P$. aeruginosa kolonisierte Siphons konnten als Risikofaktor für die Kolonisation von Patienten identifiziert werden [237, 238]. Beschrieben sind vom Siphon ausgehend Ausbrüche durch E. cloacae, P. aeruginosa, A. baumannii und Serratia spp. [238-241]. Nach 3mal täglicher Siphonreinigung und Veränderung des Siphons konnte ein sich über 5 Jahre erstreckender Ausbruch beendet werden [241]. Bei einem Multispeziesausbruch mit Enterobakterien konnten die Erreger u.a. auch im Siphon nachgewiesen werden, wenn auch die sekundäre Kontamination von Lebensmitteln offenbar der entscheidende Verbreitungsweg war [238]. Wenn Siphonstöpsel gewünscht sind, sollten sie leicht der desinfizierenden Reinigung zu unterziehen sein, also nicht aus Gummi oder Kunststoff sein. Günstig ist ein weit über die Siphonöffnung übergreifender Verschluss zur Abschirmung des durch das einlaufende Wasser entstehenden Aerosols. Automatische Siphon-Desinfektionsanlagen können in speziellen Einheiten, z. B. bei Mukoviszidosepatienten, zur Prophylaxe von Pseudomonas-Infektionen indiziert sein [242]. Silikonstöpsel sollen wegen der Kontaminationsgefahr nicht auf dem Waschbecken gelagert werden.

\subsection{Eigenschaften und Auswahl von Handwaschpräparaten}

Für in medizinischen Einrichtungen verwendete Handwaschpräparate gelten die Anforderungen an Kosmetika, d. h. $\leq 10^{3}$ $\mathrm{KbE} / \mathrm{ml}$ und kein Nachweis von $P$. aeruginosa, S. aureus und C. albicans in $0,1 \mathrm{ml}$ [243]. Es werden sowohl konservierte Produkte als auch Präparate mit nicht näher definierter antimikrobieller Wirksamkeit eingesetzt. Die Verwendung von Produkten mit antimikrobiellen Zusätzen wird in keinem Regelwerk gefordert, ist nicht mit einer besseren Wirksamkeit gegenüber der normalen Seifenwaschung belegt und ist immer dann kritisch zu beurteilen, wenn als antimikrobieller Zusatz ein Wirkstoff eingesetzt wird, für den das Risiko einer mikrobiellen Resistenzentwicklung oder einer Sensibilisierung gegeben ist.

Für die hygienische Händewaschung sind in der VAH-Liste [15] Produkte zertifiziert, die vor allem für den Lebensmittelbereich gedacht sind. Sie sind signifikant wirksamer als normale Handwaschpräparate, erreichen aber nicht die Wirksamkeit von HDM. Daher ist ihre Anwendung keine Alternative zur hygienischen Händedesinfektion.

Die Wirksamkeit der Händewaschung auf die transiente Flora korreliert mit der Dauer des Händewaschens und der Technik [244]. Da die Waschdauer im Krankenhaus zwischen 8 und 20 s beträgt [ 145 , 245], dürfte die mittlere Reduktion deutlich unter einer Log-Stufe liegen. Obwohl bereits durch Händewaschung die Rate von NI herabgesetzt werden kann [246250], ist abhängig vom Ausmaß der Kontamination die Wirksamkeit nicht ausreichend [81], so dass die Händewaschung keine Alternative für die hygienische Händedesinfektion ist.

Die bessere Hautverträglichkeit alkoholischer Einreibepräparate im Vergleich zu Handwaschpräparaten ist durch klinische und durch Anwendungsstudien belegt $[67,251]$. Werden beruflich beanspruchte Hände viermal innerhalb $1 \mathrm{~h}$ gewaschen, ist die Zeitspanne zur Normalisierung der Hautparameter nicht mehr ausreichend [252]. Wegen der mit wiederholter Händewaschung verbundenen Hautschädigung [67] soll die Hände- waschung ausschließlich der Entfernung von Schmutz bzw. gegen Alkohol unempfindlichen Erregern vorbehalten bleiben.

Auswahlkriterien für die Art des Handwaschpräparats sind das Kontaminationsrisiko des Produkts und die Hautverträglichkeit [253]. Unter Anwendungsbedingungen wurde wiederholt eine Kontamination fester Handwaschpräparate nachgewiesen [254-256]. Feste Handwaschpräparate waren sowohl mit Gram-positiven als auch mit Gram-negativen Bakterien häufiger und höher als flüssige Handwaschpräparate kontaminiert [257]. In einer Querschnittsstudie waren auf $70 \%$ fester Handwaschpräparate insgesamt 44 Spezies mit Überwiegen von $P$. aeruginosa, E. coli und $A$. baumanii nachweisbar. Bei flüssigen Handwaschpräparaten waren $16 \%$ mit 7 Spezies kontaminiert, davon überwiegend mit Pseudomonas spp. Die Rate von NI fiel nach Einführung eines flüssigen Handwaschpräparats im Verlauf eines Jahres von $4,2 \%$ auf 2,2\% [258]. Im Ergebnis einer experimentellen Studie wurde allerdings das Übertragungsrisiko durch ein mit E. coli und $P$. aeruginosa $\left(4,4 \times 10^{5} \mathrm{KbE} /\right.$ Seifenstück) kontaminiertes festes Handwaschprodukt als nicht relevant eingeschätzt, weil nach dem Waschen und Abspülen der Hände in keinem Fall Erreger auf den Händen nachweisbar waren [259]. Da feste Handwaschprodukte seit Jahren nicht mehr im medizinischen Bereich eingesetzt werden, sind in der jüngeren Literatur nur flüssige Handwaschpräparate als Kontaminationsquelle aufgeführt. Im Rahmen eines Ausbruchs mit S. liquefaciens war ein flüssiges antibakterielles Handwaschpräparat im Spender mit dem Erreger kontaminiert, weil der nicht vollständig entleerte Spender ohne Aufbereitung nachgefüllt wurde [260]. Bei ebenfalls nachgefüllten Flaschen waren $1 / 5$ bis 1/4 aller flüssigen Handwaschpräparate in öffentlichen Toiletten mit 15 verschiedenen Spezies bis $10^{7} \mathrm{KbE} / \mathrm{ml}$ kontaminiert [261, 262]. Das Nachfüllen wird auch in weiteren Studien als Kontaminationsursache verbunden mit Ausbrüchen angesehen [260, 263-266]. Auch nosokomiale $S$. marcescens Infektionen waren mit der Kontamination eines flüssigen Handwaschpräparats assoziiert [25, 267]. Experimentell wurde nachgewiesen, dass durch 
Waschen mit einem kontaminierten flüssigen Handwaschpräparat die Anzahl Gram-negativer Erreger auf den Händen ansteigt und eine Weiterverbreitung auch in Gemeinschaftseinrichtungen möglich erscheint [263]. Selbst wenn die Spender mit Einwegflaschen bestückt werden, ist bei nicht ordnungsgemäßer vollflächiger Reinigung und Desinfektion der Spender einschließlich des Steigrohrs eine Kontamination des Handwaschpräparats möglich [260, 268, 269]. Als Fazit ist die Anwendung von Handwaschprodukten in Stückform in medizinischen und pflegerischen Bereichen obsolet.

\subsection{Indikationen}

Zweck der Händewaschung ist die Reinigung der Hände zur Entfernung von Schmutz und Verunreinigungen sowie zur Entfernung lose adhärierter Krankheitserreger, sofern diese nicht durch Händedesinfektion abgetötet werden können (z.B. bei Kontamination mit Bakteriensporen, Helminthen, Kryptosporidien, Oozysten und Protozoen). Bei starker Belastung der Hände mit Schweiß (z. B. nach langer OP) empfiehlt es sich, die Hände vor der Händedesinfektion mit einem Papierhandtuch $\mathrm{zu}$ trocknen. Gegebenenfalls sollten abschließend eine Händewaschung und die Anwendung einer hautpflegenden Lotion erfolgen [270]. Nach Toilettenbenutzung ist das Standardverfahren die Händewaschung. Bei Diarrhoe oder Rhinitis kann eine Händedesinfektion sinnvoll sein.

\subsection{Technik}

Bei der Händewaschung sind besonders die subungualen Räume zu berücksichtigen, da sie den größten Teil der Handflora enthalten [271]. Stellt sich der Wasserlauf nicht automatisch $\mathrm{ab}$, wird er mit dem gebrauchten Handtuch oder dem Ellenbogen geschlossen [272].

Ist zusätzlich zur hygienischen Händedesinfektion eine Reinigung erforderlich, soll diese bis auf folgende Ausnahmen erst nach der Desinfektion durchgeführt werden [47]:

- Stark verschmutzte Hände werden zunächst vorsichtig abgespült und dann gewaschen. Dabei ist darauf zu achten, dass Umgebung und Kleidung nicht bespritzt werden (z. B. bei Blutverunreinigung). Der ggf. kontaminierte Bereich ist danach zu desinfizieren und der Kittel zu wechseln. Im Anschluss sind die Hände zu desinfizieren.

- Bei punktueller Verunreinigung kann diese mit einem mit HDM getränktem Papierhandtuch, Zellstoff o. Ä. entfernt und danach die Hand desinfiziert werden.

\section{Maßnahmen zum Schutz vor Kontamination und vor Chemikalien}

\subsection{Medizinische Einmalhandschuhe und Schutzhandschuhe}

Bei Handschuhen ist zwischen MP und PSA zu unterscheiden. Erstere dienen dem Infektionsschutz des Patienten und nur nachgeordnet auch des Trägers, während PSA ausschließlich dem Schutz des Trägers vor chemischen und physikalischen Risiken sowie vor Biostoffen dienen. MP unterliegen der Richtlinie 93/42/ EWG. PSA unterliegt der Richtlinie 89/656/EWG. Seit 2010 erlaubt die Neufassung der EU-Richtlinie 2007/47/EG die duale Kennzeichnung von Produkten für einen doppelten Verwendungszweck als MP und als PSA sowie deren entsprechende doppelte CE-Kennzeichnung. Der Einsatz von Einmalhandschuhen, die kein MP oder keine PSA sind und daher nicht den Qualitätskriterien der Normenserie EN 455 und EN 374 entsprechen, ist im Umfeld von Patienten abzulehnen.

Handschuhe werden in Gesundheitseinrichtungen mit folgenden Indikationen eingesetzt [Broschüre „Haut- und Infektionsschutz im Gesundheitswesen“ "http:// lga-archiv.landbw.de/www.gesundheitsamt-bw.de/sitecollectiondocuments/30_ gesundheitsth_arbmed/hautschutz_gesundheitswesen.pdf]:

- Schutz des Trägers vor Kontamination mit Blut, Sekreten und Exkreten einschließlich Krankheitserregern und indirekt zur Unterbrechung von Infektionsketten (pathogenfreier medizinischer Einmalhandschuh),

- Schutz vor Chemikalieneinwirkung (PSA-Einmalhandschuh),
- Strahlenschutz (PSA-Handschuh),

- Reduzierung der im Handschuh entstehenden Schweißmenge (textiler Unterziehhandschuh),

- Unterbindung der Erregerfreisetzung von der Hand in aseptische Bereiche (steriler medizinischer Einmalhandschuh; s. 6.2).

\section{Pathogenfreier medizinischer Einmalhandschuh}

Die häufig verwendete Bezeichnung keimarmer Handschuh sagt nichts über die mikrobielle Unbedenklichkeit aus, weil die Qualität „keimarm“ bisher nicht geregelt ist. Für Einmalhandschuhe ist im Unterschied $\mathrm{zu}$ sterilen medizinischen OP-Handschuhen lediglich die Qualität gemäß EN 420 [273] bzw. ISO 11193 1 [274] und 2 [275] und gemäß EN 455 Teil 1-4 [276-279] definiert; es gibt aber für den direkt aus der Originalverpackung entnommenen Einmalhandschuh keine Anforderung bezüglich des Freiseins von potentiell pathogenen Mikroorganismen oder bezüglich einer höchstzulässigen mikrobiellen Gesamtbelastung. Auch im Englischen oder Französischen erlaubt die Bezeichnung "clean single-use gloves“ bzw. „gants d'examen“ (Untersuchungshandschuhe) keinen Rückschluss auf die mikrobielle Unbedenklichkeit. Gleiches trifft für die von Hughes et al. [280] verwendete Bezeichnung „nicht steril“ zu. Eine stichprobenartige Überprüfung nicht steriler medizinischer Einmalhandschuhe aus der Originalverpackung vor der Auslieferung an den Verbraucher ergab eine Gesamtkoloniezahl aerober Bakterien $<100 \mathrm{KbE} / 100 \mathrm{ml}$ Sammelflüssigkeit, die damit deutlich unter dem zulässigen Grenzwert für Trinkwasser lag [281]. Bei aseptischer Entnahme von Handschuhen aus Boxen auf einer orthopädischen Station differierte die Gesamtbelastung zwischen 0 und $9,6 \times 10^{3} \mathrm{KbE} /$ Handschuh. Neben Bacillus spp. und Koagulase-negativen Staphylokokken wurden E. faecalis, K. pneumoniae, Pseudomonas spp. oder S. aureus in $13 \%$ der Proben nachgewiesen [280]. Da Einmalhandschuhe zur Anwendung in nicht sterilen Bereichen nicht nur mit intakter Haut, sondern auch mit Schleimhäuten in Kontakt kommen, z.B. zur Mundhöhlenpflege bei beatmeten Patienten oder zur vaginalen oder rektalen 
Untersuchung, sollten sie frei von potentiell pathogenen Mikroorganismen sein. Dabei können sich die quantitativen Anforderungen an Trinkwassergrenzwerten sowie an die Anforderungen für nicht sterile arzneiliche Zubereitungen zur Anwendung in der Mundhöhle, in der Nase und am Ohr orientieren. Für letztere sind $10^{2} \mathrm{KbE}$ pro g bzw. ml als Gesamtheit aerober Mikroorganismen sowie $10^{1} \mathrm{KbE}$ pro g bzw. ml als Gesamtwert an Hefen und Schimmelpilzen zulässig. S. aureus und $P$. aeruginosa dürfen in $1 \mathrm{~g}$ bzw. $1 \mathrm{ml}$ nicht nachweisbar sein [282]. Für Trinkwasser in medizinischen Einrichtungen sind die Anforderungen im Hinblick auf P. aeruginosa höher, d.h. kein Nachweis in $100 \mathrm{ml}$ [283], weil im Unterschied zum frisch entnommenen Leitungswasser in arzneilichen Zubereitungen das Risiko der weiteren Vermehrung gegeben ist. Unter Berücksichtigung der Anforderungen an nicht sterile arzneiliche Zubereitungen bzw. der Anforderungen an Trinkwasser ist von einer Unbedenklichkeit von medizinischen Einmalhandschuhen in Hinblick auf den Patientenschutz auszugehen, wenn in $100 \mathrm{ml}$ Sammelflüssigkeit keine potentiell pathogenen Erreger nachweisbar sind. Für die Deklarierung der Eigenschaft pathogenfrei („keimarm“) wird in Hinblick auf künftige Normungsarbeiten die Beschränkung auf je eine Indikatorspezies vorgeschlagen mit $S$. aureus als typischem Vertreter der Hautflora und $E$. coli als typischem Vertreter der Darmflora [284].

Pathogenfreie medizinische Einmalhandschuhe dienen in erster Linie der Unterbrechung von Infektionsketten [136, $285,286]$. Sie sind bei vorhersehbarer Verunreinigung mit Körperausscheidungen, Sekreten und Exkreten anzulegen wie z. B. bei der Blutentnahme, der Pflege inkontinenter Patienten, vor intensivem Kontakt mit MRE, z. B. vor der antiseptischen Waschung von mit MRE kolonisierten oder infizierten Patienten, beim Umgang mit Beatmungsschläuchen, bei Entleerung von Wasserfallen, beim endotrachealen Absaugen, bei der Tracheostomapflege, bei Entsorgung von Sekreten, Exkreten und Erbrochenem sowie bei der Entfernung von Drainagen, Verbänden oder kontaminierten Materialien. Sie sind insbesondere indiziert, wenn die erwarte- ten Erreger unempfindlich gegen Alkohol basierte Händedesinfektionsmittel sind, z.B. C. difficile, oder besonders gefährlich sind, z. B. Erreger des viralen hämorrhagischen Fiebers. Die Notwendigkeit von Schutzhandschuhen bei erwarteter hoher Kontamination lässt sich daraus ableiten, dass nach artifizieller Kontamination der Hände mit E. coli trotz Händedesinfektion ca. 2 Zehnerpotenzen auf den Händen verbleiben [287]. Analoge Daten liegen für MRSA bei hoher Kontamination der Hände mit 2-3 Zehnerpotenzen verbleibender Restkontamination nach Händedesinfektion vor [288].

Medizinische Einmalhandschuhe sind nach Beendigung der jeweiligen Tätigkeit abzulegen. Ihr Wechsel korreliert mit den Indikationen der Händedesinfektion, z. B. beim Wechsel von unreinen zu reinen Tätigkeiten wie Sekretabsaugung und anschließende Arbeit am Infusionssystem [42, 286, 289]. Nach dem Ausziehen der Handschuhe ist in jedem Fall eine Händedesinfektion durchzuführen, da Handschuhe auf Grund unerkannter Perforationen und dem Risiko der Kontamination beim fehlerhaften Ausziehen der Handschuhe keinen lückenlosen Schutz vor der Kontamination der Hände gewähren [284, 286, 290].

Medizinische Einmalhandschuhe sind wegen des Risikos der Hautschädigung und erhöhter Perforationsgefahr [206] nur auf sauberen, vollständig trockenen Händen [291] anzulegen.

Soll eine Schutzfunktion gegen Chemikalien erreicht werden, sind Handschuhe für hohe Risiken (Kategorie III der RL 686, erkennbar an der CE Kennzeichnung, gefolgt von einer vierstelligen Nummer) zu empfehlen [292]. Diese Qualität ist für alle Handschuhe, die im Gesundheitsbereich verwendet werden, anzuraten. Dabei ist nicht nur die zu erwartende Schutzleistung, sondern die reproduzierte Qualität (AQL) entscheidend für den zu erwartenden Schutz.

Behandschuhte Hände sollten nur in speziellen Fällen desinfiziert werden, z. B. in Situationen, in denen ein häufiger Handschuhwechsel erforderlich, aber erfahrungsgemäß schwierig realisierbar ist bzw. der Wechsel zu einer Unterbrechung des Arbeitsflusses führt.
Für die Desinfektion des Handschuhes sind folgende Voraussetzungen zu berücksichtigen [293]:

- Der Handschuh muss chemikalienbeständig gemäß EN 374 [294] sein, wobei die Prüfung der sog. Durchbruchzeit von $30 \mathrm{~min}$ (Schutzindex Klasse 2) mindestens einen Alkohol einschließen soll. Vom Hersteller der Handschuhe und vom Hersteller des Händedesinfektionsmittels darf es keine Angaben geben, die einer Desinfizierbarkeit des Handschuhs entgegenstehen.

- Der Handschuh soll nur während der Versorgung an ein und demselben Patienten verwendet werden und ist nach Beendigung der jeweiligen Tätigkeit abzulegen. Sofern es der Arbeitsablauf zulässt, sollte der Wechsel von Einmalhandschuhen parallel zu den Indikationen der Händedesinfektion erfolgen, d.h. immer dann, wenn die Indikation für eine Händedesinfektion gegeben ist, aber Handschuhe getragen werden. Im Ausnahmefall können behandschuhte Hände anstelle eines Handschuhwechsels desinfiziert werden, wenn andernfalls der Arbeitsablauf nicht gewährleistet werden kann, z. B. bei Tätigkeiten am selben Patienten aber zwischenzeitlichem Kontakt mit unterschiedlich kontaminierten Körperbereichen, ggf. auch bei aufeinanderfolgenden Blutentnahmen bei mehreren Patienten. Kriterium für die Entscheidung ist, dass der spezifische Arbeitsablauf keine Zeitspanne für die Lufttrocknung der desinfizierten Hände nach der Desinfektion vor dem Anlegen der neuen Handschuhe gewährt.

- Der Handschuh weist keine sichtbare Perforation auf und ist nicht mit Blut, Sekreten oder Exkreten erkennbar kontaminiert.

Da die Perforationsrate mit zunehmender Tragedauer bzw. nach belastender Tätigkeit ansteigt, ist auch bei Gewährleistung der genannten Forderungen im Intensivbereich nach spätestens $15 \mathrm{~min}$ sowie nach jeder Patientenwaschung ein Handschuhwechsel zu empfehlen [295].

Allerdings ordnet die WHO [33] die Desinfektion der behandschuhten Hände 
trotz nachgewiesener Effektivität als ungelöste Frage ein, solange die Konsequenzen für die Materialintegrität unbekannt sind.

Werden Handschuhe nicht mit einem automatischen Handschuhspender bereitgestellt oder aus einer Box entnommen, die bei Entnahme des ersten Handschuhs den nachfolgenden soweit freigibt, das die Entnahme ohne Berührung der Box und weiterer Handschuhe möglich ist, sondern aus üblichen Pappboxen entnommen, ist vor der Entnahme eine Händedesinfektion durchzuführen. Angebrochene Boxen sollen vor Kontamination durch Staub, Spritzwasser, Tröpfchen geschützt werden. Eine Bevorratung einzelner Handschuhe in der Kitteltasche ist nicht zulässig.

\section{Schutzhandschuhe (PSA) gegen Chemikalien und Mikroorganismen}

Sie müssen sowohl die allgemeinen Anforderungen der EN 420 [273] insbesondere Unschädlichkeit, Ergonomie und Widerstand gegen Wasserdurchdringung erfüllen, als auch die speziellen Anforderungen bezogen auf den Einsatzzweck, d.h. Schutz vor Chemikalien und Mikroorganismen gemäß EN 374 Teil 1,2,4 und 5 [294, 296-298] sowie mechanische Festigkeit. Die ASTM F1671 gibt Auskunft über den Widerstand gegen Krankheitserreger, die über Blut übertragen werden, z. B. Viren [299]. Die Prüfung der Barrierefunktion für Zytostatika ist derzeit ebenfalls nur durch die ASTM D6978-05 geregelt [300].

Für die Auswahl ist zu beachten, dass in Abhängigkeit von der Durchbruchzeit 6 Klassen [294] unterschieden werden. Sofern die Handschuhe für die Unterhaltsreinigung eingesetzt werden, ist auf die adäquate Auswahl (z. B. lange Stulpen) zu achten. Überschreitet die Tragedauer z. B. 2 Stunden, ist Klasse 4 auszuwählen, sofern der Hersteller des Flächendesinfektionsmittels keine andere Angabe macht. Sofern die Schutzhandschuhe tätigkeitsbzw. bereichsübergreifend getragen werden, ist eine Weiterverbreitung von Erregern möglich, sofern nicht folgende Maßnahmen eingehalten werden:

- Werden Isoliereinheiten der desinfizierenden Reinigung unterzogen, sind beim Verlassen der Einheit die Handschuhe abzuwerfen und eine Händedesinfektion durchzuführen.
- Bei der Aufbereitung von Patientenzimmern oder anderen Räumen ohne bekanntes Risiko einer Kontamination mit MRE oder mit Erregern mit dem Potential einer epidemischen Ausbreitung sind bei jedem Raumwechsel die behandschuhten Hände einer Händedesinfektion zu unterziehen.

- Die Handschuhe sind für die deklarierte Tragedauer personengebunden zu verwenden.

- Am Ende der Arbeitsschicht sind die Handschuhe zu entsorgen oder im Fall der Aufbereitbarkeit einem validierten Desinfektionsverfahren zuzuführen und danach hygienisch zu lagern.

\section{Feuchtigkeitsabsorbierende textile Unterziehhandschuhe}

Hierbei handelt es sich um dünne, mehrfach verwendbare in Desinfektions-Waschverfahren aufbereitbare Baumwollhandschuhe, deren Einsatz in der TRBA 250 [4] bei längerem Tragen von luftundurchlässigen Schutzhandschuhen zur Reduktion des Handschweißes für sinnvoll erachtet wird. Sie werden zusammen mit dem Schutzhandschuh gewechselt. Ihr Einsatz hat sich für medizinische Tätigkeiten als durchführbar erwiesen, wobei subjektiv durch Absorption der Feuchtigkeit ein günstiger Einfluss auf den Hautzustand ausgeübt wird, sodass ein Routineeinsatz in der Patientenpflege von Pflegekräften und Physiotherapeuten überwiegend bejaht wurde [301].

\subsection{Sterile Einmalhandschuhe}

Sterile Einmalhandschuhe sind MP. Gemäß europäischem Arzneibuch müssen Sterilität und Freisein von Pyrogenen gewährleistet sein; ferner werden Dichtheit, Reißfestigkeit sowie Abrieb- und Schnittfestigkeit geprüft [302].

Das Anlegen steriler Handschuhe vor operativen Eingriffen und invasiven pflegerischen Maßnahmen soll die Übertragung von Krankheitserregern auf sterile/ nicht kolonisierte Bereiche des Patienten bzw. die Kontamination steriler Materialien verhindern. Die Notwendigkeit zum Tragen von OP-Handschuhen lässt sich daraus ableiten, dass bei perforier- ten OP-Handschuhen die postoperative Wundinfektionsrate signifikant höher war als bei nicht perforierten [196, 197]. Beim Anlegen der Handschuhe ist zu beachten, dass diese am Ärmelbündchen des Kittels dicht abschließen.

Im OP-Bereich empfiehlt sich grundsätzlich der Einsatz latexallergenarmer OP-Handschuhe, da bisher von keinem anderen Material gleichwertige Eigenschaften hinsichtlich Tragekomfort, Passgenauigkeit, Griffigkeit und mechanischer Belastbarkeit wie für Naturlatex erreicht werden. Der Proteingehalt muss $<30 \mu \mathrm{g} / \mathrm{g}$ Handschuhmaterial betragen [274]. Gepuderte Latexhandschuhe sind wegen des Allergisierungsrisikos untersagt [291]. Bei Patienten mit einem erhöhten Risiko für die Entwicklung einer Latexallergie wird die naturlatexfreie Versorgung empfohlen. Das betrifft Patienten, die von Geburt an an Spina bifida, urogenitalen Fehlbildungen, Ösophagusatresie und weiteren Missbildungen leiden und die wiederholt operiert werden [303-309]. Durch latexfreie OP-Handschuhe, latexfreie Anästhesie und Latexallergenvermeidung im Alltag konnte die Latexsensibilisierungsprävalenz signifikant gesenkt werden [310, 311]. Talkum und Ersatzprodukte bergen die Gefahr der Granulombildung im OP-Gebiet und sind nicht zu empfehlen [312-316]. Für eine Emulsion mit Maisstärke ist das nicht untersucht; da aber kein Einfluss auf die Schweißmenge nachweisbar war [317], ist sie entbehrlich.

Bei chirurgischen Eingriffen mit erhöhtem Perforationsrisiko und/oder chirurgischen Eingriffen an Patienten mit erhöhtem Infektionsrisiko wird für das OP-Team das Tragen von zwei Paar übereinander gezogenen OP-Handschuhen (sog. double gloving) möglichst mit Indikatorsystem empfohlen [127, 318]. Da bekannt ist, dass die Perforationsrate mit zunehmender Dauer der OP steigt, wird bei längeren OPs diskutiert, ob bzw. wann ein routinemäßiger Handschuhwechsel sinnvoll und begründet ist. Die Vorschläge reichen von 30 bis $180 \mathrm{~min}$ [319]. Insgesamt sind die Daten jedoch unzureichend, um eine allgemeine Empfehlung geben $\mathrm{zu}$ können [26, 320].

Bei Tragen von nur einem Paar Handschuhen haben sich in der Viszeralchi- 
rurgie über die OP-Dauer ansteigende Perforationsraten für Operateur und 1. Assistenten gezeigt, woraus ein Wechsel nach spätestens $90 \mathrm{~min}$, für den 2. Assistenten und die OP-Pflegekräfte nach 150 min abgeleitet wurde [319, 321]. Für andere chirurgische Fachdisziplinen kann sich das Wechselintervall in Abhängigkeit vom Perforationsrisiko unterscheiden. Folgende Beispiele verdeutlichen die Situation. Für totale Hüftendoprothesen wurde vorgeschlagen, den Außenhandschuh nach der Prothesenreduktion bzw. bei Perforation zu wechseln. Typische Situationen einer Perforation waren bei der Inzision bzw. beim Zementieren des Hüftkopfs im Femur. Durch diese gezielten Wechsel der Außenhandschuhe konnte die Rate von OP-Handschuhen, die intraoperativ an der Außenseite steril sind, um $80 \%$ erhöht werden [320]. Der Wechsel des äußeren Handschuhpaars $1 \mathrm{~h}$ nach Beginn der OP hatte zur Folge, dass die Kontaminationsrate des äußeren Handschuhs am OP-Ende $13 \%$ anstatt $23 \%$ betrug. Deshalb empfehlen die Autoren, vor dem Einsetzen von Implantaten die äußeren Handschuhe zu wechseln [322].

Bei sichtbarer intraoperativer Handschuhbeschädigung müssen frische sterile OP-Handschuhe angelegt werden. Hat sich die Perforation zu OP-Ende ereignet, kann es ausreichend sein, einen frischen sterilen Handschuh über den perforierten Handschuh zu ziehen. Ob vor dem Anlegen des frischen OP-Handschuhs eine Händedesinfektion erforderlich ist, ist eine ungeklärte Frage. Zweifellos findet während der OP eine Rekolonisation der Haut im Handschuh statt $[323,324]$. Andererseits wäre der Handschuh ohne Perforation nicht gewechselt worden. Da nur im OP-Gebiet gearbeitet wurde, erscheint die Händedesinfektion entbehrlich, zumal es bei der Händedesinfektion zu einer Kontamination des sterilen Schutzkittels mit der Hautflora kommen kann.

Auch Handschuhe mit antibakterieller Barriere bzw. antibakterieller Imprägnierung können den Erregertransfer durch Perforationen [325] bzw. die Erregermenge auf der Hand [326] verringern, bergen jedoch in Abhängigkeit vom verwendeten Wirkstoff (z. B. Chlorhexidin) eine Allergiegefahr.
Durch unter dem OP-Handschuh angelegte sterile Baumwollhandschuhe kann dem Feuchtigkeitsstau entgegengewirkt werden.

Unmittelbar nach dem Ablegen der OP-Handschuhe sollte eine Händedesinfektion erfolgen, da Perforationen nicht auszuschließen sind.

\subsection{Vermeidung einer Kontamination}

Der Umfang erforderlicher Händedesinfektionen kann durch konsequente Planung von pflegerischen und ärztlichen medizinischen Maßnahmen mit dem Ziel der konsequenten Trennung rein/unrein bzw. nicht kontaminiert/kontaminiert sowie durch Realisierung der Non-touchTechnik z. B. im Umgang mit Devices und beim Verbandwechsel reduziert werden.

Für den Verzicht auf begrüßendes Händeschütteln gibt es bei Einhaltung der Indikationen zur Händedesinfektion weder eine epidemiologische Evidenz, noch eine stichhaltige theoretische Rationale. Wenn die von der WHO empfohlenen 5 Indikationsgruppen zur Händedesinfektion konsequent eingehalten werden, ist der Verzicht nicht begründbar. In Anbetracht der Schwierigkeit der Erreichbarkeit einer indikationsumfassenden Compliance der Händedesinfektion kann zumindest in Risikobereichen auf das begrüßende Händeschütteln verzichtet werden, wodurch zugleich die Notwendigkeit der Händedesinfektion in den Fokus gerückt wird.

\section{Anforderungen an Spender für Händedesinfektionsmittel und Handwaschpräparate}

Im Gesundheitswesen sollen für HDM vorzugsweise als MP deklarierte Spender eingesetzt werden. Daraus ergibt sich die Verpflichtung für den Hersteller, in der Packungsbeilage Angaben zur sachgerechten Aufbereitung zu machen. Alternativ können auch HDM-Spender zum Einsatz kommen, die keine MP sind, wenn der Hersteller eine sachgerechte Aufbereitungsvorschrift zur Verfügung stellt.

Das Anbruch- oder das Ablaufdatum muss auf dem Desinfektionsmittelbehältnis [327] oder separat dokumentiert sein. In Bereichen mit hohem Verbrauch an
HDM kann es ausreichend sein, die Einhaltung der Verbrauchsfrist über die Verbrauchsstatistik nachzuweisen. Da Spender für Handwaschpräparate kein $\mathrm{MP}$ sind, muss die Aufbereitung durch den Anwender selbst festgelegt werden.

Für Handwaschpräparate entfällt die Verpflichtung der Anbruchdokumentation. Trotzdem ist diese zu empfehlen, sofern dazu Herstellerangaben vorhanden sind. Dies lässt sich ableiten aus der höheren Kontaminationsanfälligkeit von Handwaschpräparatespendern im Vergleich zu Desinfektionsmittelspendern.

Grundsätzlich dürfen beide Spenderarten nicht $\mathrm{zu}$ einer Weiterverbreitung von Krankheitserregern führen. Automatisch bedienbaren Spendersystemen ist nicht nur wegen der geringeren Kontaminations- und Übertragungswahrscheinlichkeit, sondern auch wegen des höheren Bedienkomforts und des positiven Einflusses auf die Compliance der Vorzug zu geben [328].

Unabhängig vom Hersteller und von der Bauart sollten Spender für Händedesinfektionsmittel und für Handwaschpräparate folgende Anforderungen erfüllen [329]: Es soll eine Bestückung mit nicht wieder befüllbaren Gebinden (Einmalcontainer), die Möglichkeit der Verwendung von Gebinden unterschiedlicher Hersteller sowie die Vermeidung der mikrobiellen Kontamination des Pumpkopfs während der Nutzung möglich sein. Der Eurospender ist in der Größe genormt, und es können Gebinde unterschiedlicher Hersteller fixiert werden. Die im Spender verwendeten HDM oder Handwaschpräparate einschließlich wichtiger Herstellerhinweise und der Füllstand müssen ohne Manipulation identifizierbar sein. Aufgrund der einfacheren Handhabung empfiehlt sich sowohl für Händedesinfektionsmittel als auch für Handwaschpräparate die Verwendung von Einmalgebinden.

Im Hinblick auf das Risiko der mikrobiellen Besiedelung sind Spender für Handwaschpräparate kritischer einzuschätzen als mit alkoholischen HDM befüllte Spender [263, 264]. Hinzu kommt, dass nach einem Handkontakt mit dem Auslass des Spenders, anders als beim Desinfektionsmittelspender, die Hände nicht zwangsläufig desinfiziert, wohl aber abgespült werden. Günstig ist da- 
her bei Spendern für Handwaschpräparate die Verwendung von Einmalpumpen am Gebinde, die mit dem leeren Gebinde verworfen werden. Sofern aufbereitbare Spendersysteme eingesetzt werden, ist bei der Auswahl darauf zu achten, dass der Hersteller eine Vorschrift zur Aufbereitung bereitstellt. Die manuelle Aufbereitung beinhaltet konstruktionsabhängig folgende Schritte: Abwischen des Steigrohrs mit Einmaltuch, Reinigung der Dosierpumpe unter fließendem heißen Wasser, Trocknen, Reinigung des Spendergehäuses unter fließendem heißen Wasser, Trocknen, Wischdesinfizieren von Spendergehäuse, Rückwand und Dosierpumpe, Zusammensetzen des Spenders und wiederholtes Durchpumpen eines Desinfektionsmittels.

Es existieren nur wenige Daten zur Kontamination von Handwaschpräparaten. Gleich et al. zeigten [330], dass Waschlotionen nur zu $10 \%$ mit max. $2 \mathrm{KbE}$ von Vertretern der Umweltflora (Koagulase-negative Staphylokokken, Mikrokokken oder aerobe Sporenbildner) kontaminiert waren. Selbst am Auslass war trotz sichtbarer Verschmutzung zu 25\% keine Kontamination nachweisbar. Bei Ausbrüchen mit Handwaschpräparaten waren offene Flaschen bzw. nachfüllbare offene Spendersysteme für Handwaschpräparate, nicht aber geschlossene Systeme ursächlich [331-333].

Bei beiden Spenderarten müssen die fixen Außen- und Innenteile aufbereitbar sein. Das ist auch maschinell möglich [269]. Für das Aufbereitungsintervall gibt es keine Evidenz. Sichtbare Verunreinigungen des äußeren Gehäuses und aller ohne weitere Manipulation zugänglichen Teile sowie Tropfnasen am Auslass sind durch Wischdesinfektion zu beseitigen. Für Bedienhebel empfiehlt sich eine tägliche Wischdesinfektion durch den Reinigungsdienst. Umfang und Frequenz der Kontrollen und der Innenaufbereitung von Spendern sollten im hauseigenen Hygieneplan festgelegt werden, z. B. halbjährig.

\section{Qualitätssicherung der Händehygiene}

Bei den im Rahmen der nationalen Händedesinfektionskampagne im Jahr 2014 in 109 Krankenhäusern erhobenen Daten zur Compliance wurde deutlich, dass trotz einer Compliance von durchschnittlich $73 \%$ (10. Percentile 55\%, 90. Percentile 89\%) [334] noch Verbesserungspotential besteht, insbesondere, wenn davon ausgegangen wird, dass sich durch direkte Beobachtung die Rate der Händedesinfektionen deutlich erhöht (Hawthorne-Effekt) bzw. bei einer Compliance von $51 \%$ in der Größenordnung von $180 \%$ bewegen kann $[335,336]$. Auf Grund des Stellenwerts der Händehygiene müssen alle Möglichkeiten ausgeschöpft werden, eine maximale Compliance in ihrer Durchführung zu erreichen. Dazu gehören die Etablierung von Messverfahren zur Compliance sowie die Analyse und Optimierung von Routinearbeitsabläufen. Neben der Verbesserung der Compliance der Händedesinfektion ist auch die korrekte Durchführung ein weiterer wichtiger Aspekt [337].

Um einen Effekt der Händedesinfektion auf die Raten von NI und MRE zu erzielen, muss eine hohe Compliance der Händedesinfektion durch das Personal erreicht werden [338]. Die Compliance der hygienischen Händedesinfektion sowie die Faktoren für Nicht-Compliance sind in den letzten Jahren gut untersucht worden [337, 339, 340]. In Bereichen, in denen keine Interventionen zur Händedesinfektion durchgeführt worden sind, ergaben sich z.T. erhebliche Defizite mit Complianceraten zwischen 5-81\%, der Mittelwert bei etwa $40 \%$ [34, 338, 339, 341]. Bei ausreichender Anzahl von Spendern und Schulungen konnte dieser Wert bis auf $70 \%$ gesteigert werden [342]. In Deutschland wurde je nach Berufsgruppe, Fachrichtung oder Art der Tätigkeit eine durchschnittliche Compliance zwischen $41 \%$ und $55 \%$ mit hoher Variationsbreite ermittelt [343-345]. Nach Pittet et al. [34] differiert die Compliance zwischen 16$81 \%$. Im Rahmen des multimodalen Interventionsprogramms konnte die Compliance von $48 \%$ auf $66 \%$ erhöht werden. Eine Beobachtungsstudie auf einer neonatologischen Intensivstation verzeichnete nach Einführung effektiver Maßnahmen zur Verbesserung der Compliance wie Weiterbildungsprogramme, Performance-Feedback, Motivation des Pflegepersonals, alkoholische Händedesinfektion als Standardverfahren und leichtere
Zugangsmöglichkeit zu Desinfektionsmitteln einen signifikanten Anstieg der Compliance-Rate von 39\% auf 59\% (nach Patientenkontakt), verbunden mit einer Senkung von NI von 11,3 auf 6,3 pro 1000 Patiententage [83]. In der Intensivpflege war die Compliance bei Manipulationen am Beatmungssystemzubehör am höchsten, gefolgt von Manipulationen am Harnwegkatheter und an Wundverbänden. Bei Manipulationen an zentralen oder peripheren Gefäßzugängen war die Compliance am geringsten. Die vergleichsweise höchste Compliance bei Manipulationen am Zubehör des Beatmungssystems hat ihre Ursache offenbar im angestrebten Eigenschutz des Pflegepersonals [343]. Dazu steht in Übereinstimmung, dass auch das Tragen medizinischer Einmalhandschuhe zur Unterlassung der Händedesinfektion verleitet [346]. Die Beobachtungsergebnisse eröffnen die Möglichkeit, eine Verbesserung der Compliance gerade bei den Indikationen zu trainieren, für die sich entweder in Studien [342, 347, 348] oder durch eigene Beobachtungen Defizite ergaben.

Die im Rahmen der nationalen Händehygienekampagne 2014 aus 109 Krankenhäusern und 576 Stationen gewonnenen Complianceraten lagen je nach Berufsgruppe zwischen $64 \%$ und $77 \%$ und je nach Fachrichtung zwischen $64 \%$ und $83 \%$ [334]. Von $>700$ Krankenhäusern, die an der AKTION Saubere Hände teilnahmen, haben sich 180 an Beobachtungsstudien beteiligt. Die in 163 Krankenhäusern ermittelte Baseline von 60,9\% konnte in den beobachteten Bereichen auf $72,3 \%$ verbessert werden [349]. So wurde im Ergebnis einer Studie mit direkter Beobachtung gemäß Protokoll der AKTION Saubere Hände 2008 eine Ausgangscompliance bei Ärzten und Pflegekräften von $53 \%$ bzw. $57 \%$ ermittelt. 2011 war die Compliance bei den Ärzten auf $64 \%$ angestiegen, aber 2013 auf $48 \%$ abgefallen. Bei den Pflegekräften wurde die Compliance auf $71 \%$ erhöht mit einem nachfolgenden Abfall auf $56 \%$, d.h. auf den Ausgangswert [350].

Bei Pädiatern wurde durch multimodale Intervention die Compliance von $46 \%$ auf $90 \%$ [351] bzw. von $68 \%$ auf über $95 \%$ gesteigert, letzteres für einen Zeitraum von 6 Monaten [352]. Auf einer neo- 
natologischen Station konnte die Compliance während des 9 monatigen Follow up dagegen nur von $42 \%$ auf $55 \%$ verbessert werden $[353,354]$.

Das Problem der Compliance liegt in der Art des Vorgangs. Anders als beim Waschen der Hände, bei dem Schmutz weggewaschen wird, was uns seit der frühesten Kindheit als hygienisches Ritual vor Mahlzeiten oder nach Toilettenbesuchen anerzogen wird, ist bei der Desinfektion der Effekt nicht sichtbar. Insofern ist die Motivation einer der Schlüsselpunkte zur Verbesserung der Compliance. Das Herausbilden einer Motivation setzt Interventionen vor allem in den Bereichen Risikowahrnehmung, Handlungs-Ergebnis-Erwartung und Selbstwirksamkeitserwartung (also die Überzeugung in die eigene Kompetenz, ein Verhalten mittels eigener Ressourcen ausführen zu können) voraus. So zeigte eine Studie auf Intensivstationen, dass insgesamt drei Viertel der Ärzte und des Pflegepersonals hoch motiviert waren und dieser Anteil bei einer starken Überzeugung, durch die eigene Händedesinfektion Erregertransmissionen vermeiden zu können, sogar bei über $90 \%$ lag [355]. Die Motivation allein führt allerdings nur in einem kleinen Prozentsatz auch zum Handeln. Um diese sog. Intentions-Verhaltens-Lücke zu schließen, sollten entsprechende psychosoziale Faktoren wie die Verhaltensplanung und -kontrolle sowie die Zusammenarbeit im Stationsteam gefördert werden [356]. Inwieweit das Händewaschen mit einer besseren Compliance durchgeführt wird, ist unklar. In den Beobachtungsdaten macht das Waschen der Hände deutlich $<3 \%$ aller Händehygieneaktionen aus (unveröffentlichte Daten AKTION Saubere Hände).

Ferner wurde abgeleitet, dass vor allem der Parameter Zeit korrelierend $\mathrm{zu}$ den Faktoren Personalmangel, Überbelegung und den daraus resultierenden Arbeitsbelastungen einer der Hauptgründe für mangelnde Compliance darstellt [357]. Wenn Voss und Widmer [358] anhand des Zeitbedarfs in einer Schicht für die Händedesinfektion ableiteten, dass eine $100 \%$ ige Compliance erreichbar ist, kann sich die Situation 20 Jahre nach der Veröffentlichung geändert haben. Scheithauer et al. [347] ermittelten 162 Indikationen für die Händedesinfektion pro $\mathrm{Pa}$ - tiententag auf einer internistischen ITS. Betreut ein Pflegender 2 Patienten, nimmt das etwa 50 min in Anspruch. Da nach der Händedesinfektion nicht selten ein Ortswechsel erfolgt, während dessen die Einwirkungszeit andauert, kann sich der tatsächliche Zeitbedarf verkürzen. Trotzdem ergibt sich aus dieser Kalkulation ein nicht zu vernachlässigender Zeitbedarf für die Händedesinfektion, der bei gleichzeitigem Personalmangel durchaus ein Problem darstellen kann.

Um die Einhaltung der Indikationen für die Händedesinfektion im Interesse der Patientensicherheit zu erreichen, sind alle Anstrengungen zu bündeln und fortlaufend zu evaluieren, wobei die praktische Umsetzung durch Festlegung von Zwischenschritten oder Etappenzielen gefördert werden kann.

\subsection{Maßnahmen zur Verbesserung der Compliance}

Um die Compliance zu erhöhen, ist es wichtig, sich einrichtungsbezogen mit den Gründen für die Non-Compliance auseinanderzusetzen. Die in Untersuchungen am häufigsten genannten Gründe für Non-Compliance sind Personalmangel, Nichtvorhandensein eines institutionellen Bewusstseins für die Patientensicherheit (Sicherheitskultur), Unsicherheiten, wann eine Händedesinfektion notwendig ist, Angst vor Hautschäden bzw. Hautunverträglichkeit sowie eine schlechte Verfügbarkeit von Händedesinfektionsmitteln. Darüber hinaus werden genannt: keine positiven Vorbilder durch Kollegen oder Vorgesetzte, andere Tätigkeiten am Patienten haben Vorrang, Händedesinfektion kann die Beziehung zum Patienten stören, Handschuhe machen eine Händedesinfektion unnötig, Vergesslichkeit, Zweifel an der Wertigkeit der Händehygiene, keine individuelle Übereinstimmung bzw. Akzeptanz der Richtlinien sowie Zweifel an der Evidenz, dass Händedesinfektion die Zahl der NI verhindern kann [33, 346, 359-361]. Weitere Untersuchungen weisen auf die Organisationskultur [362] sowie die explizite und implizite Einstellung der Mitarbeiter [363, 364] als Einflussfaktoren für die Compliance hin.

Eine Intervention zur Verbesserung der Händehygiene-Compliance hat im- mer auch eine individuelle Verhaltensänderung zum Ziel. Um diese zu erreichen, sind Interventionen auf verschiedenen Ebenen notwendig, wobei die Überprüfung des Wissens in einem Online Testprogramm mit Teilnahmebestätigung die Bemühungen unterstützen kann [365]. Die Einstellungen und Haltungen der Mitarbeiter gegenüber dem Thema Händehygiene sind uneinheitlich und komplex. Viele Faktoren beeinflussen das letztendliche Verhalten [366, 367].

In den letzten Jahren hat eine Vielzahl von Studien die Effizienz sogenannter multimodaler Interventionsmodelle zur Verbesserung der Compliance gezeigt [34, 88, 92, 368-371]. Die WHO hat im Rahmen ihrer weltweiten „Clean Care is Safer Care" Kampagne ein multimodales Interventionsprogramm entwickelt und in 58 Pilothäusern weltweit erfolgreich getestet [33]. Auf der Grundlage dieser Erkenntnisse sollte ein multimodales Interventionsprogramm folgende grundlegende Maßnahmen beinhalten: regelmäßige Personalfortbildungen, Messungen mit Ergebnisrückmeldung, Verbesserung der Verfügbarkeit von HDM, Nutzung von Erinnerungs- und Werbematerialien, sichtbare Unterstützung durch die administrativen Ebenen. Zusätzlich haben sich Zielvereinbarungen, Anreizsysteme (incentives) und Strategien zur Förderung der Übernahme von Verantwortung (accountability) als effektiv erwiesen [372]. Im Rahmen eines solchen Interventionsprogramms haben Fortbildungen insbesondere in standardisierter Form [373] und Training [374] eine Schlüsselfunktion, jedoch als alleinige Interventionsmaßnahme nur einen geringen, kurz anhaltenden Effekt [132, 370, 371, 375].

Neben Faktoren, die für Überwindung der Intentions-Verhaltens-Lücke relevant sind, hat auch die Beteiligung von Patienten z.B. durch ihre institutionelle Einladung, Hygienethemen anzusprechen (empowerment), im Hinblick auf nachhaltige Effekte ein großes Potenzial [141, 376, 377].

Zur nachhaltigen Verbesserung der Compliance nimmt die Prozessoptimierung eine Schlüsselfunktion ein, indem durch optimalen Workflow die Anzahl der Indikationen zur Händedesinfektion reduziert werden kann. Selbst in Be- 
Tab. 3 Vor- und Nachteile verschiedener Methoden zur Beobachtung der Compliance.

\begin{tabular}{|llll}
\hline & Direkte Beobachtung & Elektronische Systeme & Verbrauchsmessung \\
\hline Kosten & Hohe Personalkosten & Herstellerabhängig & Gering \\
\hline Frequenz des Feedbacks & Gering (aus Kostengründen) & $\begin{array}{l}\text { Hoch - individuell mit Mobilgerät und } \\
\text { kollektiv durch Statistik }\end{array}$ & $\begin{array}{l}\text { Gering } \\
\text { (z. B. monatlich) }\end{array}$ \\
\hline $\begin{array}{l}\text { Qualität und Präzision } \\
\text { der Information }\end{array}$ & $\begin{array}{l}\text { Individuell/punktuell sehr hoch, Gene- } \\
\text { ralisierbarkeit für Stationen und längere } \\
\text { Zeiträume fraglich, Beeinflussung durch } \\
\text { den HAWTHORNE-Effekt, Vorteil der } \\
\text { Beurteilung der Performance und des } \\
\text { korrekten Timings }\end{array}$ & $\begin{array}{l}\text { Abhängig von System und System- } \\
\text { nutzung, meist werden nur die WHO }\end{array}$ & $\begin{array}{l}\text { Indikationen 1, 4 und 5 erfasst } \\
\text { 24 h täglich und 365 Tage im Jahr }\end{array}$ \\
\hline
\end{tabular}

reichen, die bereits jahrelang geschult wurden und Teilnehmer von Interventionskampagnen sind, können so ohne Mehrarbeit erhebliche Effekte erzielt werden $[133,378,379]$. Daher sollten Routinemaßnahmen kritisch in ihrem Ablauf überprüft und standardisiert werden mit dem Ziel, Händedesinfektionen zu sparen $[133,342]$.

Zugleich sollten Interventionsprogramme auch auf den Zeitdruck und die hohe Arbeitsbelastung des Personals zugeschnitten werden. Dazu gehört auch die großzügige Ausstattung mit HDM, um zusätzliche Wege für das Personal zu vermeiden. Die kritische Überprüfung der Spenderausstattung unter Berücksichtigung der Arbeitsabläufe vor allem am Patienten sowie ggf. die Verbesserung der Ausstattung können bereits zu einer Verbesserung der Compliance führen [34, 380-382]. Die WHO empfiehlt die Verfügbarkeit von HDM ,at point of care“, d.h. dort, wo die Indikationen zur Händedesinfektion entstehen: vor allem am Patienten bzw. am Patientenbett, an sauberen Arbeitsplätzen, an Behandlungsplätzen usw. [33]. In Abhängigkeit von den räumlichen Gegebenheiten sowie von der Art der versorgten Patienten können fest montierte oder mobile Spendersysteme verwendet werden.

Die 2008 in Deutschland gestartete nationale Aktion Saubere Hände ist ein wichtiger Beitrag zur Umsetzung der von der WHO 2005 ins Leben gerufenen Kampagne „Clean Care is Safer Care“. Seit Juni 2011 können Krankenhäuser und Rehabilitationskliniken, seit August 2015 auch Einrichtungen der Ambulanten Medizin ein Zertifikat über die Teilnahme an der Aktion Saubere Hände erwerben [http:// www.aktion-sauberehaende.de/ash/module/krankenhaeuser/zertifizierung/].
Auch durch die Teilnahme am Internationalen Tag der Händehygiene wird der Stellenwert der Händehygiene unterstrichen. Nach dem Erreichen des Goldzertifikats der Aktion Saubere Hände ist es möglich, sich am Wettbewerb „European Hand Hygiene Excellence Award“ zu beteiligen und damit einen Beitrag zur Nachhaltigkeit der erreichten Compliance zu leisten.

Als Basismaßnahme zur Gewährleistung der Compliance der Händehygiene ist mindestens jährlich und zusätzlich zeitnah bei Hinweisen auf Probleme in diesem Bereich eine Schulung aller Mitarbeiter zu den Indikationen der Händedesinfektion in Verbindung mit einem Training und der Evaluation der Einreibetechnik z. B. mit fluoreszierendem Farbstoff im HDM [383] zu gewährleisten. Im Rahmen dieser Schulungen ist es zu empfehlen, dass die Verbrauchsdaten für HDM innerhalb der Organisationseinheiten bewertet werden. Das setzt die Übermittlung von auf die Organisationseinheiten aufgeschlüsselten Verbrauchsdaten pro Patiententag (3 $\mathrm{ml}=$ eine Händedesinfektionseinheit) voraus. Die Verbräuche sollten zusätzlich jährlich der ärztlichen und der pflegerischen Leitung mitgeteilt und in der Hygienekommission bewertet werden. Hier kommt es vor allem darauf an, die Situation in Organisationseinheiten mit sehr niedrigem Verbrauch pro Patiententag kritisch zu hinterfragen und ggf. dort gezielt $\mathrm{zu}$ intervenieren.

\subsection{Ermittlung der Compliance}

Um Defizite in der Händedesinfektions-Compliance bzw. deren Veränderungen sichtbar zu machen, ist die Etablierung von Messsystemen unerlässlich [33, 34, 384]. Als Messinstrument für die Hän- dedesinfektion stehen die direkte Beobachtung der Mitarbeiter zur Bestimmung der Compliance, elektronische Systeme und als Surrogatparameter die Bestimmung des Verbrauchs an HDM zur Verfügung (• Tab. 3).

Die Erhebung von Daten zu unterschiedlichen Zeitpunkten im Rahmen einer Intervention oder auch zur Langzeiterfassung ist ein wichtiges Instrument, um qualitative und quantitative Aussagen zu Ausgangssituationen sowie zu Veränderungen treffen zu können. Die drei Methoden haben ihre Vor- und Nachteile und sollten idealerweise kombiniert angewandt werden $[385,386]$. Die Messung des Verbrauchs an HDM ist eine weniger ressourcenintensive Möglichkeit der Datenerhebung und als Langzeitmesssystem geeignet, Veränderungen im Händedesinfektionsverhalten abzubilden. Es ist zu beachten, dass der Verbrauch nicht mit der Compliance gleichzusetzen ist. Verbrauchszahlen geben einen Anhalt über die Menge durchgeführter Händedesinfektionen, die durchschnittlich an einem Patienten in $24 \mathrm{~h}$ (also an einem Patiententag) in einer Organisationseinheit (z. B. pro Station, pro Klinik, pro Einrichtung) durchgeführt worden sind. Die Qualität der Daten hängt entscheidend davon $\mathrm{ab}$, inwieweit die Verbrauchszahlen der Organisationseinheit sicher zugeordnet werden können. Sinnvoll ist der Vergleich nur mit Verbrauchszahlen aus vergleichbaren Organisationseinheiten, da im Gegensatz zur Compliance bisher keine verlässlichen Sollwerte zur Verfügung stehen. Verbrauchsdaten lassen keine linearen Rückschlüsse hinsichtlich Compliance (fehlende Nennerdaten, indikationsgerechte Händedesinfektion, Technik der Händedesinfektion und Sicherheit im Erkennen der Indikationen zur Händedesin- 
fektion im klinischen Alltag) zu [347]. Da die Unterschiede in den einzelnen Fachbereichen und zwischen Intensiv- und Nicht-Intensivstationen erheblich sein können, ist eine stations- bzw. bereichsbezogene Erfassung sinnvoll [371]. Es wird empfohlen, die Verbrauchsdaten auf Organisationseinheiten aufgeschlüsselt in die Qualitätsberichte der Krankenhäuser aufzunehmen.

Die Bestimmung der Compliance für die Händedesinfektion durch direkte Beobachtung ist der Goldstandard [33]. Allerdings sind Beobachtungsdaten aus der Literatur für bestimmte Bereiche oft nicht einfach auf individuelle Settings übertragbar, da es große Unterschiede in der Methode der Beobachtung sowie in der Definition der Indikationen zur Händedesinfektion gibt. Die WHO hat mit dem Modell der 5 Indikationen die Grundlage für vergleichbare Beobachtungen geschaffen [134]. Voraussetzung dafür ist eine intensive Schulung mit regelmäßiger Validierung der Beobachter. Die Beobachtung ist eine punktuelle Messung. Sie ermöglicht die Einschätzung, in wieweit Mitarbeiter die Indikationen erkennen und welche Maßnahmen für eine verbesserte Compliance notwendig sind. Sie sollte als Fehleranalyse auch als Grundlage für Interventionen genutzt werden [387]. Da die Compliance einzelner Mitarbeiter große Unterschiede aufweisen kann, sollten möglichst viele Mitarbeiter in eine Beobachtung eingeschlossen werden, um eine Aussage über die generelle Compliance eines Bereichs treffen zu können [33, 34].

Der Verbrauch an HDM kann durch elektronische Erfassungsmöglichkeiten im zeitlichen Verlauf am Ort des Verbrauchs erfasst werden, wodurch zeitnah Einfluss auf die Compliance und damit auf die NI-Rate genommen werden kann [388-391]. Einem krankenhausweiten Einsatz können allerdings die Systemkosten entgegenstehen. Neuere elektronische Systeme erfassen Händedesinfektionen zusätzlich auf individueller Ebene, etwa mit mobilen „badges“ oder Erfassungsgeräten, ermöglichen ein individuelles Feedback zur Händehygiene oder können an fällige Desinfektionen erinnern [376], z. B. durch Überwachung bestimmter Zonen, deren Betreten häufig mit der Indikation für eine Händedesinfektion verbunden ist. Heutige Systeme erlauben noch keine präzise Erinnerung der Mitarbeiter an alle Indikationen zur Händehygiene. Auch wenn sie das verfügbare Instrumentarium zur Steigerung der Compliance erweitern, konnte bisher nur ein geringer Einfluss auf die Verbesserung der Compliance nachgewiesen werden [392]. Evaluation und Feedback sind wichtige Komponenten einer Umsetzungsstrategie zur Steigerung der Compliance [33, 132]. Aspekte des Datenschutzes, der Akzeptanz und der notwendigen Eigenmotivation der Beschäftigten sind als Randbedingungen zu beachten.

Aufklärung, Trainingsprogramme mit regelmäßigen Schulungen (mindestens jährlich) und die Auswahl der HDM in Desinfektionsplänen dienen in Verbindung mit der Festlegung des Vorgehens in einrichtungsverbindlichen SOPs und mit gezielten Kontrollmaßnahmen der Qualitätssicherung der Händehygiene. Mikrobiologische Untersuchungen, z. B. durch Abdruckkulturen von den Händen, können bei speziellen epidemiologischen Fragestellungen durchgeführt werden, eignen sich aber nicht für eine routinemäßige Überprüfung der Wirksamkeit einer Händedesinfektion.

\section{Hautschutz und Hautpflege}

Berufsbedingte Hauterkrankungen stehen seit vielen Jahren an der Spitze der Berufskrankheiten [393]. Das liegt zum einen an falschen Methoden der Händehygiene, d.h. die Hände werden zu viel gewaschen, anstatt alkoholische HDM zu benutzen, zum anderen am ungenügenden Einsatz von Hautschutz- und Hautpflegemitteln [394, 395].

Hautschutz und Hautpflege dienen vorrangig dem Arbeitsschutz, sind aber zugleich Voraussetzung für eine effektive Händedesinfektion [252], da bereits kleinste Risse bzw. Mikrotraumen zu Eintrittspforten für Krankheitserreger und zum Erregerreservoir werden können $[395,396]$. Beim Einsatz von Hautschutz- und -pflegemitteln ist das Risiko der mikrobiellen Kontamination zu beachten [397, 398], d.h. keine Entnahme aus Salbentöpfchen und bei Verwendung von Tuben Vermeiden eines Rücksogs des ausgedrückten Salbenstrangs.
Hautschutzpräparate schützen vor Irritation [399-407] und werden vor und während der Arbeit und ggf. zusätzlich in Arbeitspausen aufgetragen [402, 408]. Hautpflegepräparate unterstützen die Regeneration der Haut [409]. Ihre Anwendung wird am Dienstende empfohlen [291]. Zusätzlich können sie während der Arbeit bei individuellem Bedürfnis angewendet werden. Bei sichtbarer Verschmutzung der Hände sollte vor dem Auftragen von Hautschutz- oder -pflegepräparaten die Haut gereinigt werden, um dem Eindringen von auf der Haut verbliebenen Substanzen mit hautreizenden Eigenschaften entgegen zu wirken [410]. In Ergänzung dazu empfiehlt es sich, auch im Freizeitbereich Hautschutz und Hautpflege zu beachten.

Sowohl bei Pflegepersonal als auch bei Ärzten ergaben sich große Wissensdefizite in Bezug auf Hautschutz und Hautpflege [411-413]. Deshalb ist die Wissensvermittlung in Verbindung mit der Etablierung eines Hautschutzplans wichtig und leistet einen Beitrag zur Verbesserung beruflich irritierter Haut [414-416].

Bei Gefährdung der Haut durch Arbeiten im feuchten Milieu - dazu gehört auch das Tragen flüssigkeitsdichter Handschuhe - hat der Arbeitgeber zu prüfen, ob solche Belastungen reduziert werden können. Insbesondere sollen Handschuhe nur so lange wie nötig getragen werden. Der Arbeitgeber hat geeignete Hautschutz- und Pflegemittel bereitzustellen, einen Hautschutzplan zur Auswahl von Präparaten für die Hautreinigung, den Hautschutz und -pflege zu erstellen und die Mitarbeiter in deren regelmäßige und richtige Anwendung $\mathrm{zu}$ unterweisen [4]. Für hautbelastende Tätigkeiten (z. B. Nass- und Feuchtreinigung, Desinfektion von Flächen und Gegenständen) muss der Arbeitgeber PSA bereitstellen, in einer Betriebsanweisung die Schutz- und Verhaltensregeln festlegen und die arbeitsmedizinische Vorsorge und Überwachung gewährleisten [417]. Bei beginnenden Hautschäden sind unverzüglich der betriebsärztliche Dienst oder ein Hautarzt zu konsultieren.

Für die Auswahl von Hautschutz- und Hautpflegepräparaten sind der Wirksamkeitsnachweis (vorzugsweise durch in vivo Verfahren) gemäß Leitlinie berufliche Hautmittel [393] bzw. Ergebnisse von Studien [418] sowie die Sicherheitsbewertung 
[393] Voraussetzung. Wegen des Risikos der Sensibilisierung sollten Produkte ohne Duft- und ohne Konservierungszusatz ausgewählt werden [393, 419]. Bei Hautschutzpräparaten sind wegen der Penetrationsförderung Präparate ohne Harnstoff zur bevorzugen [408].

Ob ein zeitlicher Abstand zwischen der Anwendung von Hautschutz- und Hautpflegepräparaten zur Händedesinfektion eingehalten werden muss, ist nicht ausreichend untersucht. In praxisfremden Modellen wurde eine Wirkungsverminderung z. B. für alkoholische HDM durch Pflegeprodukte [420], für kationische Antiseptika wie Chlorhexidin durch anionische Emulgatoren, Feuchthaltesubstanzen und Surfactants in Pflegeprodukten [421, 422] sowie für chirurgische Handwaschpräparate durch Hautschutzprodukte nachgewiesen [401]. Deshalb empfiehlt die Association for Professionals in Infection Control die Kompatibilität von Pflegeprodukt und HDM bereits bei der Produktauswahl zu berücksichtigen, gibt jedoch keine Hinweise zu einem Verfahren der Kompatibilitätsprüfung [423]. Nach Anwendung von Hautschutz und Hautpflege (je 3x/d) bei einem chirurgischen Team wurde der Hautzustand signifikant verbessert, ohne dass die Wirksamkeit der Händedesinfektion beeinträchtigt wurde [413]. Da es Hinweise gibt, dass einige Hautpflegemittel die Wirkung alkoholischer HDM beeinträchtigen können, ist deren Anwendung - sofern ihr Einfluss auf die Wirksamkeit der Händedesinfektion nicht untersucht ist am günstigsten in Arbeitspausen und zusätzlich nach Arbeitsschluss vorzunehmen.

\section{Rechtliche Aspekte}

Zur Unterlassung der Händedesinfektion existieren zahlreiche Gerichtsentscheidungen. So wurde in sieben Fällen das Unterlassen der hygienischen Händedesinfektion als grober Behandlungsfehler angesehen. Auch das Unterlassen der chirurgischen Händedesinfektion oder die fehlende Benutzung steriler Handschuhe waren als grobe Behandlungsfehler Gegenstand von Entscheidungen im Arzthaftungsrecht [14]. Aufgrund der Tatsache, dass die Durchführung der Händedesinfektion und das Tragen von Handschuhen den Kategorien IA bzw. IB entsprechen, sind diese Maßnahmen unbedingt einzuhalten.

\section{Empfehlungen}

\subsection{Hygienische Händedesinfektion}

\section{Voraussetzungen}

- Klinik, Praxis, medizinischer Arbeitsbereich oder Pflegeeinrichtungen sind mit sauberen Händen und Fingernägeln zu betreten; Hände und Fingernägel sind bei erneuter Verschmutzung zu reinigen [Kat. II].

- Fingernägel sollen kurzgeschnitten sein und mit den Fingerkuppen abschließen. Nagellack ist nicht zulässig [Kat. II]. Das Tragen künstlicher und gegelter Fingernägel ist unzulässig [Kat. IB] .

- In allen Bereichen, in denen eine Händedesinfektion durchgeführt wird, dürfen an Händen und Unterarmen keine Ringe, Armbänder, Armbanduhren oder Piercings (z. B. Dermal Anchor) getragen werden [Kat. IB/IV]. Sofern Ringdosimeter außerhalb von OP-Einheiten getragen werden müssen, sind diese nach jedem Patienten abzulegen und erst nach erfolgter Desinfektion wieder anzulegen [Kat. II].

- Bei Kontamination der Unterarme mit potentiell infektiösem Material sind diese in die Durchführung der Desinfektion einzubeziehen [Kat. II].

- Bei Vorliegen chronischer Hauterkrankungen ist zu überprüfen, ob eine Kolonisation mit potentiell pathogenen Erregern vorliegt und wenn ja, ob diese eradizierbar ist [Kat. IB]. Eine Vorstellung beim Betriebsarzt ist anzuraten.

- Überall dort, wo eine Händedesinfektion durchgeführt werden muss, sind in unmittelbarer Nähe Desinfektionsmittelspender vorzuhalten $[$ Kat. IB, $I V]$. Für Patientenzimmer wird in Abhängigkeit von der Anzahl der Patientenbetten bettennah als Mindestausstattung ein Spender pro Patientenbett auf Intensiv- und Dialysestationen und auf Nicht-Intensivstationen ein Spender für je zwei Patientenbetten sowie in der Sanitärzelle empfohlen. Die Art der eingesetzten Spender, d.h. wand- oder bettmontierte Spen- der, mobile Spender mit Dosierpumpen bzw. Kittelflaschen, richtet sich nach den räumlichen Verhältnissen und den zu versorgenden Patienten. Z. B. kann es in der Geriatrie, Psychiatrie und Pädiatrie sowie in stationären Pflegeeinrichtungen sowie ambulanten Diensten sinnvoll sein, auf Kittelflaschen sowie auf Spender am Visiten- oder Verbandwagen zurückzugreifen, um Gefährdungen der Patienten durch das Desinfektionsmittel auszuschließen.

- Ferner sind mobile oder montierte Spender an reinen und unreinen Arbeitsplätzen, am Visiten- oder Verbandwagen und in Schleusen vorzuhalten [Kat. II].

- Spender müssen so zu betreiben und zu warten sein, dass eine mikrobielle Kontamination des Pumpkopfes problemlos vermieden wird. Der Füllstand muss gut erkennbar sein [Kat. II].

- Sofern keine Einmalgebinde verwendet werden, müssen die Außen- und Innenteile des Spenders aufbereitbar sein und so gewartet werden, dass ihre mikrobielle Besiedelung verhindert wird [Kat. II]. Das Anbruchsdatum eines Gebindes muss für HDM dokumentiert werden [Kat. IV].

- Desinfektionsmittelspender sollten wegen des Risikos der Kontamination mit nicht wiederbefüllbaren Gebinden (Einmalflaschen) bestückt werden [Kat. II].

\section{Indikationen, Auswahl und Durchführung}

- Bei den von der WHO unterschiedenen fünf Indikationsgruppen ist ausnahmslos eine Händedesinfektion durchzuführen [Kat. IA]. Das betrifft folgende Indikationen: Unmittelbar vor direktem Patientenkontakt, unmittelbar vor aseptischen Tätigkeiten, unmittelbar nach Kontakt mit potentiell infektiösem Material, nach Kontakt mit der direkten Patientenumgebung und nach direktem Patientenkontakt. Das gilt unabhängig davon, ob nachfolgend nicht sterile oder sterile Einmalhandschuhe angelegt werden. Zusätzlich ist nach dem Ablegen nicht steriler $[$ Kat. IB] sowie ste- 
riler Einmalhandschuhe [Kat. II] eine Händedesinfektion durchzuführen.

- Es ist zu empfehlen, Patienten und Besucher in die Maßnahmen der Händehygiene einzubeziehen, um ein zusätzliches Präventionspotential zu etablieren [Kat. II].

- Alle Bereiche der Hand müssen für die Dauer der deklarierten Einwirkungszeit vom Desinfektionsmittel benetzt sein; dabei sind insbesondere Fingerspitzen, Nagelfalze und Daumen zu berücksichtigen [Kat. IB]. Das wird durch Applikation von etwa 3-5 ml Desinfektionslösung, bzw. der Menge, die in eine Hohlhand passt, erreicht.

- Bei sichtbarer Kontamination der Hände sollte diese mit einem mit HDM getränkten Papierhandtuch, Zellstoff oder ähnlichem entfernt werden [Kat. II]. Danach ist die Händedesinfektion durchzuführen. Falls im Anschluss eine Händewaschung durchgeführt werden soll, ist das Wasser dem auf den Händen verteilten Desinfektionsmittel erst nach Ablauf der für die Desinfektion vorgesehenen Einwirkungszeit zuzusetzen [Kat. IB].

- Stark verschmutzte Hände können zunächst vorsichtig abgespült und dann gewaschen werden. Dabei ist darauf zu achten, dass Umgebung und Kleidung nicht bespritzt werden. Der ggf. kontaminierte Bereich ist danach zu desinfizieren und bei Kontamination der Kittel zu wechseln. Im Anschluss sind die Hände zu desinfizieren [Kat. II].

- Für die hygienische Händedesinfektion sind Alkohol basierte Formulierungen einzusetzen [Kat. IB]. Präparate mit Zusatz antimikrobiell remanent wirksamer Wirkstoffe sind nicht zu empfehlen, da dadurch keine verbesserte Wirksamkeit erreichbar ist, aber das Risiko von Nebenwirkungen ansteigt [Kat. II]. Für die Auswahl der Präparate gewährleistet die Desinfektionsmittelliste des VAH die Erfüllung der Anforderungen an die Wirksamkeit [Kat. IB].

- Bei Risiko der Weiterverbreitung behüllter Viren sind begrenzt viruzide HDM, im Fall unbehüllter Viren viruzide HDM einzusetzen [Kat. IB]. Bei viruziden HDM ist die ggf. verlängerte deklarierte Einwirkungszeit zu be- achten [Kat. IB]. Für die Auswahl der Präparate gewährleistet zusätzlich zur Desinfektionsmittel-Liste des VAH die Desinfektionsmittelliste des RKI die Erfüllung der Anforderungen an die Wirksamkeit (Kat. IB).

- Da Alkohole nicht gegen Bakteriensporen, Helminthen, Protozoen und Oocysten wirken, sind bei gegebenem Übertragungsrisiko medizinische Einmalhandschuhe anzulegen. Nach dem Ablegen und durchgeführter Händedesinfektion ist eine gründliche Seifenwaschung vorzunehmen [Kat. IB].

\section{Maßnahmen zur Verbesserung der Compliance und zur Qualitätssicherung}

- Interventionen zur Verbesserung der Compliance der Händehygiene, insbesondere regelmäßige Evaluation und Feedback, sind unverzichtbare Maßnahme des Qualitätsmanagements und als solche in jeder Einrichtung zu implementieren [Kat. IA/IV].

- Als Messsysteme stehen die direkte Beobachtung der Mitarbeiter, elektronische Systeme und als Surrogatparameter die Bestimmung des HDM-Verbrauchs zur Verfügung. Für stationäre Einrichtungen wird empfohlen, die Verbrauchsdaten für HDM nach Organisationseinheiten aufgeschlüsselt jährlich der ärztlichen und der pflegerischen Leitung mitzuteilen und für den entsprechenden Zeitraum gemäß Empfehlung im Modul HAND-KISS in Händedesinfektionseinheiten pro Patiententag ( $3 \mathrm{ml}=$ eine Händedesinfektionseinheit) im Krankenhaus darzustellen [Kat. IB].

- In Auswertung dieser Ergebnisse ist eine interdisziplinäre Diskussion sowohl in der Organisationseinheit als auch in der Hygienekommission zu führen (hier kommt es v.a. darauf an, die Situation in Organisationseinheiten mit sehr niedrigem Verbrauch pro Patiententag kritisch zu hinterfragen und ggf. dort gezielt zu intervenieren) [Kat. IB].

- Auch für ambulante Einrichtungen und Pflegeeinrichtungen kann die jährliche Bewertung des HDM-Verbrauchs durchgeführt werden, z. B. in Bezug auf die Anzahl der Behandlungsfälle pro Tag [Kat. III].
- Alle neuen Mitarbeiter müssen im Rahmen der Unterweisung in den Infektions- und Arbeitsschutz in die Festlegungen der Einrichtung zur Händehygiene unterwiesen werden, bevor sie mit der Aufnahme ihrer patientennahen Tätigkeit beginnen [Kat. $I A / I V]$. Abhängig von ihrem Ausbildungsstand können eine Schulung bzw. ein Training sinnvoll sein und sollten in diesem Fall angeboten werden [Kat. II].

- Zur Gewährleistung der Compliance der Händehygiene ist mindestens jährlich (und zeitnah bei Hinweisen auf Probleme in diesem Bereich) eine Schulung aller Mitarbeiter zu den Indikationen der Händedesinfektion in Verbindung mit einem Training z. B. mit fluoreszierendem Farbstoff im HDM zu gewährleisten [Kat. IB].

- Die Empfehlungen der KRINKO zur Händehygiene müssen im Hygieneplan und hierzu relevanten SOPs berücksichtigt werden [Kat. IA/IV]. Im Hygieneplan sind die Indikationen, die Durchführung der Händedesinfektion, die ausgewählten HDM, sowie Auswahl und Umgang mit nicht sterilen und sterilen Einmalhandschuhen festzulegen [Kat. IA/IV]. Gleichzeitig sind die Bestimmungen des Arbeitsschutzes einzuarbeiten [Kat. IB/IV].

- Die Empfehlung der KRINKO zur Händehygiene sollte den Mitarbeitern (z. B. in elektronischer Form als im Intranet abrufbare Datei) zur Verfügung stehen. An gleicher Stelle können weitere klinikspezifische Materialien zum Thema abgelegt werden (Hygieneplan, einrichtungsverbindliche SOPs, Schulungsfolien, Videos, Handouts, Poster, Broschüren usw.) [Kat. II].

- Bei einem Anstieg nosokomialer Infektionen oder verstärkter Ausbreitung von MRE wird die direkte Beobachtung der Compliance empfohlen, um daraus ggf. die Notwendigkeit zur Verbesserung der Händehygiene ableiten zu können [Kat. II]. 


\subsection{Chirurgische} Händedesinfektion

\section{Indikationen und Voraussetzungen}

- Die chirurgische Händedesinfektion ist vor dem Anlegen der sterilen OP-Handschuhe bei beabsichtigtem direkten Kontakt zum OP-Feld und zu sterilen MP oder Materialien sowie vor sonstigen Eingriffen mit gleichen Anforderungen an die Asepsis wie bei einer Operation durchzuführen [Kat. IB].

- Der OP-Trakt ist mit sauberen Händen und Fingernägeln zu betreten; diese sind bei erneuter Verschmutzung zu reinigen [Kat. II]. Andernfalls ist eine adäquate Reinigung spätestens im unreinen Bereich der Personalschleuse vor dem Anlegen der Bereichskleidung durchzuführen, damit eine ausreichende Trocknungszeit erreicht und die Wirksamkeit der chirurgischen Händedesinfektion nicht durch Restfeuchte beeinträchtigt wird (Kat. IB). Während Nägel und Nagelfalze bei Verschmutzung mit einer Bürste zu säubern sind, sollen Hände und Unterarme nicht mit einer Bürste gereinigt werden (Kat. II).

- Fingernägel sollen kurzgeschnitten sein und mit den Fingerkuppen abschließen. Nagellack ist abzulehnen (Kat. II). Das Tragen künstlicher und gegelter Fingernägel ist unzulässig [Kat. IB].

- An Händen und Unterarmen dürfen keine Ringe, Armbänder, Armbanduhren oder Piercings getragen werden [Kat. IB/ IV]. Ringdosimeter sind am OP-Ende abzulegen und erst nach deren Desinfektion wieder anzulegen [Kat. IB].

- Bei Vorliegen chronischer Hauterkrankungen ist zu überprüfen, ob eine Kolonisation mit potentiell pathogenen Erregern vorliegt und wenn ja, ob diese eradizierbar ist [Kat. IB]. Eine Vorstellung beim Betriebsarzt ist anzuraten.

\section{Durchführung}

- Für die chirurgische Händedesinfektion sind Alkohol basierte Formulierungen einzusetzen $[K a t . I B]$, wobei keine zusätzliche tuberkulozide, fungizide oder viruzide Wirksamkeit benötigt wird. Die Einwirkungszeit ist gemäß Produktdeklarierung einzuhalten $[K a t . I B / I V]$.

- Für den Einsatz von Präparaten mit Zusatz antimikrobiell remanent wirksamer Wirkstoffe kann wegen der ungeklärten Nutzen-Risiko-Bewertung derzeit keine Empfehlung gegeben werden [Kat. III]. Alkohol basierte Präparate mit Zusatz von PVP-Iod sind wegen der Schilddrüsengefährdung für die wiederholte Anwendung ungeeignet [Kat. IB]. Auch Alkohol basierte Präparate mit Zusatz von Chlorhexidin sind wegen erhöhter Irritabilität, dem Risiko von Allergien und Anaphylaxien sowie der Möglichkeit der Resistenzentwicklung für den täglichen Einsatz kritisch zu bewerten [Kat. II].

- Vor der am Operationstag erstmalig durchgeführten chirurgischen Händedesinfektion ist eine chirurgische Händewaschung unter Einschluss der Unterarme bis zum Ellenbogen mit nachfolgendem Abtrocknen mit nicht sterilem Einmalhandtuch oder Lufttrocknung durchzuführen. Bei nachfolgenden chirurgischen Händedesinfektionen ist die Händewaschung nicht erforderlich, sofern die Hände nicht sichtbar verschmutzt wurden [Kat. II].

- Es empfiehlt sich folgender Ablauf für die chirurgische Händedesinfektion: Zunächst werden die Hände, danach die Unterarme vollständig benetzt. Dem schließt sich die Händedesinfektionsphase mittels Einreibeverfahren an. Alle Bereiche der Hand müssen für die Dauer der deklarierten Einwirkungszeit (z. B. 1, 1,5, 3 oder 5 min) vom Desinfektionsmittel mittels eingeübter Einreibetechnik benetzt sein [Kat. II/IV].

- Die Hände sollen luftgetrocknet sein, bevor die OP-Handschuhe angelegt werden [Kat. II].

\subsection{Medizinische Einmalhandschuhe und Schutzhandschuhe}

- Bei vorhersehbarem oder wahrscheinlichem Kontakt mit Körperausscheidungen, Sekreten und Exkreten einschließlich Krankheitserregern sind pathogenfreie („keimarme“) medizi- nische Einmalhandschuhe anzulegen [Kat. IB/IV].

- Die Handschuhe sind nur auf vollständig trockenen Händen anzulegen [Kat. II].

- Der Wechsel der Handschuhe korreliert mit den Indikationen zur Händedesinfektion. Immer wenn die Indikation für eine Händedesinfektion gegeben ist, aber Handschuhe getragen werden, müssen die Einmalhandschuhe gewechselt werden, sofern nicht eine Handschuhdesinfektion vertretbar ist [Kat. IB].

- Behandschuhte Hände sollen nur in Ausnahmefällen desinfiziert werden, wenn andernfalls der Arbeitsablauf nicht gewährleistet werden kann [Kat. IB]. Voraussetzung ist die Chemikalienbeständigkeit gemäß EN 374. Bezüglich der Anzahl möglicher Desinfektionen ist die Produktinformation zum Handschuh zu beachten. Bei sichtbarer Perforation, bei Kontamination mit Blut, Sekreten oder Exkreten sowie mit unbehüllten Viren sowie nach Benutzung zur Patientenwaschung sollte in jedem Fall ein Handschuhwechsel erfolgen [Kat. II].

- Nach dem Ablegen von Einmalhandschuhen ist eine Händedesinfektion durchzuführen [Kat. IB].

- Soll zugleich eine Schutzfunktion gegen Chemikalien erreicht werden, sind als PSA deklarierte Handschuhe bzw. Handschuhe mit dualer Deklarierung als Medizinprodukt und als PSA einzusetzen [Kat. II/IV].

- Falls aufbereitbare Haushaltshandschuhe in Gesundheitseinrichtungen eingesetzt werden, muss sowohl die Schutzfunktion vor Chemikalien als auch vor Mikroorganismen für die deklarierte Tragedauer gewährleistet sein [Kat. II]. Zugleich wird eine verlängerte Stulpe benötigt [Kat. II]. Alternativ sind mechanisch belastbare Einmal-Schutzhandschuhe mit langen Stulpen zu empfehlen.

- Bei dem Einsatz beider Handschuharten ist eine Weiterverbreitung von Krankheitserregern zu unterbinden [Kat. IB]. Werden Isoliereinheiten der desinfizierenden Reinigung unterzogen, sind die Handschuhe beim Verlassen der Einheit abzuwerfen und 
eine Händedesinfektion durchzuführen. Ansonsten sind bei jedem Raumwechsel die behandschuhten Hände einer Händedesinfektion zu unterziehen.

\subsection{Sterile OP-Handschuhe}

- Vor allen invasiven Eingriffen, die über die Basishygienemaßnahmen hinausgehende Barrieremaßnahmen erfordern, im Umgang mit sterilen Medizinprodukten oder bei direktem Kontakt mit sterilem Material sind sterile OP-Handschuhe anzulegen [Kat. IB].

- Für OP-Handschuhe sind latexallergenarme Fabrikate zu bevorzugen [Kat. II] Gepuderte Latexhandschuhe sind wegen der Allergiegefahr untersagt [Kat. IV]. Die Verwendung von Talkum und Ersatzprodukten vor dem Anlegen des OP-Handschuhs auf den Händen ist nicht zu empfehlen [Kat. II].

- Zur OP von Patienten mit einem erhöhten Risiko für die Entwicklung einer Latexallergie (insbesondere Spina bifida, urogenitale Fehlbildungen und Ösophagusatresie) sollen naturlatexfreie OP-Handschuhe getragen werden [Kat. IB].

- Bei chirurgischen Eingriffen mit erhöhtem Perforationsrisiko und/oder chirurgischen Eingriffen an Patienten mit erhöhtem Infektionsrisiko wird für das operativ tätige chirurgische Team das Tragen von zwei Paar übereinander gezogenen OP-Handschuhen (double gloving) empfohlen [Kat. $I I]$. Andernfalls ist abhängig von der OP-Dauer und der Art des Eingriffs ein intraoperativer Handschuhwechsel zu empfehlen [Kat. II]. Im Bereich der Endoprothetik sollte vor Annahme eines Implantats generell ein Handschuhwechsel erfolgen [Kat. II].

- Ob vor dem Anlegen neuer steriler OP-Handschuhe bei sichtbarer intraoperativer Perforation eine Händedesinfektion durchgeführt werden sollte, ist eine ungeklärte Frage, erscheint aber entbehrlich, da nur im OP-Gebiet gearbeitet wurde [Kat. III] .

- Nach Ablegen der OP-Handschuhe ist eine hygienische Händedesinfektion zu empfehlen [Kat. II].

\subsection{Händewaschung}

- Ein hygienischer Handwaschplatz muss mit Zulauf für warmes und kaltes Wasser ausgestattet sein [Kat. IV]. Der Wasserstrahl sollte nicht direkt in den Siphon bzw. auf den Abfluss gerichtet sein [Kat. II]. Bei Neueinrichtung oder wesentlicher Umgestaltung eines Handwaschplatzes ist auf ein ausreichend groß dimensioniertes, tief ausgeformtes Handwaschbecken ohne Überlauf zu achten [Kat. II]. Falls Arbeitsflächen für aseptische Arbeiten an den Waschplatz angrenzen, sind diese durch einen Spritzschutz abzuschirmen [Kat. IB]. Der Waschplatz muss abhängig von den räumlichen Bedingungen mit wandmontierten Spendern für HDM und Handwaschpräparat sowie mit Einmalhandtüchern ausgestattet sein [Kat. IV].

- Handwaschplätze müssen in Räumen vorhanden oder in der Nähe erreichbar sein, in denen diagnostische oder invasive Maßnahmen stattfinden, in Räumen, die der Vorbereitung solcher Maßnahmen dienen, sowie in der Nähe unreiner Arbeitsbereiche.

- Für jedes Patientenzimmer sollte eine für die Beschäftigten leicht erreichbare Waschgelegenheit verfügbar sein, die analog wie der Handwaschplatz ausgestattet sein sollte [Kat. II]. Für Tätigkeiten mit biologischen Arbeitsstoffen ist die Verfügbarkeit von Spendern für Handwaschpräparate als Mindestschutzmaßnahme vorgeschrieben [Kat. IV].

- Alle Armaturen, die von Beschäftigten mit direktem Patientenkontakt genutzt werden, oder sich in kritischen Bereichen befinden, sollen mit verlängerter Hebelarmatur zu bedienen sein [Kat. II]. Da Armaturen mit Sensor ein Kontaminationsrisiko für das entnommene Wasser bergen, ist ihr Einsatz nur unter sorgfältiger hygienisch-mikrobiologischer Überwachung vertretbar [Kat. II].

- Spender für Einmalhandtücher müssen eine einfache Entnahme ermöglichen, ohne dass die nachfolgenden Handtücher und die Entnahmeöffnung kontaminiert werden [Kat. II]. Für die gebrauchten Handtücher ist ein Sammelbehälter vorzusehen und für dessen regelmäßige Entleerung Sorge zu tragen. Alternativ kommen Retraktivspender mit automatischem Handtuchvorschub in Betracht.

- Vor Arbeitsbeginn und ggf. zum Arbeitsende empfiehlt sich eine Händewaschung, erstere um anhaftenden Schmutz einschließlich ggf. anhaftender Bakteriensporen zu entfernen, letztere um ggf. arbeitsbedingte Verunreinigungen zu entfernen [Kat. II]. Nach Toilettenbenutzung ist das Standardverfahren die Händewaschung. Bei Diarrhoe oder Rhinitis kann eine Händedesinfektion sinnvoll sein [Kat. II].

- Verschmutzte Hände sind zu waschen [Kat. II]. Da die Händewaschung die transiente Hautflora nicht auf ein unkritisches Niveau reduziert, ist nach Entfernung einer massiven Kontamination die hygienische Händedesinfektion indiziert [Kat. IB].

- Händewaschungen sind auf das notwendige Minimum zu beschränken, weil diese im Unterschied zur Händedesinfektion durch ein ausgeprägtes Irritationspotential charakterisiert sind und ihr Einfluss auf die Prävention von NI zu vernachlässigen ist $[$ Kat. IB]. Eine Ausnahme bildet die Entfernung von gegen alkoholische HDM unempfindlichen Krankheitserregern wie C. difficile, Helminthen oder Protozoen.

- Anstelle fester wird der Einsatz flüssiger Handwaschpräparate empfohlen [Kat. II]. Bei Verwendung flüssiger Handwaschpräparate ist das Nachfüllen nicht entleerter und nicht nachfolgend aufbereiteter Seifenspender wegen des Kontaminationsrisikos zu unterlassen [Kat. IB].

- Spender für Handwaschpräparate müssen mit verlängerter Hebelarmatur oder anderen Vorrichtungen, die eine Kontamination des Bedienelements verhindern, zu bedienen sein [Kat. IV].

- Wegen der im Vergleich zum Papierhandtuch geringeren Trocknungswirkung und der fehlenden mechanischen Entfernung von Rückständen (Seifenreste, Hautschuppen, Reste der Hautflora) sind elektrische Warmlufttrockner für Gesundheitseinrichtungen ungeeignet $[$ Kat. II]. 


\subsection{Hautschutz und Hautpflege}

- Bei Gefährdung der Haut durch Arbeiten im feuchten Milieu (sog. Feuchtarbeit) sind feuchtigkeitsdichte Handschuhe zu tragen, eine gezielte arbeitsmedizinische Vorsorge zu gewährleisten, eine Betriebsanweisung zu erstellen und ein Hautschutzplan zu erarbeiten. Zugleich ist die Möglichkeit zur Reduzierung der Feuchtigkeitsexposition zu überprüfen [Kat. $I B / I V]$.

- Auf Grund der erhöhten Belastung der Haut empfiehlt sich für alle in der ärztlichen und pflegerischen Versorgung tätigen Mitarbeiter die regelmäßige Pflege der Hände durch Einsatz von für den Hauttyp geeigneten Hautschutz- und Hautpflegemitteln mit dermatologisch nachgewiesener Effektivität [Kat. II].

- Der Wissenserwerb zur Notwendigkeit und zur Durchführung von Hautschutz und -pflege ist in Schulungsmaßnahmen zur Händedesinfektion zu integrieren [Kat. IB].

- Bei der Auswahl von Hautschutzund Hautpflegemitteln sind Produkte ohne Duft- und ohne Konservierungszusatz zu bevorzugen [Kat. II]. Hautschutzpräparate sollten auch keinen Harnstoff enthalten.

- Hautpflegemittel sollen wegen der Kontaminationsgefahr in Spendern oder Tuben bereitgestellt werden [Kat. II].

Die Empfehlungen wurden ehrenamtlich und ohne Einflussnahme kommerzieller Interessengruppen im Auftrag der Kommission für Krankenhaushygiene und Infektionsprävention bearbeitet von Herrn Prof. Dr. Axel Kramer (Leiter der Arbeitsgruppe), Frau Heike Briesch, Frau Dr. Bärbel Christiansen, Herr Prof. Dr. Harald Löffler, Frau Dr. Christin Perlitz, Frau Dr. Christiane Reichardt.

\section{Literatur}

1. Kommission für Krankenhaushygiene und Infektionsprävention (KRINKO) (2010) Die Kategorien in der Richtlinie für Krankenhaushygiene und Infektionsprävention-Aktualisierung der Definitionen. Bundesgesundheitsblatt 53(7):754-756

2. Infektionsschutzgesetz vom 20. Juli 2000 (BGBI. I S. 1045), das durch Artikel 6 a des Gesetzes vom 10. Dezember 2015 (BGBI. I S. 2229) geändert worden ist. http://www.gesetze-im-internet. de/bundesrecht/ifsg/gesamt.pdf. Zugegriffen: 22. Dez. 2015
3. Landers T, Abusalem S, Coty MB, Bingham J (2012) Patient-centered hand hygiene: the next step in infection prevention. Am J Infect Control 40(Suppl 1):S11-S17

4. TRBA 250: Biologische Arbeitsstoffe im Gesundheitswesen und in der Wohlfahrtspflege. GMBI 2014(10-11):206, Letzte Änderung vom: 21. Juli 2015

5. Berufsgenossenschaft für Gesundheitsdienst und Wohlfahrtspflege (BGW) (Hrsg) (2013) Hauptsache Hautschutz. Hände schützen, pflegen - gesund bleiben

6. Kloesel A, Cyran W (2002) Arzneimittelrecht. Kommentar Bd. II, S 3, Deutscher Apotheker Verlag, Stuttgart

7. Arzneimittelgesetz in der Fassung der Bekanntmachung vom 12. Dezember 2005 (BGBI. I S. 3394), das zuletzt durch Artikel 3 des Gesetzes vom 10. Dezember 2015 (BGBI. I S. 2210) geändert worden ist. https:// www.google.de/url?sa $=t \& r c t=j \& q=\& e s-$ $r c=s \&$ source $=$ web \&cd $=1 \&$ cad $=$ rja \&uact $=8 \&$ ved=0ahUKEwj6_ef6yYbMAhXFOBoKHQaLC zoQFggdMAA\&url=https\%3A\%2F\%2Fwww. gesetze-im-internet.de\%2Fbundesrecht $\% 2 \mathrm{Fam}$ g_1976\%2Fgesamt.pdf\&usg=AFQjCNFFGXg2uWjV_8X1DyEf40TOtPnfmA

8. Hengesbach B, Schneider A (2013) Umfüllen von Händedesinfektionsmitteln - hygienische und haftungsrechtliche Aspekte. Hyg Med 38(6):259-260

9. Durchführungsbeschluss (EU) 2016/904 der Kommission vom 8. Juni 2016 gemäß Artikel 3 Absatz 3 der Verordnung (EU) Nr. 528/2012 des Europäischen Parlaments und des Rates über 2-Propanol-haltige Produkte für die Händedesinfektion (ABI. L 152 vom 9. Juni 2016, S. 45-46)

10. Weuffen W, Berling $H$, Hetmanek R (1981) Verwendung von Äthanol für Desinfektionszwecke. In: Weuffen W, Oberdoerster F, Kramer A (Hrsg) Krankenhaus-hygiene. Barth, Leipzig, S 518-519

11. Danchaivijitr $S$, Dhiraputra $C$, Rongrungruang Y, Srihapol N, Pumsuwan V (2005) Microbial contamination of antiseptics and disinfectants. $J$ Med Assoc Thai 88(Suppl 10):S133-S139

12. Kampf G, McDonald C, Ostermeyer C (2005) Bacterial in-use contamination of an alcohol-based hand rub under accelerated test conditions. J Hosp Infect 59(3):271-272

13. Kramer A, Kedzia W, Lebek G, Grün L, Weuffen W, Poczta A (1984) In-vitro- und In-vivo-Befunde zur Resistenzsteigerung bei Bakterien gegen Antiseptika und Desinfektionsmittel. In: Faktoren der mikrobiellen Kolonisation. Handbuch der Antiseptik, Bd. I/4, Fischer, Stuttgart, S 79-121

14. Schneider A, Bierling G (Hrsg) (2007) Hygiene und Recht. Entscheidungssammlung-Richtlinien. Loseblattsammlung. mhp-Verlag, Wiesbaden

15. Verbund für Angewandte Hygiene (VAH) (Hrsg) (2015) Desinfektionsmittel-Liste des VAH. mhp-Verlag, Wiesbaden

16. Desinfektionsmittel-Kommission im VAH (Hrsg) (2015) Anforderungen und Methoden zur VAH-Zertifizierung chemischer Desinfektionsverfahren, mhp-Verlag, Wiesbaden

17. DIN EN 1500:2013-07 Chemische Desinfektionsmittel und Antiseptika, Hygienische Händedesinfektion, Prüfverfahren und Anforderungen (Phase 2/Stufe 2). Beuth Verlag: Berlin

18. DIN EN 12791:2005-10 Chemische Desinfektionsmittel und Antiseptika - Chirugische Händedesinfektionsmittel - Prüfverfahren und Anforderungen (Phase 2/Stufe 2). Beuth Verlag: Berlin
19. DIN EN 14476:2015-12 Chemische Desinfektionsmittel und Antiseptika - Quantitativer Suspensionsversuch Viruzidie für in der Humanmedizin verwendete Desinfektionsmittel und Antiseptika - Prüfverfahren und Anforderungen (Phase 2/Stufe 1). Beuth Verlag: Berlin

20. DIN EN 13727:2015-12 Chemische Desinfektionsmittel und Antiseptika - Quantitativer Suspensionsversuch zur Bestimmung der bakteriziden Wirkung im humanmedizinischen Bereich - Prüfverfahren und Anforderungen (Phase 2, Stufe 1). Beuth Verlag: Berlin

21. DIN EN 13624:2013-12 Chemische Desinfektionsmittel und Antiseptika - Quantitativer Suspensionsversuch zur Prüfung der fungiziden oder levuroziden Wirkung im humanmedizinischen Bereich - Prüfverfahren und Anforderungen (Phase 2, Stufe 1). Beuth Verlag: Berlin

22. Rabenau H, Schwebke I, Blümel J et al (2015) Leitlinie der Deutschen Vereinigung zur Bekämpfung der Viruskrankheiten (DVV) e. V. und des Robert Koch-Instituts (RKI) zur Prüfung von chemischen Desinfektionsmitteln auf Wirksamkeit gegen Viren in der Humanmedizin. Fassung vom 1. Dezember 2014. Bundesgesundheitsblatt 58(6):493-504

23. Robert Koch-Institut (2013) Liste der vom Robert Koch-Institut geprüften und anerkannten Desinfektionsmittel und -verfahren. Bundesgesundheitsblatt 56(12):1706-1728

24. Gwaltney JM, Hendley JO (1982) Transmission of experimental rhinovirus infection by contaminated surfaces. Am J Epidemiol 116(5):828-833

25. Sartor C, Jacomo V, Duvivier C, Tissot-Dupont $\mathrm{H}$, Sambuc R, Drancourt M (2000) Nosocomial Serratia marcescens infections associated with extrinsic contamination of a liquid nonmedicated soap. Infect Control Hosp Epidemiol 21(3):196-199

26. Scott E, Bloomfield SF (1990) The survival and transfer of microbial contamination via cloths, hands and utensils. J Appl Bacteriol 68(3):271278

27. Rangel-Frausto $M$, Houston A, Bale M, Fu C, Wenzel R (1994) An experimental model for study of Candida survival and transmission in human volunteers. Eur J Clin Microbiol Infect Dis 13(7):590-595

28. Ward RL, Bernstein D, Knowlton D et al (1991) Prevention of surface-to-human transmission of rotaviruses by treatment with disinfectant spray. J Clin Microbiol 29(9):1991-1996

29. Rusin P, Maxwell S, Gerba C (2002) Comparative surface-to-hand and fingertip-to-mouth transfer efficiency of gram-positive bacteria, gram-negative bacteria, and phage. J Appl Microbiol 93(4):585-592

30. Weber DJ, Rutala WA, Miller MB, Huslage K, Sickbert-Bennett E (2010) Role of hospital surfaces in the transmission of emerging health care-associated pathogens: norovirus, Clostridium difficile, and Acinetobacter species. Am J Infect Control 38(Suppl 1):S25-S33

31. Larson E (1988) A causal link between handwashing and risk of infection? Examination of the evidence. Infect Control Hosp Epidemiol 9(1):28-36

32. Lucet J, Rigaud M, Mentre F et al (2002) Hand contamination before and after different hand hygiene techniques: a randomized clinical trial. J Hosp Infect 50(4):276-280

33. Pittet D, Allegranzi B, Boyce J et al (2009) The World Health Organization Guidelines on Hand 
Hygiene in Health Care and their consensus recommendations. Infect Control Hosp Epidemiol 30(7):611-622

34. Pittet D, Hugonnet $S$, Harbarth $S$ et al (2000) Effectiveness of a hospital-wide programme to improve compliance with hand hygiene. Infection Control Programme. Lancet 356(9238):13071312

35. Ellingson K, Haas JP, Aiello AE et al (2014) Strategies to prevent healthcare-associated infections through hand hygiene. Infect Control Hosp Epidemiol 35(8):937-960

36. Mathai E, Allegranzi B, Kilpatrick C, Pittet D (2010) Prevention and control of health care-associated infections through improved hand hygiene. Indian J Med Microbiol 28(2):100-106

37. Hirschmann H, Fux L, Podusel J et al (2001) The influence of hand hygiene prior to insertion of peripheral venous catheters on the frequency of complications. J Hosp Infect 49(3):199-203

38. Charles MP, Kali A, Easow JM et al (2014) Ventilator-associated pneumonia. Australas Med J 7(8):334-344

39. Kampf G, Löffler H, Gastmeier P (2009) Hand hygiene for the prevention of nosocomial infections. Dtsch Ärztebl Int 106(40):649-655

40. Hübner NO, Hübner C, Wodny M, Kampf G, Kramer A (2010) Effectiveness of alcohol-based hand disinfectants in a public administration: Impact on health and work performance related to acute respiratory symptoms and diarrhoea. BMC Infect Dis 10(1):250

41. Kampf G, Kramer A (2004) Epidemiologic background of hand hygiene and evaluation of the most important agents for scrubs and rubs. Clin Microbiol Rev 17(4):863-893

42. Pittet D, Dharan S, Touveneau S, Sauvan V, Perneger TV (1999) Bacterial contamination of the hands of hospital staff during routine patient care. Arch Intern Med 159(8):821-826

43. Pessoa-Silva CL, Dharan $\mathrm{S}$, Hugonnet $\mathrm{S}$ et al (2004) Dynamics of bacterial hand contamination during routine neonatal care. Infect Control Hosp Epidemiol 25(3):192-197

44. Robert Koch-Institut, Deutsche Vereinigung zur Bekämpfung der Viruskrankheiten e. V., Deutsche Gesellschaft für Hygiene und Mikrobiologie (2004) Prüfung und Deklaration der Wirksamkeit von Desinfektionsmitteln gegen Viren - Stellungnahme des Arbeitskreises Viruzidie* beim Robert Koch-Institut (RKI) sowie des Fachausschusses "Virusdesinfektion“ der Deutschen Vereinigung zur Bekämpfung der Viruskrankheiten (DVV) und der Desinfektionsmittelkommission der Deutschen Gesellschaft für Hygiene und Mikrobiologie (DGHM). Bundesgesundheitsblatt 47(1):62-66

45. Robert Koch-Institut (RKI), Deutsche Vereinigung zur Bekämpfung der Viruskrankheiten e. V. (DVV) (2014) Desinfektion bei Noroviren - Erläuterungen zur Prüfung und Deklaration der Wirksamkeit von Desinfektionsmitteln. Epidemiol Bull 32:289-290

46. Reichel M, Heisig P, Kohlmann T, Kampf G (2009) Alcohols for skin antisepsis at clinically relevant skin sites. Antimicrob Agents Chemother 53(11):4778-4782

47. Rotter ML (1999) Hand washing and hand disinfection. In: Hospital epidemiology and infection control, 2. Aufl. Lippincott Williams \& Wilkins, Philadelphia, S 1339-1355

48. Kramer A, Rudolph P, Kampf G, Pittet D (2002) Limited efficacy of alcohol-based hand gels. Lancet 359(9316):1489-1490
49. Kampf G, Rudolf M, Labadie JC, Barrett SP (2002) Spectrum of antimicrobial activity and user acceptability of the hand disinfectant agent Sterillium Gel. J Hosp Infect 52(2):141-147

50. Rupp ME, Fitzgerald T, Puumala S et al (2008) Prospective, controlled, cross-over trial of alcohol-based hand gel in critical care units. Infect Control Hosp Epidemiol 29(1):8-15

51. Klein M, Deforest A (1963) Antiviral action of germicides. Soap Chem Spec 39(70-72):95-97

52. Schürmann W, Eggers HJ (1983) Antiviral activity of an alcoholic hand disinfectant. Comparison of the in vitro suspension test with in vivo experiments on hands, and on individual fingertips. Antiviral Res 3(1):25-41

53. Steinmann J, Nehrkorn R, Meyer A, Becker K (1995) Two in-vivo protocols for testing virucida efficacy of handwashing and hand disinfection. Zentralbl Hyg Umweltmed 196(5):425-436

54. Kramer A, Galabov A, Sattar S et al (2006) Virucidal activity of a new hand disinfectant with reduced ethanol content: comparison with other alcohol-based formulations. J Hosp Infect 62(1):98-106

55. Steinmann J, Nehrkorn R, Losche E, Sasse E, Bogumil-Puchert B (1990) Viruswirksamkeit der hygienischen Händedesinfektion. Hyg Med 15:7-14

56. Fritz SA, Hogan PG, Camins BC et al (2013) Mupirocin and chlorhexidine resistance in Staphylococcus aureus in patients with community-onset skin and soft tissue infections. Antimicrob Agents Chemother 57(1):559-568

57. Kramer A, Assadian O, Wilhelm M (2012) Konsequenzen der Nutzen-Risiko-Bewertung von Desinfektionswirkstoffen. In: Kramer A, Assadian O, Exner M, Hübner NO, Simon A (Hrsg) Krankenhaus-und Praxishygiene. Hygienemanagement und Infektionsprävention in medizinischen und sozialen Einrichtungen, 2. Aufl., Urban \& Fischer in Elsevier, München, S 56-59

58. Cherednichenko G, Zhang R, Bannister RA et al (2012) Triclosan impairs excitation-contraction coupling and $\mathrm{Ca} 2+$ dynamics in striated muscle. Proc Natl Acad Sci U S A 109(35):14158-14163

59. Wahlberg JE (1976) Routine patch testing with Irgasan DP 300. Contact Derm 2(5):292

60. Kramer A, Below H, Assadian O (2012) Health risks of surface disinfection in households with special consideration on quaternary ammonium compounds (QACS). In: Bioaerosols-6th International Scientific Conference on Bioaerosols, Fungi, Bacteria, Mycotoxins in Indoor and Outdoor Environments and Human Health. Fungal Research Group Foundation, Albany

61. Below H, Brauer V, Kramer A (2007) lodresorption bei antiseptischer Anwendung von lodophoren und Schlussfolgerungen zur Risikobewertung. GMS Krankenhhyg Interdiszip 2(2):1-11

62. Winnefeld M, Richard M, Drancourt M, Grob J (2000) Skin tolerance and effectiveness of two hand decontamination procedures in everyday hospital use. Br J Dermatol 143(3):546-550

63. Grove G, Zerweck C, Heilman J, Pyrek J (2001) Methods for evaluating changes in skin condition due to the effects of antimicrobial hand cleansers: two studies comparing a new waterless chlorhexidine gluconate/ethanol-emollient antiseptic preparation with a conventional water-applied product. Am J Infect Control 29(6):361-369

64. Larson EL, Aiello AE, Bastyr J et al (2001) Assessment of two hand hygiene regimens for intensive care unit personnel. Crit Care Med 29(5):944-951

65. Larson EL, Aiello AE, Heilman JM et al (2001) Comparison of different regimens for surgical hand preparation. AORN J 73(2):412-432

66. Sauermann G, Proske O, Keyhani R, Leneveu MC, Pietsch H, Rohde B (1995) Hautverträglichkeit von Sterillium und Hibiscrub in einer klinischen Vergleichsstudie. Hyg Med 20:184-189

67. Kramer A, Mersch-Sunfermann V, Gerdes H, Pitten FA, Tronnier H (2003) Toxikologische Bewertung für die Händedesinfektion relevanter antimikrobieller Wirkstoffe. In: Hände-Hygiene im Gesundheitswesen. Springer, Berlin, S 105-174

68. Larson EL, Cimiotti J, Haas J et al (2005) Effect of antiseptic handwashing vs alcohol sanitizer on health care-associated infections in neonatal intensive care units. Arch Pediatr Adolesc Med 159(4):377-383

69. Rotter ML, Koller W, Neumann R (1991) The influence of cosmetic additives on the acceptability of alcohol-based hand disinfectants. J Hosp Infect 18(Suppl B):57-63

70. Kramer A, Bernig T, Kampf G (2002) Clinical double-blind trial on the dermal tolerance and user acceptability of six alcohol-based hand disinfectants for hygienic hand disinfection. J Hosp Infect 51(2):114-120

71. Kampf G, Wigger-Alberti W, Schoder V, Wilhelm KP (2005) Emollients in a propanol-based hand rub can significantly decrease irritant contact dermatitis. Contact Derm 53(6):344-349

72. Kramer A, Reichwagen S, Below H et al (2008) Alkohole. In: Kramer A, Assadian O (Hrsg) Wallhäußers Praxis der Sterilisation. Thieme, Stuttgart, S643-669

73. Kramer A, Below H, Bieber N et al (2007) Quantity of ethanol absorption after excessive hand disinfection using three commercially available hand rubs is minimal and below toxic levels for humans. BMC Infect Dis 7:117

74. Below H, Partecke I, Hübner NO et al (2012) Dermal and pulmonary absorption of propan-1ol and propan-2-ol from hand rubs. Am J Infect Control 40(3):250-257

75. Geßner S, Below E, Wegner C et al (2014) Beeinflussung der Alkoholabstinenzkontrolle durch Händedesinfektion. Rechtsmedizin 24(4):252257

76. Gessner S, Below E, Diedrich S, et al. (in press) Ethanol and ethyl glucuronide urine concentrations after ethanol-based hand antisepsis with and without permitted alcohol consumption. Am J Infect Control (Available online 11 April 2016) doi:10.1016/j.ajic.2016.1002.1021

77. Kramer A, Adrian V, Rudolph P, Wurster S, Lippert H (1998) Explantationstest mit Haut und Peritoneum der neonatalen Ratte als Voraussagetest zur Verträglichkeit lokaler Antiinfektiva für Wunden und Körperhöhlen. Chirurg 69(8):840-845

78. Schamberger J (2009) Sporozide Wirksamkeit von 2 Peressigsäure-basierten Desinfektionsmitteln im Modell der hygienischen Händedesinfektion. Dissertation. Universitätsmedizin Greifswald

79. Weber DJ, Sickbert-Bennett E, Gergen MF, Rutala WA (2003) Efficacy of selected hand hygiene agents used to remove Bacillus atrophaeus (a surrogate of Bacillus anthracis) from contaminated hands. JAMA 289(10):1274-1277

80. Bettin K, Clabots C, Mathie P, Willard K, Gerding DN (1994) Effectiveness of liquid soap vs. chlor- 
hexidine gluconate for the removal of Clostridium difficile from bare hands and gloved hands. Infect Control Hosp Epidemiol 15(11):697-702

81. Semmelweis IP (1861) Die Aetiologie, der Begriff und die Prophylaxis des Kindbettfiebers. Hartleben, Pest

82. Noakes T, Borresen J, Hew-Butler T, Lambert M, Jordaan E (2008) Semmelweis and the aetiology of puerperal sepsis 160 years on: an historical review. Epidemiol Infect 136(01):1-9

83. Lam BC, Lee J, Lau YL (2004) Hand hygiene practices in a neonatal intensive care unit: a multimodal intervention and impact on nosocomial infection. Pediatrics 114(5):e565-571

84. Won SP, Chou HC, Hsieh WS et al (2004) Handwashing program for the prevention of nosocomial infections in a neonatal intensive care unit. Infect Control Hosp Epidemiol 25(9):742-746

85. Rosenthal VD, Guzman S, Safdar N (2005) Reduction in nosocomial infection with improved hand hygiene in intensive care units of a tertiary care hospital in Argentina. Am J Infect Control 33(7):392-397

86. Zerr DM, Allpress AL, Heath J, Bornemann R, Bennett E (2005) Decreasing hospital-associated rotavirus infection: a multidisciplinary hand hygiene campaign in a children's hospital. Pediatr Infect Dis J 24(5):397-403

87. Larson EL, Quiros D, Lin SX (2007) Dissemination of the CDC's Hand Hygiene Guideline and impact on infection rates. Am J Infect Control 35(10):666-675

88. Thu LTA et al (2007) Reduction in surgical site infections in neurosurgical patients associated with a bedside hand hygiene program in Vietnam. Infect Control Hosp Epidemiol 28(5):583588

89. Capretti MG, Sandri F, Tridapalli E, Galletti S, Petracci E, Faldella G (2008) Impact of a standardized hand hygiene program on the incidence of nosocomial infection in very low birth weight infants. Am J Infect Control 36(6):430-435

90. Brown SM, Lubimova AV, Khrustalyeva NM et al (2003) Use of an alcohol-based hand rub and quality improvement interventions to improve hand hygiene in a Russian neonatal intensive care unit. Infect Control Hosp Epidemiol 24(3):172-179

91. Larson E (1999) Skin hygiene and infection prevention: more of the same or different approaches? Clin Infect Dis 29(5):1287-1294

92. Ling ML, How KB (2012) Impact of a hospital-wide hand hygiene promotion strategy on healthcare-associated infections. Antimicrob Resist Infect Control 1(1):1-5

93. Mathur P (2011) Hand hygiene: back to the basics of infection control. Indian J Med Res 134(5):611-620

94. Huang GKL, Stewardson AJ, Grayson ML (2014) Back to basics: hand hygiene and isolation. Curr Opin Infect Dis 27(4):379-389

95. Harrington G, Watson K, Bailey M et al (2007) Reduction in hospitalwide incidence of infection or colonization with methicillin-resistant Staphylococcus aureus with use of antimicrobial hand-hygiene gel and statistical process control charts. Infect Control Hosp Epidemiol 28(7):837-844

96. Gordin FM, Schultz ME, Huber RA, Gill JA (2005) Reduction in nosocomial transmission of drug-resistant bacteria after introduction of an alcohol-based handrub. Infect Control Hosp Epidemiol 26(7):650-653
97. Girou E, Legrand P, Soing-Altrach S et al (2006) Association between hand hygiene compliance and methicillin-resistant staphylococcus aureus prevalence in a french rehabilitation hospital. Infect Control Hosp Epidemiol 27(10):1128-1130

98. Trick WE, Vernon MO, Welbel SF, DeMarais $P$, Hayden MK, Weinstein RA (2007) Multicenter intervention program to increase adherence to hand hygiene recommendations and glove use and to reduce the incidence of antimicrobial resistance. Infect Control Hosp Epidemiol 28(1):42-49

99. Kaier K, Frank U, Hagist C, Conrad A, Meyer E (2009) The impact of antimicrobial drug consumption and alcohol-based hand rub use on the emergence and spread of extended-spectrum beta-lactamase-producing strains: a time-series analysis. J Antimicrob Chemother 63(3):609-614

100. Gagne D, Bedard G, Maziade PJ (2010) Systematic patients' hand disinfection: impact on meticillin-resistant Staphylococcus aureus infection rates in a community hospital. J Hosp Infect 75(4):269-272

101. MacDonald A, Dinah F, MacKenzie D, Wilson A (2004) Performance feedback of hand hygiene, using alcohol gel as the skin decontaminant, reduces the number of inpatients newly affected by MRSA and antibiotic costs. J Hosp Infect 56(1):56-63

102. Barnett AG, Page K, Campbell M et al (2014) Changes in healthcare-associated Staphylococcus aureus bloodstream infections after the introduction of a national hand hygiene initiative. Infect Control Hosp Epidemiol 35(8):1029-1036

103. Fung I, Cairncross S (2007) How often do you wash your hands? A review of studies of hand-washing practices in the community during and after the SARS outbreak in 2003. Int J Environ Health Res 17(3):161-183

104. Cheng V, Wu A, Cheung C et al (2007) Outbreak of human metapneumovirus infection in psychiatric inpatients: implications for directly observed use of alcohol hand rub in prevention of nosocomial outbreaks. J Hosp Infect 67(4):336-343

105. Armbrust $S$, Kramer A, Olbertz D, Zimmermann K, Fusch C (2009) Norovirus infections in preterm infants: wide variety of clinical courses. BMC Res Notes 2:96

106. De Angelis G, Cataldo MA, De Waure C et al (2014) Infection control and prevention measures to reduce the spread of vancomycin-resistant enterococci in hospitalized patients: a systematic review and meta-analysis. J Antimicrobial Chemother 69(5):1185-1192

107. Casewell MW, Dalton MT, Webster M, Phillips I (1977) Gentamicin-resistant Klebsiella aerogenes in a urological ward. Lancet 2(8035):444446

108. Webster J, Faoagali J, Cartwright D (1994) Elimination of methicillin-resistant Staphylococcus aureus from a neonatal intensive care unit after hand washing with triclosan. J Paediatr Child Health 30(1):59-64

109. Zafar A, Butler R, Reese D, Gaydos L, Mennonna $P$ (1995) Use of $0.3 \%$ triclosan (Bacti-Stat) to eradicate an outbreak of methicillin-resistant Staphylococcus aureus in a neonatal nursery. Am J Infect Control 23(3):200-208

110. Maki D (1989) The use of antiseptics for handwashing by medical personnel. J Chemother 1(Suppl):3-11
111. Assadian O, Blacky A, Hübner NO, Diab-Elschahawi M, Suchomel M, Nußbaum B, Kramer A (2012) Einfluß von Nagellack auf die Effektivität der Händedesinfektion. Hyg Med 37(Supplement DGKH Kongress):9

112. Pottinger J, Burns S, Menske C (1989) Bacterial carriage by artificial versus natural nails. Am J Infect Control 17(6):340-344

113. Hedderwick SA, McNeil SA, Lyons MJ, Kauffman CA (2000) Pathogenic organisms associated with artificial fingernails worn by healthcare workers. Infect Control Hosp Epidemiol 21(8):505-509

114. McNeil SA, Foster CL, Hedderwick SA, Kauffman CA (2001) Effect of hand cleansing with antimicrobial soap or alcohol-based gel on microbial colonization of artificial fingernails worn by health care workers. Clin Infect Dis 32(3):367-372

115. Saiman L, Lerner A, Saal L et al (2002) Banning artificial nails from health care settings. Am J Infect Control 30(4):252-254

116. Toles A (2002) Artificial nails: are they putting patients at risk? A review of the research. J Pediatr Oncol Nurs 19(5):164-171

117. Parry MF, Grant B, Yukna M et al (2001) Candida osteomyelitis and diskitis after spinal surgery: an outbreak that implicates artificial nail use. Clin Infect Dis 32(3):352-357

118. Passaro DJ, Waring L, Armstrong R et al (1997) Postoperative serratia marcescens wound infections traced to an out-of-hospital source. J Infect Dis 175(4):992-995

119. Foca M, Jakob K, Whittier S et al (2000) Endemic pseudomonas aeruginosa infection in a neonatal intensive care unit. N Engl J Med 343(10):695-700

120. Moolenaar RL, Crutcher JM, San Joaquin VH et al (2000) A prolonged outbreak of pseudomonas aeruginosa in a neonatal intensive care unit: did staff fingernails play a role in disease transmission? Infect Control Hosp Epidemiol 21(2):80-85

121. Porteous J (2002) Artificial nails... very real risks. Can Oper Room Nurs J 20(3):16-21

122. Gupta A, Della-Latta P, Todd B et al (2004) Outbreak of extended-spectrum beta-lactamase-producing Klebsiella pneumoniae in a neonatal intensive care unit linked to artificial nails. Infect Control Hosp Epidemiol 25(3):210-215

123. Gordin FM, Schultz ME, Huber R, Zubairi S, Stock F, Kariyil J (2007) A cluster of hemodialysis-related bacteremia linked to artificial fingernails. Infect Control Hosp Epidemiol 28(6):743-744

124. Trick WE, Vernon MO, Hayes RA et al (2003) Impact of ring wearing on hand contamination and comparison of hand hygiene agents in a hospital. Clin Infect Dis 36(11):1383-1390

125. Fagernes $M$, Lingaas $E, B$ Bjark $P$ (2007) Impact of a single plain finger ring on the bacterial load on the hands of healthcare workers. Infect Control Hosp Epidemiol 28(10):1191-1195

126. Fagernes $M$, Lingaas $E$ (2009) Impact of finger rings on transmission of bacteria during hand contact. Infect Control Hosp Epidemiol 30(5):427-432

127. Nicolai P, Aldam CH, Allen PW (1997) Increased awareness of glove perforation in major joint replacement. A prospective, randomised study of regent biogel reveal gloves. J Bone Jt Surg 79(3):371-373

128. Suh L, Coffin S, Leckerman KH, Gelfand JM, Honig PJ, Yan AC (2008) Methicillin-resistant staphylococcus aureus colonization in children with atopic dermatitis. Pediatr Dermatol 25(5):528-534 
129. Boguniewicz M, Leung DYM (2010) Recent insights into atopic dermatitis and implications for management of infectious complications. J Allergy Clin Immunol 125(1):4-13

130. Maury E, Alzieu M, Baudel JL et al (2000) Availability of an alcohol solution can improve hand disinfection compliance in an intensive care unit. Am J Respir Crit Care Med 162(1):324-327

131. Suresh G, Cahill J (2007) How "user friendly" is the hospital for practicing hand hygiene? An ergonomic evaluation. Jt Comm J Qual Patient Saf 33(3):171-179

132. Dubbert PM, Dolce J, Richter W, Miller M, Chapman SW (1990) Increasing ICU staff handwashing: effects of education and group feedback. Infect Control Hosp Epidemiol 11(4):191-193

133. Scheithauer S, Eitner F, Mankartz J et al (2012) Improving hand hygiene compliance rates in the haemodialysis setting: more than just more hand rubs. Nephrol Dial Transplant 27(2):766770

134. Sax H, Allegranzi B, Uckay I, Larson E, Boyce J, Pittet $D$ (2007) 'My five moments for hand hygiene': a user-centred design approach to understand, train, monitor and report hand hygiene. J Hosp Infect 67(1):9-21

135. Boyce JM, Havill NL, Otter JA, Adams NM (2007) Widespread environmental contamination associated with patients with diarrhea and methicillin-resistant staphylococcus aureus colonization of the gastrointestinal tract. Infect Control Hosp Epidemiol 28(10):1142-1147

136. Hayden MK, Blom DW, Lyle EA, Moore CG, Weinstein RA (2008) Risk of hand or glove contamination after contact with patients colonized with vancomycin-resistant enterococcus or the colonized patients' environment. Risk 29(2):149-154

137. Otter JA, Yezli S, French GL (2011) The role played by contaminated surfaces in the transmission of nosocomial pathogens. Infect Control Hosp Epidemiol 32(7):687-699

138. Donskey CJ (2004) The role of the intestinal tract as a reservoir and source for transmission of nosocomial pathogens. Clin Infect Dis 39(2):219-226

139. Weber DJ, Anderson D, Rutala WA (2013) The role of the surface environment in healthcare-associated infections. Curr Opin Infect Dis 26(4):338-344

140. Luksamijarulkul P, Pipitsangjan S (2015) Microbial air quality and bacterial surface contamination in ambulances during patient services. Oman Med J 30(2):104-110

141. Kramer A, Assadian O, Simon A, Ryll S, Wendt M, Heidecke CD (2016) Einbeziehung des Patienten und seiner Angehörigen in die Infektionsprävention. In: Kramer A, Assadian O, Exner M, Hübner NO, Simon A (Hrsg) Krankenhaus-und Praxishygiene: Hygienemanagement und Infektionsprävention in medizinischen und sozialen Einrichtungen, 3. Aufl., Urban \& Fischer in Elsevier, München, S 752-760

142. Kampf G, Ruselack S, Eggerstedt S, Nowak N, Bashir M (2013) Less and less-influence of volume on hand coverage and bactericidal efficacy in hand disinfection. BMC Infect Dis 13:472

143. Kampf G, Reichel M, Feil Y, Eggerstedt S, Kaulfers PM (2008) Influence of rub-in technique on required application time and hand coverage in hygienic hand disinfection. BMC Infect Dis 8:149

144. Widmer AF, Conzelmann M, Tomic M, Frei R, Stranden AM (2007) Introducing alcohol based hand rub for hand hygiene: the critical need for training. Infect Control Hosp Epidemiol 28(1):50-54

145. Taylor LJ (1978) An evaluation of handwashing techniques-1. Nurs Times 74(3):108-110

146. Widmer AF (2013) Surgical hand hygiene: scrub or rub? J Hosp Infect 83(Suppl 1):S35-S39

147. Bundesverband Deutscher Krankenhausapotheker (ADKA) (2013) ADKA-Leitlinie: Aseptische Herstellung und Prüfung applikationsfertiger Parenteralia. Version vom 12.12.2012. Krankenhauspharmazie 34:93-106

148. Parienti JJ, Thibon $P$, Heller R et al (2002) Hand-rubbing with an aqueous alcoholic solution vs traditional surgical hand-scrubbing and 30-day surgical site infection rates. JAMA 288(6):722-727

149. Carro C, Camilleri L, Traore O et al (2007) An inuse microbiological comparison of two surgical hand disinfection techniques in cardiothoracic surgery: hand rubbing versus hand scrubbing. J Hosp Infect 67(1):62-66

150. Hindson T (1975) Irgasan DP300 in a deodorant. Contact Derm 1(5):328

151. Roed-Petersen J, Auken G, Hjorth N (1975) Contact sensitivity to Irgasan DP 300 . Contact Derm 1(5):293-294

152. Sissoko $B$, Sütterlin $R$, Blaschke $M$, Stefaniak $S$, Daeschlein G, Kramer A (2005) Emission von Bakterien aus Geruchsverschlüssen. Hyg Med 30(4):100-104

153. Döring G, Ulrich M, Müller W et al (1991) Generation of pseudomonas aeruginosa aerosols during handwashing from contaminated sink drains, transmission to hands of hospital personnel, and its prevention by use of a new heating device. Zentralbl Hyg Umweltmed 191(494):5-6

154. Mulberrry G, Snyder AT, Heilman J, Pyrek J, Stahl $J$ (2001) Evaluation of a waterless, scrubless chlorhexidine gluconate/ethanol surgical scrub for antimicrobial efficacy. Am J Infect Control 29(6):377-382

155. Olson LK, Morse DJ, Duley C, Savell BK (2012) Prospective, randomized in vivo comparison of a dual-active waterless antiseptic versus two alcohol-only waterless antiseptics for surgical hand antisepsis. Am J Infect Control 40(2):155-159

156. Rotter ML, Kampf G, Suchomel M, Kundi M (2007) Population kinetics of the skin flora on gloved hands following surgical hand disinfection with 3 propanol-based hand rubs: a prospective, randomized, double-blind trial. Infect Control Hosp Epidemiol 28(3):346-350

157. Pham N, Weiner J, Reisner G, Baldo B (2000) Anaphylaxis to chlorhexidine. Case report. Implication of immunoglobulin $\mathrm{E}$ antibodies and identification of an allergenic determinant. Clin Exp Allergy 30(7):1001-1007

158. Nakonechna A, Dore P, Dixon T et al (2014) Immediate hypersensitivity to chlorhexidine is increasingly recognised in the United Kingdom. Allergol Immunopathol (Madr) 42(1):44-49

159. Garvey LH, Kroigaard M, Poulsen LK et al (2007) IgE-mediated allergy to chlorhexidine. J Allergy Clin Immunol 120(2):409-415

160. Stingni L, Lapomarda V, Lisi P (1995) Occupational hand dermatitis in hospital environments. Contact Derm 33(3):172-176

161. Hartmann S, Pietsch H, Sauermann G, Neubert R (1994) Untersuchungen zur Hautverträglichkeit von alkoholischen Händedesinfektionsmitteln. Dermatosen 42(6):241-245
162. Krasilnikow A, Adartschenko A (1987) Resistenzentwicklung von Staph. aureus, Pseud. aeruginosa und Enterobacteriaceae gegen Antiseptika. In: Handbuch der Antiseptik,

Bd. II/3, Antibakterielle, antifungielle und antivirale Antiseptik - ausgewählte Wirkstoffe. Fischer, Stuttgart, S 123-142

163. Thomas L, Maillard JY, Lambert RJ, Russell AD (2000) Development of resistance to chlorhexidine diacetate in Pseudomonas aeruginosa and the effect of a "residual" concentration. J Hosp Infect 46(4):297-303

164. Kamagate A, Kone D, Coulibaly NT, Brou E, Sixou $M$ (2002) In vitro study of chlorhexidine resistance in subgingival bacteria. Odontostomatol Trop 25(97):5-10

165. Klemperer $R$, Ismail $N$, Brown $M$ (1980) Effect of R-plasmid RP1 and nutrient depletion on the resistance of escherichia coli to cetrimide, chlorhexidine and phenol. J Appl Bacteriol 48(3):349-357

166. Lebek G (1981) Genetische Grundlagen der Resistenzentwicklung von Mikroorganismen gegenüber Antiseptika bzw. Desinfektionsmitteln. In: Handbuch der Antiseptik, Bd. I/2, Grundlagen der Antiseptik. Fischer, Stuttgart, S 179-182

167. Yamamoto T, Tamura Y, Yokota T (1988) Antiseptic and antibiotic resistance plasmid in staphylococcus aureus that possesses ability to confer chlorhexidine and acrinol resistance. Antimicrob Agents Chemother 32(6):932-935

168. Russell $A D$ (1997) Plasmids and bacterial resistance to biocides. J Appl Microbiol 83(2):155-165

169. Tattawasart U, Maillard JY, Furr J, Russell A (1999) Development of resistance to chlorhexidine diacetate and cetylpyridinium chloride in pseudomonas stutzeri and changes in antibiotic susceptibility. J Hosp Infect 42(3):219-229

170. Tattawasart U, Maillard JY, Furr J, Russell A (2000) Outer membrane changes in pseudomonas stutzeri resistant to chlorhexidine diacetate and cetylpyridinium chloride. Int J Antimicrob Agents 16(3):233-238

171. Stickler DJ (1974) Chlorhexidine resistance in proteus mirabilis. J Clin Pathol 27(4):284-287

172. Thomas B, Stickler DJ (1979) Chlorhexidine resistance and the lipids of Providencia stuartii. Microbios 24(97-98):141-150

173. Nakahara H, Kozukue $H$ (1981) Chlorhexidine resistance in escherichia coli isolated from clinical lesions. Zentralbl Bakteriol Mikrobiol Hyg A 251(2):177-184

174. Ismaeel N, El-Moug T, Furr JR, Russell AD (1986) Resistance of providencia stuartii to chlorhexidine: a consideration of the role of the inner membrane. J Appl Bacteriol 60(4):361-367

175. Baillie L (1987) Chlorhexidine resistance among bacteria isolated from urine of catheterized patients. J Hosp Infect 10(1):83-86

176. Dance D, Pearson A, Seal D, Lowes J (1987) A hospital outbreak caused by a chlorhexidine and antibiotic-resistant proteus mirabilis. J Hosp Infect 10(1):10-16

177. McAllister T, Lucas C, Mocan H et al (1989) Serratia marcescens outbreak in a paediatric oncology unit traced to contaminated chlorhexidine. Scott Med J 34(5):525

178. Lambert R, Joynson J, Forbes B (2001) The relationships and susceptibilities of some industrial, laboratory and clinical isolates of Pseudomonas aeruginosa to some antibiotics and biocides. J Appl Microbiol 91(6):972-984 
179. Noguchi N, Hase M, Kitta M, Sasatsu M, Deguchi K, Kono M (1999) Antiseptic susceptibility and distribution of antiseptic-resistance genes in methicillin-resistant Staphylococcus aureus. FEMS Microbiol Lett 172(2):247-253

180. Longtin J, Seah C, Siebert K et al (2011) Distribution of antiseptic resistance genes qacA, qacB, and smr in methicillin-resistant staphylococcus aureus isolated in Toronto, Canada, from 2005 to 2009. Antimicrob Agents Chemother 55(6):2999-3001

181. Veronesi S, de Padova MP, Vanni D, Melino M (1986) Contact dermatitis to triclosan. Contact Derm 15(4):257-258

182. Steinkjer B, Braathen LR (1988) Contact dermatitis from triclosan (Irgasan DP 300). Contact Derm 18(4):243-244

183. Fuchs T, Meinert A, Aberer W et al (1993) Benzalkoniumchlorid: relevantes Kontaktallergen oder Irritans? Ergebnisse einer Multicenter-Studie der Deutschen Kontaktallergiegruppe. Hautarzt 44(11):699-702

184. Schnuch A (1997) Benzalkoniumchlorid. Dermatosen 45(4):179-180

185. Wong C, Beck M (2001) Allergic contact dermatitis from triclosan in antibacterial handwashes. Contact Derm 45(5):307

186. Gloor M, Becker A, Wasik B, Kniehl E (2002) Triclosan, ein dermatologisches Lokaltherapeutikum. Hautarzt 53(11):724-729

187. Widulle $H$, Kramer $A$, Reichwagen $S$, Heldt $P$ (2008) Oberflächenaktive Verbindungen. In: Kramer A, Assadian O (Hrsg) Wallhäußers Praxis der Sterilisation, Desinfektion, Antiseptik und Konservierung. Thieme, Stuttgart, S 770-787

188. Grinbaum RS, de Mendonca JS, Cardo DM (1995) An outbreak of handscrubbing-related surgical site infections in vascular surgical procedures. Infect Control Hosp Epidemiol 16(4):198-202

189. Kikuchi-Numagami K, Saishu T, Fukaya M, Kanazawa E, Tagami H (1999) Irritancy of scrubbing up for surgery with or without a brush. Acta Derm Venereol 79(3):230-232

190. Kommission für Krankenhaushygiene und Infektionsprävention (KRINKO) (2007) Prävention postoperativer Infektionen im Operationsgebiet. Bundesgesundheitsblatt 50(3):377-393

191. de Vries JJ, Baas WH, Kees van der Ploeg M, Heesink A, Degener JE, Arends JP (2006) Outbreak of Serratia marcescens Colonization and Infection Traced to a Healthcare Worker With Long-Term Carriage on the Hands. Infect Control Hosp Epidemiol 27(11):1153-1158

192. Leitgeb J, Schuster R, Yee BN et al (2015) Antibacterial activity of a sterile antimicrobial polyisoprene surgical glove against transient flora following a 2-hours simulated use. BMC Surg 15:81

193. Kramer A, Jünger $M$, Kampf G (2005) Hygienische und dermatologische Aspekte der Händedesinfektion und der prophylaktischen Hautantiseptik. Hautarzt 56(8):743-751

194. Kramer A, Hübner NO, Below $H$, Heidecke CD, Assadian $O$ (2008) Improving adherence to surgical hand preparation. J Hosp Infect 70(Suppl 1):35-43

195. Reber H (1981) Einfluss der Seifenwaschung auf die Keimabgabe durch die Haut. In: Internationales wissenschaftliches Seminar Händedesinfektion. Selecta Symposien-Service, Gräfelfing, München

196. Rotter M (1984) Hygienic hand disinfection. Infect Control 5(1):18-22
197. Heeg P, Ulmer R, Schwenzer N (1988) Verbessern Händewaschen und Verwendung der Handbürste das Ergebnis der chirurgischen Händedesinfektion? Hyg Med 13:270-272

198. Rotter M, Koller W (1990) Effekt der sequentiellen Anwendung von Chlorhexidinseife und einer alkoholischen CHX-Präparation versus Flüssigseife und einer solchen Präparation bei der Chirurgischen Händedesinfektion. Hyg Med 15(10):437-440

199. Hübner NO, Kampf G, Kamp P, Kohlmann T, Kramer A (2006) Does a preceding hand wash and drying time after surgical hand disinfection influence the efficacy of a propanol-based hand rub? BMC Microbiol 6:57

200. Rotter M, Wewalka G, Koller W (1982) Einfluss einiger Variablen auf die Ergebnisse von Prüfungen hygienischer Händedesinfektionsverfahren. Hyg Med 7:157-166

201. Heeg P, Oswald W, Schwenzer N (1986) Wirksamkeitsvergleich von Desinfektionsverfahren zur chirurgischen Händedesinfektion unter experimentellen und klinischen Bedingungen. Hyg Med 11:107-111

202. Larson EL, Butz AM, Gullette DL, Laughon BA (1990) Alcohol for surgical scrubbing? Infect Control Hosp Epidemiol 11(3):139-143

203. Kampf G, Ostermeyer C, Heeg P (2005) Surgical hand disinfection with a propanol-based hand rub: equivalence of shorter application times. J Hosp Infect 59(4):304-310

204. Hübner NO, Kellner NB, Partecke LI et al (2011) Determination of antiseptic efficacy of rubs on the forearm and consequences for surgical hand disinfection. J Hosp Infect 78(1):11-15

205. Kampf G, Ostermeyer C (2004) Efficacy of alcohol-based gels compared with simple hand wash and hygienic hand disinfection. J Hosp Infect 56(Suppl 2):13-15

206. Pitten FA, Herdemann G, Kramer A (2000) The integrity of latex gloves in clinical dental practice. Infection 28(6):388-392

207. Hübner NO (2004) Experimentelle Untersuchungen zur Verbesserung der chirurgischen Händedesinfektion. Dissertation. Universitätsmedizin Greifswald

208. Hübner NO, Kampf G, Löffler H, Kramer A (2006) Effect of a $1 \mathrm{~min}$ hand wash on the bactericidal efficacy of consecutive surgical hand disinfection with standard alcohols and on skin hydration. Int J Hyg Environ Health 209(3):285-291

209. Li X, Xu CJ, Zhao SJ (2014) Experimental study on disinfection effect of different dose of rapid hand disinfectant. Int J Nurs Sci 1(2):212-214

210. Engelhart S, Saborowski F, Krakau M, Scherholz-Schlösser G, Heyer I, Exner M (2003) Severe serratia liquefaciens sepsis following vitamin $C$ infusion treatment by a naturopathic practitioner. J Clin Microbiol 41(8):3986-3988

211. Kommission für Krankenhaushygiene und Infektionsprävention (KRINKO) (2011) Anforderungen an die Hygiene bei Punktionen und Injektionen Bundesgesundheitsblatt 54(9-10):1135-1144

212. Hota B (2004) Contamination, disinfection, and cross-colonization: are hospital surfaces reservoirs for nosocomial infection? Clin Infect Dis 39(8):1182-1189

213. Hota S, Hirji Z, Stockton K et al (2009) Outbreak of multidrug-resistant pseudomonas aeruginosa colonization and infection secondary to imperfect intensive care unit room design. Infect Control Hosp Epidemiol 30(1):25-33
214. Halabi M, Wiesholzer-Pittl M, Schöberl J, Mittermayer $\mathrm{H}$ (2001) Non-touch fittings in hospitals: a possible source of pseudomonas aeruginosa and legionella spp. J Hosp Infect 49(2):117-121

215. Assadian O, El-Madani N, Seper E et al (2002) Sensor-operated faucets: A possible source of nosocomial infection? Infect Control 23(1):44-46

216. van der Mee-Marquet N, Bloc D, Briand $L$, Besnier JM, Quentin R (2005) Non-touch fittings in hospitals: a procedure to eradicate pseudomonas aeruginosa contamination. J Hosp Infect 60(3):235-239

217. Yapicioglu H, Gokmen TG, Yildizdas D et al (2012) Pseudomonas aeruginosa infections due to electronic faucets in a neonatal intensive care unit. J Paediatr Child Health 48(5):430-434

218. Chaberny IF, Gastmeier P (2004) Should electronic faucets be recommended in hospitals? Infect Control 25(11):997-1000

219. Hargreaves J, Shireley L, Hansen S et al (2001) Bacterial contamination associated with electronic faucets: a new risk for healthcare facilities. Infect Control 22(4):202-205

220. Merrer J, Girou E, Ducellier D et al (2005) Should electronic faucets be used in intensive care and hematology units? Intensive Care Med 31(12):1715-1718

221. Patrick D, Findon G, Miller T (1997) Residual moisture determines the level of touch-contact-associated bacterial transfer following hand washing. Epidemiol Infect 119(3):319-325

222. Redway K, Knights B (1998) Hand drying: studies of the hygiene and efficiency of different hand drying methods. WOMEN 93(94):68

223. Yamamoto Y, Ugai K, Takahashi Y (2005) Efficiency of hand drying for removing bacteria from washed hands: comparison of paper towel drying with warm air drying. Infect Control Hosp Epidemiol 26(3):316-320

224. Redway K, Fawdar S (2008) A comparative study of three different hand drying methods: paper towel, warm air dryer, jet air dryer. http://www. europeantissue.com/pdfs/090402-2008\%20 WUS\%20Westminster\%20University\%20hygiene\%20study,\%20nov2008.pdf. Zugegriffen: 1. Juni 2016

225. Merry A, Miller T, Findon G, Webster C, Neff S (2001) Touch contamination levels during anaesthetic procedures and their relationship to hand hygiene procedures: a clinical audit. Br J Anaesth 87(2):291-294

226. Huang C, Ma W, Stack S (2012) The hygienic efficacy of different hand-drying methods: a review of the evidence. Mayo Clin Proc 87(8):791-798

227. Ngeow YF, Ong HW, Tan P (1989) Dispersal of bacteria by an electric air hand dryer. Malays J Pathol 11:53-56

228. Matthews J, Newsom S (1987) Hot air electric hand driers compared with paper towels for potential spread of airborne bacteria. J Hosp Infect 9(1):85-88

229. Meers P, Leong K (1989) Hot-air hand driers. J Hosp Infect 14(2):169-171

230. Blackmore M (1989) A comparison of hand drying methods. Cater Health 13(1):189-198

231. Hanna PJ, Richardson BJ, Marshall M (1996) A comparison of the cleaning efficiency of three common hand drying methods. Appl Occup Environ Hyg 11(1):37-43

232. Snelling AM, Saville T, Stevens D, Beggs CB (2011) Comparative evaluation of the hygienic efficacy of an ultra-rapid hand dryer vs conven- 
tional warm air hand dryers. J Appl Microbiol 110(1):19-26

233. Margas E, Maguire E, Berland C, Welander F, Holah J (2013) Assessment of the environmental microbiological cross contamination following hand drying with paper hand towels or an air blade dryer. J Appl Microbiol 115(2):572-582

234. Best E, Parnell P, Wilcox M (2014) Microbiological comparison of hand-drying methods: the potential for contamination of the environment, user, and bystander. J Hosp Infect 88(4):199-206

235. Van Saene HK, Van Putte JC, Van Saene JJ, Van De Gronde TW, Van Warmerdam EG (1989) Sink flora in a long-stay hospital is determined by the patients' oral and rectal flora. Epidemiol Infect 102(2):231-238

236. Brown DG, Baublis J (1977) Reservoirs of pseudomonas in an intensive care unit for newborn infants: mechanisms of control. J Pediatr 90(3):453-457

237. Berthelot P, Grattard F, Mahul P et al (2001) Prospective study of nosocomial colonization and infection due to pseudomonas aeruginosa in mechanically ventilated patients. Intensive Care Med 27(3):503-512

238. Leclerc H, Schwartzbrod L, Dei-Cas E (2002) Microbial agents associated with waterborne diseases. Crit Rev Microbiol 28(4):371-409

239. Exner M, Kramer A, Lajoie L, Gebel J, Engelhart S, Hartemann P (2005) Prevention and control of health care-associated waterborne infections in health care facilities. Am J Infect Control 33(5 Suppl 1):S26-S40

240. Hota S, Hirji Z, Stockton K et al (2009) Outbreak of multidrug-resistant pseudomonas aeruginosa colonization and infection secondary to imperfect intensive care unit room design. Infect Control 30(01):25-33

241. Lowe C, Willey B, O'Shaughnessy A et al (2012) Outbreak of extended-spectrum $\beta$-lactamase-producing Klebsiella oxytoca infections associated with contaminated handwashing sinks. Emerg Infect Dis 18(8):1242-1247

242. Gudowius $P$, Boßhammer J, Römling U, Tümmler $B$, von der Hardt H (1995) Erprobung eines chemischen Waschbeckendesinfektionssystems an der Medizinischen Hochschule Hannover. Hyg Med 20(10):482-491

243. Scientific Comittee on Consumer Safety (SCCS) (Hrsg) (2012) The SCCS's notes of guidance for the testing of cosmetic substances and their safety evaluation. 8th Revision. SCCS/1051/12. http://ec.europa.eu/health/scientific_committees/consumer_safety/docs/sccs_s_006.pdf. Zugegriffen: 1. Juni 2016.

244. Rotter M (2008) Desinfektion der Hände. In: Kramer A, Assadian O (Hrsg) Wallhäußers Praxis der Sterilisation, Desinfektion, Antiseptik und Konservierung. Thieme, Stuttgart, S 146-160

245. Larson E, Leyden JJ, McGinley KJ, Grove GL, Talbot GH (1986) Physiologic and microbiologic changes in skin related to frequent handwashing. Infect Control 7(2):59-63

246. Ojajarvi J (1980) Effectiveness of hand washing and disinfection methods in removing transient bacteria after patient nursing. J Hyg (Lond.) 85(2):193-203

247. Isaacs D, Dickson $H, O^{\prime}$ Callaghan C, Sheaves $R$, Winter A, Moxon ER (1991) Handwashing and cohorting in prevention of hospital acquired infections with respiratory syncytial virus. Arch Dis Child 66(2):227-231
248. Shahid NS, Greenough W, Samadi AR, Huq MI, Rahman N (1996) Hand washing with soap reduces diarrhoea and spread of bacterial pathogens in a Bangladesh village. J Diarrhoeal Dis Res 14(2):85-89

249. Friedman CR, Torigian C, Shillam PJ et al (1998) An outbreak of salmonellosis among children attending a reptile exhibit at a zoo. J Pediatr 132(5):802-807

250. Malik RK, Montecalvo MA, Reale MR et al (1999) Epidemiology and control of vancomycin-resistant enterococci in a regional neonatal intensive care unit. Pediatr Infect Dis J 18(4):352-356

251. Löffler H, Kampf G, Schmermund D, Maibach $\mathrm{H}$ (2007) How irritant is alcohol? Br J Dermatol 157(1):74-81

252. Mäkelä P (1993) Gesunde Haut als Voraussetzung für eine effektive Händedesinfektion. In: Klinische Antiseptik. Springer, Berlin, S 97-103

253. Kramer A, Weuffen W, Schwenke W (1973) Mikrobiologische und dermatologische Anforderungen an antiseptische Seifen. Dermatol Monatsschr 159(5):526-539

254. Kabara JJ, Brady MB (1984) Contamination of bar soaps under "in-use" conditions. J Environ Pathol Toxicol Oncol 5(4-5):1-14

255. Hegde P, Andrade A, Bhat K (2006) Microbial contamination of "In use" bar soap in dental clinics. Ind J Dent Res 17(2):70-73

256. Zeiny $S$ (2009) Isolation of some microorganisms from bar soaps and liquid soaps in hospital environments. Iraqi J Pharm Sci 18(1):28-32

257. McBride ME (1984) Microbial flora of in-use soap products. Appl Environ Microbiol 48(2):338-341

258. Senol G, Cakan A, Özacar R (2011) Bacterial colonization of bar soaps and liquid soaps in hospital environments. Near East Med J 1(2):53-59

259. Heinze JE, Yackovich F (1988) Washing with contaminated bar soap is unlikely to transfer bacteria. Epidemiol Infect 101(1):135-142

260. Buffet-Bataillon $S$, Rabier $V$, Bétrémieux $P$ et al (2009) Outbreak of serratia marcescens in a neonatal intensive care unit: contaminated unmedicated liquid soap and risk factors. J Hosp Infect 72(1):17-22

261. Chattman M, Gerba CP, Maxwell SL (2011) Occurrence of heterotrophic and coliform bacteria in liquid hand soaps from bulk refillable dispensers in public facilities. J Environ Health 73(7):26-29

262. Lorenz LA, Ramsay BD, Goeres DM, Fields MW Zapka CA, Macinga DR (2012) Evaluation and remediation of bulk soap dispensers for biofilm. Biofouling 28(1):99-109

263. Zapka CA, Campbell EJ, Maxwell SL et al (2011) Bacterial hand contamination and transfer after use of contaminated bulk-soap-refillable dispensers. Appl Environ Microbiol 77(9):28982904

264. Weber DJ, Rutala WA, Sickbert-Bennett EE (2007) Outbreaks associated with contaminated antiseptics and disinfectants. Antimicrob Agents Chemother 51(12):4217-4224

265. Barry MA, Craven DE, Goularte TA, Lichtenberg DA (1984) Serratia marcescens contamination of antiseptic soap containing triclosan: implications for nosocomial infection. Infect Control 5(9):427-430

266. Spainhour S (1998) Serratia marcescens outbreak associated with extrinsic contamination of $1 \%$ chloroxylenol soap. Infect Control Hosp Epidemiol 19(7):476

267. Archibald LK, Corl A, Shah B et al (1997) Serratia marcescens outbreak associated with extrinsic contamination of $1 \%$ chlorxylenol soap. Infect Control Hosp Epidemiol 18(10):704-709

268. Gräf W, Kersch D, Scherzer G (1988) Mikrobielle Kontamination von Flüssigseifen-Wandspendern mit Einwegflaschensystem. Zentralbl Bakteriol Mikrobiol Hyg B 186(2):166-179

269. Trautmann M, Notburga P, Bobic R et al (2013) Reinigungs- und Desinfektionsleistung eines Aufbereitungsprogramms für die routinemäßige Reinigung von Dosierspendern im Krankenhaus. Hyg Med 38(11):468-472

270. Kampf G, Ennen J (2006) Regular use of a hand cream can attenuate skin dryness and roughness caused by frequent hand washing. BMC Dermatol 6:1

271. McGinley KJ, Larson EL, Leyden JJ (1988) Composition and density of microflora in the subungual space of the hand. J Clin Microbiol 26(5):950-953

272. Larson E (1993) Skin cleansing. In: Prevention and control of Nosocomial infections, 2. Aufl. Lippincott Williams \& Wilkins, Philadelphia, $S$ 450-459

273. DIN EN 420:2010-03 Schutzhandschuhe - Allgemeine Anforderungen und Prüfverfahren. Beuth Verlag: Berlin

274. ISO 11193-1:2008-09 Single-use medical examination gloves - Part 1: Specification for gloves made from rubber latex or rubber solution. Beuth Verlag: Berlin

275. ISO 11193-2:2006 Single-use medical examination gloves - Part 2: Specification for gloves made from poly(vinyl chloride). Beuth Verlag, Berlin

276. DIN EN 455-1:2001-01 Medizinische Handschuhe zum einmaligen Gebrauch - Teil 1: Anforderungen und Prüfung auf Dichtheit. Beuth Verlag: Berlin

277. DIN EN 455-2:2015-07 Medizinische Handschuhe zum einmaligen Gebrauch - Teil 2: Anforderungen und Prüfung der physikalischen Eigenschaften. Beuth Verlag: Berlin

278. DIN EN 455-3:2015-07 Medizinische Handschuhe zum einmaligen Gebrauch - Teil 3: Anforderungen und Prüfung für die biologische Bewertung. Beuth Verlag: Berlin

279. DIN EN 455-4:2009-10 Medizinische Handschuhe zum einmaligen Gebrauch - Teil 4: Anforderungen und Prüfung zur Bestimmung der Mindesthaltbarkeit. Beuth Verlag: Berlin

280. Hughes KA, Cornwall J, Theis JC, Brooks HJ (2013) Bacterial contamination of unused disposable non-sterile gloves on a hospital orthopaedic ward. Australas Med J 6(6):331-338

281. Kramer A, Assadian O (2016) Indications and the requirements for single use medical gloves. GMS Hyg Infect Control 11:Doc01

282. Europäisches Arzneibuch 8.0 - 8.4. Amtliche Deutsche Ausgabe (2015) Deutscher Apotheker Verlag: Stuttgart

283. Empfehlung des Umweltbundesamtes nach Anhörung der Trinkwasserkommission des Bundesministeriums für Gesundheit. Hygienisch-mikrobiologische Untersuchung im Kaltwasser von Wasserversorgungsanlagen nach $\S 3 \mathrm{Nr}$. 2 Buchstabe c TrinkwV 2001, aus denen Wasser für die Öffentlichkeit im Sinne des § 18 Abs. 1 TrinkwV 2001 bereit gestellt wird. Bundesgesundheitsbl 2005; 49: 693-6.

284. Doebbeling BN, Pfaller MA, Houston AK, Wenzel RP (1988) Removal of nosocomial pathogens from the contaminated glove. Implications for glove reuse and handwashing. Ann Intern Med 109(5):394-398 
285. Johnson S, Gerding DN, Olson MM et al (1990) Prospective, controlled study of vinyl glove use to interrupt clostridium difficile nosocomial transmission. Am J Med 88(2):137-140

286. Tenorio AR, Badri SM, Sahgal NB et al (2001) Effectiveness of gloves in the prevention of hand carriage of vancomycin-resistant enterococcus species by health care workers after patient care. Clin Infect Dis 32(5):826-829

287. Kampf G, Ostermeyer C (2002) Intra-laboratory reproducibility of the hand hygiene reference procedures of EN 1499 (hygienic handwash) and EN 1500 (hygienic hand disinfection). J Hosp Infect 52(3):219-224

288. Guilhermetti $M$, Hernandes SE, Fukushigue $Y$, Garcia LB, Cardoso CL (2001) Effectiveness of hand-cleansing agents for removing methicillin-resistant staphylococcus aureus from contaminated hands. Infect Control Hosp Epidemiol 22(2):105-108

289. Olsen RJ, Lynch P, Coyle MB, Cummings J, Bokete T, Stamm WE (1993) Examination gloves as barriers to hand contamination in clinical practice. JAMA 270(3):350-353

290. Korniewicz DM, Laughon BE, Butz A, Larson E (1989) Integrity of vinyl and latex procedure gloves. Nurs Res 38(3):144-146

291. TRGS 401: Gefährdung durch Hautkontakt, Ermittlung - Beurteilung -Maßnahmen. Ausgabe: Juni 2008(GMBI Nr. 40/41vom 19.August 2008, S. 818, Letzte Änderung vom: 30. März 2011

292. Richtlinie 89/686/EWG des Rates vom 21.12. 1989 zur Angleichung der Rechtsvorschriften der Mitgliedstaaten für persönliche Schutzausrüstungen

293. Pitten FA, Müller P, Heeg P, Kramer A (1998) Untersuchungen zur wiederholten Desinfizierbarkeit von Einweghandschuhen während des Tragens. Zentralbl Hyg Umweltmed 201(6):555562

294. DIN EN 374-4:2014-03 Schutzhandschuhe gegen Chemikalien und Mikroorganismen - Teil 4: Bestimmung des Widerstandes gegen Degradation durch Chemikalien. Beuth Verlag: Berlin

295. Hübner NO, Goerdt AM, Mannerow A et al (2013) The durability of examination gloves used on intensive care units. BMC Infect Dis 13:226

296. DIN EN 374-1:2003-12 Schutzhandschuhe gegen Chemikalien und Mikroorganismen-Teil 1:Terminologie und Leistungsanforderungen. Beuth Verlag: Berlin

297. DIN EN 374-2:2015-03 Schutzhandschuhe gegen gefährliche Chemikalien und Mikroorganismen - Teil 2: Bestimmung des Widerstandes gegen Penetration. Beuth Verlag: Berlin

298. DIN EN ISO 374-5:2015-05 Schutzhandschuhe gegen Chemikalien und Mikroorganismen - Teil 5: Terminologie und Leistungsanforderungen für Risiken durch Mikroorganismen (ISO/DIS 374-5:2015); Deutsche und Englische Fassung prEN ISO 374-5:2015. Beuth Verlag: Berlin

299. ASTM F1671/F 1671 M:2013 Standard Test Method for Resistance of Materials Used in Protective Clothing to Penetration by Blood-Borne Pathogens Using Phi-X174 Bacteriophage Penetration as a Test System. ASTM International: West Conshohocken, PA

300. ASTM D6978:2013 - 05 Standard Practice for Assessment of Resistance of Medical Gloves to Permeation by Chemotherapy Drugs. ASTM International: West Conshohocken, PA

301. Hübner NO, Rubbert $K$, Pohrt U, Heidecke CD, Partecke LI, Kramer A (2016) Einsatz wiederauf- bereitbarer textiler Unterziehhandschuhe für medizinische Tätigkeiten: eine Machbarkeitsstudie. Zentralbl Chir 141(1):62-67

302. DIN EN 388:2014 Schutzhandschuhe gegen mechanische Risiken. Beuth Verlag: Berlin

303. Ruëff F, Przybilla B (1999) Gemeinsame Leitlinie von DGAI und ÄDA. Soforttyp-Allergie gegen Naturlatex. Allergo J 8(5):181-182

304. Hochleitner BW, Menardi G, Häussler B, Ulmer $\mathrm{H}$, Kofler H, Reider N (2001) Spina bifida as an independent risk factor for sensitization to latex. J Urol 166(6):2370-2373

305. Cremer R, Lorbacher M, Hering F, Engelskirchen $R$ (2007) Natural rubber latex sensitisation and allergy in patients with spina bifida, urogenital disorders and oesophageal atresia compared with a normal paediatric population. Eur J Pediatr Surg 17(3):194-198

306. Ausili E, Tabacco F, Focarelli B, Nucera E, Patriarca $G$, Rendeli C (2007) Prevalence of latex allergy in spina bifida: genetic and environmental risk fac tors. Eur Rev Med Pharmacol Sci 11(3):149-153

307. Rueff F, Schöpf $P$, Huber R, Lang S, Kapfhammer W, Przybilla B (1996) Naturlatexallergie. Die verdrängte Berufskrankheit. Dtsch Ärztebl 96(A):1204-1207

308. Bauer $\mathrm{X}$, Allmers $\mathrm{H}$, Raulf-Heimsoth $\mathrm{M}$ et al (1996) Empfehlungen der interdisziplinären Arbeitsgruppe "Naturlatex - Allergie". Ergebnisse eines Treffens am 18. Dezember 1995 im Berufsgenossenschaftlichen Forschungsinstitut für Arbeitsmedizin in Bochum. Dermatosen 44(6):270-272

309. Niggemann B, Buck D, Michael T, Haberl H, Wahn U (2000) Latex allergy in spina bifida: at the turning point? J Allergy Clin Immunol 106(6):1201

310. Cremer R, Kleine-Diepenbruck U, Hering $F$, Holschneider AM (2002) Reduction of latex sensitisation in spina bifida patients by a primary prophylaxis programme (five years experience). Eur J Pediatr Surg 12(Suppl 1):19-21

311. Blumchen K, Bayer P, Buck D et al (2010) Effects of latex avoidance on latex sensitization, atopy and allergic diseases in patients with spina bifida. Allergy 65(12):1585-1593

312. Osman MO, Jensen SL (1999) Surgical gloves: current problems. World J Surg 23(7):630-637

313. Sjösten A, Ellis H, Edelstam G (2004) Retrograde migration of glove powder in the human female genital tract. Hum Reprod 19(4):991-995

314. Ellis $\mathrm{H}$ (2008) Evolution of the surgical glove. J Am Coll Surg 207(6):948-950

315. Juaneda I, Moser F, Eynard H, Diller A, Caeiro E (2008) Peritonitis granulomatosa por el almidón en guantes quirúrgicos; granulomatous peritonitis due to the starch used in surgical gloves. Medicina (B Aires) 68(3):222-224

316. Edlich RF, Long IIIWB, Gubler DK et al (2009) Dangers of cornstarch powder on medical gloves: seeking a solution. Ann Plast Surg 63(1):111-115

317. Scholz S (2013) Einfluss von Biosorb auf die Langzeitwirkung der chirurgischen Händedesinfektion und die Schweißproduktion der Hand. Dissertation. Universitätsmedizin Greifswald

318. Thomas S, Agarwal M, Mehta G (2001) Intraoperative glove perforation-single versus double gloving in protection against skin contamination. Postgrad Med J 77(909):458-460

319. Harnoss J, Kramer A, Heidecke CD, Assadian $O$ (2010) Wann sollte in Operationsräumen ein Wechsel chirurgischer Handschuhe erfolgen? Zentralbl Chir 135(01):25-27
320. Beldame J, Lagrave B, Lievain L, Lefebvre B, Frebourg N, Dujardin F (2012) Surgical glove bacterial contamination and perforation during total hip arthroplasty implantation: when gloves should be changed. Orthop Traumatol Surg Res 98(4):432-440

321. Partecke LI, Goerdt AM, Langner I et al (2009) Incidence of microperforation for surgical gloves depends on duration of wear. Infect Control Hosp Epidemiol 30(5):409-414

322. Ward WG, Cooper JM, Lippert D, Kablawi RO, Neiberg RH, Sherertz RJ (2014) Glove and gown effects on intraoperative bacterial contamination. Ann Surg 259(3):591-597

323. Kampf G, Ostermeyer C, Kohlmann T (2008) Bacterial population kinetics on hands during 2 consecutive surgical hand disinfection procedures. Am J Infect Control 36(5):369-374

324. Kampf G, Ostermeyer C (2009) A 1-minute hand wash does not impair the efficacy of a propanol-based hand rub in two consecutive surgical hand disinfection procedures. Eur J Clin Microbiol Infect Dis 28(11):1357-1362

325. Daeschlein G, Kramer A, Arnold A, Ladwig A, Seabrook GR, Edmiston CE Jr. (2011) Evaluation of an innovative antimicrobial surgical glove technology to reduce the risk of microbial passage following intraoperative perforation. Am J Infect Control 39(2):98-103

326. Assadian O, Kramer A, Ouriel K et al (2014) Suppression of surgeons' bacterial hand flora during surgical procedures with a new antimicrobial surgical glove. Surg Infect (Larchmt) 15(1):43-49

327. Heeg P (2015) Ausstattung des Handwaschplatzes in Arztpraxen. Hyg Med 40(3):121-122

328. Larson EL, Albrecht S, O'Keefe M (2005) Hand hygiene behavior in a pediatric emergency department and a pediatric intensive care unit: comparison of use of 2 dispenser systems. Am J Crit Care 14(4):304-311

329. Assadian O, Kramer A, Christiansen B et al (2012) Recommendations and requirements for soap and hand rub dispensers in healthcare facilities. [Empfehlung zu Anforderungen an Seifen- und Desinfektionsmittelspender in Einrichtungen des Gesundheitswesens.] GMS Krankenhhyg Interdiszip 7(1):Doc03, doi:10.3205/dgkh000187

330. Gleich S, Vieweg C, von Baum H (2015) Untersuchung der mikrobiellen Kontamination von Waschlotionsspendern aus unterschiedlichen Risikobereichen. Hyg Med 40(6):236-241

331. Spainhour S (1998) Serratia marcescens outbreak associated with extrinsic contamination of 1\% chloroxylenol soap. Infect Control Hosp Epidemiol 19(7):476

332. Lanini S, D'Arezzo S, Puro V et al (2011) Molecular epidemiology of a pseudomonas aeruginosa hospital outbreak driven by a contaminated disinfectant-soap dispenser. PLoS ONE 6(2):e17064

333. Takahashi H, Kramer MH, Yasui Y et al (2004) Nosocomial serratia marcescens outbreak in Osaka, Japan, from 1999 to 2000. Infect Control Hosp Epidemiol 25(2):156-161

334. Wetzker W, Bunte-Schönberger K, Walter J, Pilarski G, Gastmeier P, Reichardt C (2016) Compliance with hand hygiene: reference data from the national hand hygiene campaign in Germany. J Hosp Infect 92:328-331

335. Srigley JA, Furness CD, Baker GR, Gardam M (2014) Quantification of the Hawthorne effect in hand hygiene compliance monitoring using 
an electronic monitoring system: a retrospective cohort study. BMJ Qual Saf 23(12):974-980

336. Hagel S, Reischke J, Kesselmeier M et al (2015) Quantifying the Hawthorne effect in hand hygiene compliance through comparing direct observation with automated hand hygiene monitoring. Infect Control Hosp Epidemiol 36(8):957-962

337. Pittet D, Simon A, Hugonnet S, Pessoa-Silva CL, Sauvan V, Perneger TV (2004) Hand hygiene among physicians: performance, beliefs, and perceptions. Ann Intern Med 141(1):1-8

338. Kirkland KB, Homa KA, Lasky RA, Ptak JA, Taylor EA, Splaine ME (2012) Impact of a hospital-wide hand hygiene initiative on healthcare-associated infections: results of an interrupted time series. BMJ Qual Saf 21(12):1019-1026

339. Marra AR, Noritomi DT, Westheimer Cavalcante AJ et al (2013) A multicenter study using positive deviance for improving hand hygiene compliance. Am J Infect Control 41(11):984-988

340. Chakravarthy M, Myatra SN, Rosenthal VD et al (2015) The impact of the International Nosocomial Infection Control Consortium (INICC) multicenter, multidimensional hand hygiene approach in two cities of India. J Infect Public Health 8(2):177-186

341. Karaaslan A, Kepenekli Kadayifci E, Atıcı S et al (2014) Compliance of healthcare workers with hand hygiene practices in neonatal and pediatric intensive care units: overt observation. Interdiscip Perspect Infect Dis, Article ID 306478

342. Scheithauer S, Lemmen S (2013) How can compliance with hand hygiene be improved in specialized areas of a university hospital? J Hosp Infect 83(S1):S17-S22

343. Eckmanns T, Rath $A$, Brauer $H$, Daschner F, Rüden $\mathrm{H}$, Gastmeier P (2001) Compliance der Händedesinfektion auf Intensivstationen. Dtsch Med Wochenschr 126(25-26):745-749

344. Eckmanns T, Bessert J, Behnke M, Gastmeier $P$, Rüden H (2006) Compliance with antiseptic hand rub use in intensive care units: the Hawthorne effect. Infect Control Hosp Epidemiol 27(9):931-934

345. Wendt C, Knautz D, von Baum H (2004) Differences in hand hygiene behavior related to the contamination risk of healthcare activities in different groups of healthcare workers. Infect Control Hosp Epidemiol 25(3):203-206

346. Boyce JM, Pittet D (2002) Guideline for hand hygiene in health-care settings: recommendations of the Healthcare Infection Control Practices Advisory Committee and the HICPAC/SHEA/ APIC/IDSA Hand Hygiene Task Force. Infect Control Hosp Epidemiol 23(Suppl 12):S3-S40

347. Scheithauer S, Haefner H, Schwanz T et al (2009) Compliance with hand hygiene on surgical, medical, and neurologic intensive care units: direct observation versus calculated disinfectant usage. Am J Infect Control 37(10):835-841

348. FitzGerald G, Moore G, Wilson A (2013) Hand hygiene after touching a patient's surroundings: the opportunities most commonly missed. J Hosp Infect 84(1):27-31

349. Reichardt C, Königer D, Bunte-Schönberger $\mathrm{K}$ et al (2013) Three years of national hand hygiene campaign in Germany: what are the key conclusions for clinical practice? J Hosp Infect 83(S1):S11-S16

350. Schwadtke L, Graf K, Lutze B, von Lengerke T, Chaberny I (2014) Hygienische Händedesinfektion-Leitlinien-Compliance auf Intensivstationen eines Universitätsklinikums mit chirurgischem Schwerpunkt. Dtsch Med Wochenschr 139(25/26):1341-1345

351. Linam WM, Margolis PA, Atherton $\mathrm{H}$, Connelly BL (2011) Quality-improvement initiative sustains improvement in pediatric health care worker hand hygiene. Pediatrics 128(3):e689-e698

352. White CM, Statile AM, Conway PH et al (2012) Utilizing improvement science methods to improve physician compliance with proper hand hygiene. Pediatrics 129(4):e1042-e1050

353. Pessoa-Silva $\mathrm{CL}$, Hugonnet $\mathrm{S}$, Pfister $\mathrm{R}$ et al (2007) Reduction of health care associated infection risk in neonates by successful hand hygiene promotion. Pediatrics 120(2):e382-e390

354. Pessoa-Silva CL, Posfay-Barbe K, Pfister R, Touveneau S, Perneger TV, Pittet D (2005) Attitudes and perceptions toward hand hygiene among healthcare workers caring for critically ill neonates. Infect Control Hosp Epidemiol 26(3):305-311

355. Lutze B, Chaberny IF, Graf K et al (2015) Intensive care physicians' and nurses' perception that hand hygiene prevents pathogen transmission: Belief strength and associations with other cognitive factors. J Health Psychol (Avialable online 11 April 2016) doi:10.1177/1359105315595123

356. von Lengerke T, Lutze B, Graf K et al (2015) Psychosocial determinants of self-reported hand hygiene behaviour: a survey comparing physicians and nurses in intensive care units. $J$ Hosp Infect 91(1):59-67

357. Harbarth S, Sudre P, Dharan S, Cadenas M, Pittet D (1999) Outbreak of Enterobacter cloacae related to understaffing, overcrowding, and poor hygiene practices. Infect Control Hosp Epidemiol 20(9):598-603

358. Voss A, Widmer AF (1997) No time for handwashing!? Handwashing versus alcoholic rub: can we afford $100 \%$ compliance? Infect Control Hosp Epidemiol 18(3):205-208

359. Larson E (1985) Handwashing and skin. Physiologic and bacteriologic aspects. Infect Control 6(1):14-23

360. Benzer H, Brühl P, Dietzel W et al (1996) Meine Hände sind sauber. mhp-Verlag, Wiesbaden

361. Pittet D, Boyce JM (2001) Hand hygiene and patient care: pursuing the Semmelweis legacy. Lancet Infect Dis 1(S1):S19-S20

362. De Bono S, Heling G, Borg MA (2014) Organizational culture and its implications for infection prevention and control in healthcare institutions. J Hosp Infect 86(1):1-6

363. Whitby M, Pessoa-Silva C, McLaws ML et al (2007) Behavioural considerations for hand hygiene practices: the basic building blocks. J Hosp Infect 65(1):1-8

364. Diefenbacher S, Sassenrath C, Siegel A, Grünewald M, Keller J (2012) Implizite Einstellung zur Händehygiene als relevanter Prädiktor von Händehygieneverhalten. Hyg Med 37(11):448-455

365. Deutsche Gesellschaft für Krankenhaushygiene e.V. (2016) DGKH Test- und Lernprogramm "Klinische Händehygiene". http://www.klinischehaendehygiene.de/loader.html. Zugegriffen: 5. Jan. 2016

366. Pittet D, Perneger T (1999) Compliance with handwashing. Ann Intern Med 131(4):310

367. Arenas MD, Sánchez-Payá J, Barril G et al (2005) A multicentric survey of the practice of hand hygiene in haemodialysis units: factors affecting compliance. Nephrol Dial Transplant 20(6):1164-1171
368. Allegranzi B, Gayet-Ageron A, Damani N et al (2013) Global implementation of WHO's multimodal strategy for improvement of hand hygiene: a quasi-experimental study. Lancet Infect Dis 13(10):843-851

369. Derde LP, Cooper BS, Goossens H et al (2014) Interventions to reduce colonisation and transmission of antimicrobial-resistant bacteria in intensive care units: an interrupted time series study and cluster randomised trial. Lancet Infect Dis 14(1):31-39

370. Raskind CH, Worley S, Vinski J, Goldfarb J (2007) Hand hygiene compliance rates after an educational intervention in a neonatal intensive care unit. Infect Control Hosp Epidemiol 28(9):10961098

371. Behnke M, Gastmeier P, Geffers C, Mönch N, Reichardt C (2012) Establishment of a national surveillance system for alcohol-based hand rub consumption and change in consumption over 4 years. Infect Control Hosp Epidemiol 33(6):618-620

372. Luangasanatip N, Hongsuwan M, Limmathurotsakul D et al (2015) Comparative efficacy of interventions to promote hand hygiene in hospital: systematic review and network meta-analysis. BMJ 351. doi:10.1136/bmj.h3728

373. Zhang R (2015) Investigating the prevention of hospital-acquired infection through standardized teaching ward rounds in clinical nursing. Genet Mol Res 14(2):3753-3759

374. Di Muzio M, Cammilletti V, Petrelli E, Di Simone E (2014) Hand hygiene in preventing nosocomial infections: a nursing research. Ann lg 27(2):485-491

375. Gould DJ, Moralejo D, Drey N, Chudleigh JH (2010) Interventions to improve hand hygiene compliance in patient care. Cochrane Database Syst Rev 9:CD005186

376. McGuckin M, Govednik J (2013) Patient empowerment and hand hygiene, 1997-2012. J Hosp Infect 84(3):191-199

377. Davis R, Parand A, Pinto A, Buetow S (2015) Systematic review of the effectiveness of strategies to encourage patients to remind healthcare professionals about their hand hygiene. J Hosp Infect 89(3):141-162

378. Scheithauer S, Eitner F, Häfner H, Floege J, Lemmen SW (2013) Long-term sustainability of hand hygiene improvements in the hemodialysis setting. Infection 41(3):675-680

379. Scheithauer S, Rosarius A, Rex S et al (2013) Improving hand hygiene compliance in the anesthesia working room work area: More than just more hand rubs. Am J Infect Control 41(11):1001-1006

380. Thomas BW, Berg-Copas GM, Vasquez DG, Jackson BL, Wetta-Hall R (2009) Conspicuous vs customary location of hand hygiene agent dispensers on alcohol-based hand hygiene product usage in an intensive care unit. J Am Osteopath Assoc 109(5):263-267

381. Boog M, Erasmus V, de Graaf J, van Beeck EH, Melles M, van Beeck E (2013) Assessing the optimal location for alcohol-based hand rub dispensers in a patient room in an intensive care unit. BMC Infect Dis 13(1):510

382. Cure L, Van Enk R, Tiong E (2014) A systematic approach for the location of hand sanitizer dispensers in hospitals. Health Care Manag Sci 17(3):245-258

383. Widmer AE, Dangel M (2004) Alcohol-based handrub: evaluation of technique and microbio- 
logical efficacy with international infection control professionals. Infect Control Hosp Epidemiol 25(3):207-209

384. Sax H, Allegranzi B, Chraïti MN, Boyce J, Larson E, Pittet D (2009) The World Health Organization hand hygiene observation method. Am J Infect Control 37(10):827-834

385. Sodré da Costa LS, Neves VM, Marra AR et al (2013) Measuring hand hygiene compliance in a hematology-oncology unit: A comparative study of methodologies. Am J Infect Control 41(11):997-1000

386. Haas J, Larson E (2007) Measurement of compliance with hand hygiene. J Hosp Infect 66(1):6-14

387. Yin J, Reisinger $\mathrm{H}$, Vander Weg $\mathrm{M}$ et al (2014) Establishing evidence-based criteria for directly observed hand hygiene compliance monitoring programs: A prospective, multicenter cohort study. Infect Control Hosp Epidemiol 35(9):11631168

388. Swoboda SM, Earsing K, Strauss K, Lane S, Lipsett PA (2004) Electronic monitoring and voice prompts improve hand hygiene and decrease nosocomial infections in an intermediate care unit. Crit Care Med 32(2):358-363

389. Kinsella G, Thomas AN, Taylor RJ (2007) Electronic surveillance of wall-mounted soap and alcohol gel dispensers in an intensive care unit. J Hosp Infect 66(1):34-39

390. Boyce JM, Cooper T, Dolan MJ (2009) Evaluation of an electronic device for real-time measurement of alcohol-based hand rub use. Infect Control Hosp Epidemiol 30(11):1090-1095

391. Sahud AG, Bhanot N (2009) Measuring hand hygiene compliance: a new frontier for improving hand hygiene. Infect Control Hosp Epidemiol 30(11):1132

392. Kramer A, Heidecke CD (2015) Präoperative Hautantiseptik und Hautschutz. Trauma Berufskrankh 17(Suppl 2):322-329

393. Arbeitsgemeinschaft der Wissenschaftlichen Medizinischen Fachgesellschaften (AWMF), Arbeitsgemeinschaft für Berufs- und Umweltdermatologie (ABD) in der Deutschen Dermatologischen Gesellschaft (DDG)(Hrsg) (2014) AWMF-Regelwerk "S1-Leitlinie 013/056 Berufliche Hautmittel: Hautschutz - Hautpflege Hautreinigung".

394. Stutz NC (2008) Wahrnehmung von Handhygienemaßnahmen durch Pflegepersonal: alkoholische Händedesinfektion versus hygienische Händewaschung - eine Multicenterfragebogenstudie mit anschließender Epikutantestung. Dissertation. Universitätsmedizin Marburg

395. Forrester BG, Roth VS (1998) Hand dermatitis in intensive care units. J Occup Environ Med 40(10):881-885

396. Lammers T (1978) Zur Prüfung der Händedesinfektion. Hyg Med 3:316-318

397. Brannan DK, Dille J (1990) Type of closure prevents microbial contamination of cosmetics during consumer use. Appl Environ Microbiol 56(5):1476-1479

398. Lundov MD, Johansen JD, Zachariae C, Moesby $L$ (2012) Creams used by hand eczema patients are often contaminated with staphylococcus aureus. Acta Derm Venereol 92(4):441-442

399. Frosch PJ, Kurte A (1994) Efficacy of skin barrier creams (IV). The repetitive irritation test (RIT) with a set of 4 standard irritants. Contact Derm 31(3):161-168
400. Fluhr J, Gloor M, Lehmann L, Lazzerini S, Distante F, Berardesca E (1999) Glycerol accelerates recovery of barrier function in vivo. Acta Derm Venereol 79:418-421

401. Larson E, Anderson JK, Baxendale L, Bobo L (1993) Effects of a protective foam on scrubbing and gloving. Am J Infect Control 21(6):297-301

402. Berndt $U$, Wigger-Alberti W, Gabard B, Elsner $P$ (2001) Vergleich einer Hautschutzcreme und ihrer Grundlage bezüglich Wirksamkeit gegen das berufsbedingte irritative Handekzem bei Krankenschwestern. Eine Anwendungsuntersuchung. Derm Beruf Umw 49(1):77-80

403. Held E, Wolff C, Gyntelberg F, Agner T (2001) Prevention of work-related skin problems in student auxiliary nurses: an intervention study. Contact Derm 44(5):297-303

404. Held E, Mygind K, Wolff C, Gyntelberg F, Agner T (2002) Prevention of work related skin problems: an intervention study in wet work employees. Occup Environm Med 59(8):556-561

405. Gehring W (2004) Das stratum corneum in vitro - ein Modell zur Entwicklung von Hautschutzpräparaten mit entquellenden Eigenschaften auf die Hornschicht. Dermatol Beruf Umw 52(4):139-145

406. Ibler KS, Jemec GB, Diepgen TL et al (2012) Skin care education and individual counselling versus treatment as usual in healthcare workers with hand eczema: randomised clinical trial. BMJ 345:e7822

407. Kramer A, Henschel W, Wegner C (2013) Prospektive Studie zum dermatologischen Nutzen von Hautschutz und Hautpflege bei einem chirurgischen Team. In: 10. Ulmer Symposium Krankenhausinfektionen. Epidemiologie. Maßnahmen. Antibiotikatherapie. 19.-22. März 2013.

408. Berndt U, Gabard B, Schliemann-Willers S, Wigger-Alberti W, Zitterbart D, Elsner P (2002) Integrated skin protection from workplace irritants: a new model for efficacy assessment. Exog Dermatol 1(1):45-48

409. Mahler V (2007) Skin protection in the healthcare setting. In: Schliemann S, Elsner P (Hrsg) Skin Protection. Curr Probl Dermatol. Karger, Basel, $\mathrm{S}$ 120-132

410. Kresken J, Klotz A (2003) Occupational skin-protection products - a review. Int Arch Occup Environ Health 76(5):355-358

411. Große-Schütte $K$, Assadian O, Hübner NO, Löffler $\mathrm{H}$, Kramer A (2011) Practices of skin care among nurses in medical and surgical intensive care units: results of a self-administered questionnaire. GMS Krankenhhyg Interdiszip 6(1):Doc08

412. Brune L, Harnoss JC, Ansorg J, Heidecke CD, Assadian O, Kramer A (2014) Ergebnisse einer Fragebogenerhebung des BDC zum Stellenwert von Hautschutz und Hautpflege bei chirurgischem Personal/Handschutz und Pflege als berufliche Pflicht. Passion Chir 4:2-6

413. Harnoss JC, Brune L, Ansorg J, Heidecke CD, Assadian O, Kramer A (2014) Practice of skin protection and skin care among German surgeons and influence on the efficacy of surgical hand disinfection and surgical glove perforation. BMC Infect Dis 14(1):315

414. Löffler $H$, Dickel $H$, Bruckner T, Effendy I, Happle $R$ (2002) Skin changes in geriatric nurses prior to training heralding a particular risk of hand dermatitis. Eur J Dermatol 12(5):452-454

415. Weisshaar E, Radulescu M, Bock M, Albrecht U, Zimmermann E, Diepgen TL (2005) Hautschutz- seminare zur sekundären Individualprävention bei Beschäftigten in Gesundheitsberufen: erste Ergebnisse nach über 2jähriger Durchführung. J Dtsch Dermatol Ges 3(1):33-38

416. Kütting B, Drexler H (2008) Der dreistufige Hautschutzplan. Dtsch Med Wochenschr 133(05):201-205

417. TRGS 531: Technische Regeln für Gefahrstoffe - Gefährdung der Haut durch Arbeiten im Feuchten Milieu (Feuchtarbeit). GMBI 1996, Letzte Änderung vom: 09/1996

418. Weinberg D (1977) Acne therapy: Neutrogena hand cream as an aid to topical treatment. Cutis 20(1):141-143

419. Uter W, Geier J, Lessmann H, Schnuch A (2005) Inhaltsstoffe von Hautschutz-und-pflegemitteln aus allergologischer Sicht. Analyse von IVDK-Daten und Literaturübersicht. Derm Beruf Umw 53:172-182

420. Schubert R (1982) Zur Kompatibilität von Hautpflege-Cremes mit Hautdesinfektions-Präparaten. Umweltmed 3:56-58

421. Walsh B, Blakemore P, Drabu Y (1987) The effect of handcream on the antibacterial activity of chlorhexidine gluconate. J Hosp Infect 9(1):30-33

422. Benson L, LeBlanc D, Bush L, White J (1990) The effects of surfactant systems and moisturizing products on the residual activity of a chlorhexidine gluconate handwash using a pigskin substrate. Infect Control Hosp Epidemiol 11:67-70

423. Larson EL (1995) APIC guidelines for handwashing and hand antisepsis in health care settings. Am J Infect Control 23(4):251-269 